\title{
Sedimente und Ablagerungsmechanismen in instabilen proglaziären Seen (Eisrandstauseen) in Westgrönland
}

\author{
Herbert Scholz*
}

\author{
Recent lake sediments, unstable lakes, West Greenland
}

\begin{abstract}
Kurzfassung: Am Rande des grönländischen Inlandeises bei Søndre Strømfjord ist eine ganze Reihe von Eisrandstauseen mit instabilen Wasserständen zu finden. Sie neigen dazu, sich von Zeit zu Zeit unter das Eis hinein zu entleeren. Die Sedimente am Boden der ausgelaufenen Seebecken können ohne technischen Aufwand untersucht werden. 7 solcher Seen, von denen 3 im Sommer 1993 ausgelaufen waren, konnten im Rahmen eines von der DFG geförderten Projektes eingehender untersucht werden. Die Seefüllungen bestehen demnach vor allem aus locker gelagerten Diamikten, bei denen es sich größtenteils um die Sedimentfracht von Eisbergen handeln dürfte. Daneben spielen Delta- und Schwemmfächersedimente sowie Rutschmassen, die von den Flanken der Seebecken stammen, eine wichtge Rolle. Feinkörnige Seesedimente, wie man sie in eisrandnahen Seen eigentlich erwarten würde, treten demgegenüber stark in den Hintergrund. Sedimentfüllungen von derartigen instabilen Seen weichen also offensichtlich von gewöhnlichen, bisher bekannten glazilakustrinen Schichtfolgen stark ab. Fossile Ablagerungen aus derartigen Seen, die am Rande des nordeuropäischen Inlandeises oder der alpinen Vorlandgletscher nicht seltener gewesen sein dürften als im heutigen Grönland, sollten aufgrund der vorliegenden Untersuchungen in Zukunft leicht zu erkennen sein.
\end{abstract}

\section{[Sediments and sedimentary processes within unstable proglacial lakes (ice-dammed lakes) in West Greenland]}

\begin{abstract}
Close to Søndre Strømfjord in West Greenland, a number of ice-contact lakes with unstable water levels are dammed by the margin of the inland ice. From time to time they drain more or less completely beneath the glacier. Thus, the sediments at the bottom of such dry lake basins can be examinated in an easy way. 7 lakes of this type, 3 of which were empty in summer 1993, could be investigated in detail by help of a grant of the DFG. The sedimentary infill of the lakes mainly consists of diamiktons, presumably sediments of drift ice. Besides of the debris of mass movements, derived from the flanks of the lake basins, deltaic and fluvial deposits play an important role. Fine grained lake sediments, however, which may be expected within a lake close to a glacier, are scarcely to be found. The sedimentary infill of unstable lakes of this type is obviously different from normal glacilacustrine successions. The sedimentary record of fossil lakes of this type,
\end{abstract}

\footnotetext{
*) Anschrift des Verfassers: Priv.-Doz. Dr. H. Scholz, Lehrstuhl für Allgemeine, Angewandte und Ingenieur-Geologie der Technischen Universität München, Lichtenbergstr. 4, 85747 Garching.
}

which may have been as common in Pleistocene Europe as in modern Greenland, should be identified easily in the future, due to the investigations presented in this paper.

\section{Einleitung}

Pleistozäne Seeablagerungen sind in den ehedem vergletscherten Gebieten Europas weit verbreitet (ScHolz, 1991 und 1993). Bei den Sedimenten handelt es sich gewöhnlich um laminierte Feinsedimente (Bändertone, Beckenschluffe und Beckensande), die von gröberkörnigen Deltabildungen (Kiesen und Sanden) vertreten werden können. Die Feinsedimente sind meist einige Meter bis einige Dekameter mächtig und werden gewöhnlich von Grundmoränen unterlagert (SCHOLZ \& PETER, 1995). Im Hangenden der Beckenfüllungen folgen oft fluviatile Kiese, manchmal aber liegen die Seeablagerungen auch frei oder sind - bei Beckensedimenten aus älteren Vereisungsperioden - von Moränen bedeckt. Allerdings sind längst nicht alle Profile in derartigen Sedimentfolgen einfach zu deuten, vor allem solche, wo in Feinsediment-Folgen geschichtete Kies- und Grobsandfolgen eingeschaltet sind.

Einige dieser Folgen scheinen in instabilen Schmelzwasserseen entstanden zu sein. Darunter sollen hier Schmelzwasserseen verstanden werden, die in zum Gletscher hin abfallenden Tälern und Rinnen vom Gletschereis selbst aufgestaut werden („glacier-dammed lakes“ sensu Dawson, 1983). Sie neigen dazu, sich in gewissen Abständen immer wieder zu entleeren (z. B. Marcus, 1960; Sugden et al., 1985; Scholz et al., 1988). Dabei entstehen Flutwellen, die als Gletscherläufe (jökullhlaups) die Schmelzwasserflächen im Vorfeld des Gletschers erreichen. Die Böden solcher instabilen Seen fallen dann eine Zeitlang großflächig trocken. Selbst im Profundal der Seebecken können so Schmelzwasserrinnen und grobkörnige Sedimente entstehen.

Es sind eine ganze Reihe von rezenten Eisrandstauseen (auch "icecontact lakes" sensu CHurch \& GILBERT, 1975 oder "terminoglacial lakes“ sensu Ashiley et al., 1985) bekannt, die Gletscherläufe verursachen (z. B. THORARINSson, 1953; Marcus, 1960; Stone, 1963; Jahn, 1968; WaitT, 1980; Dawson, 1983; Sugden et al., 1985; LoRd \& Ke- 
HEW, 1987; RuSSELl \& DEJONG, 1989; Russell et al., 1990; Scholz et al., 1988; Russell, 1993). Es gibt auch eine Anzahl von Untersuchungen zu Gletscherläufen, zu ihren Wirkungen auf die betroffenen Sanderflächen und zu den Mechanismen, die Gletscherläufe auslösen (z. B. Gilbert, 1971; BeEcroft, 1985; Scholz et al., 1988). Tatsächlich aber sind in der Literatur, die sich mit glaziären Seen befaßt, kaum Hinweise auf die Sedimente, Schichtfolgen und Ablagerungsmechanismen in derartigen instabilen proglaziären Seen zu finden, obwohl Seen dieses Typs z.B. am Rande des Inlandeises in Westgrönland ungemein verbreitet sind (ScHOLz et al., 1988; Weidick, 1988). Vor allem in der Umgebung des internationalen Flughafens Søndre Strømfjord sind sie relativ leicht zu erreichen. Da hier zudem Klima und Vegetation, Relief und Geometrie der Eisränder den Verhältnissen im hochglazialen Mitteleuropa bis zu einem gewissen Grad vergleichbar sind (ScHolz, 1984 und 1986a), lag es nahe, einige dieser Seen eingehender zu untersuchen.

\section{Die praktische Durchführung des Projektes}

An dem knapp einmonatigen Grönlandaufenthalt nahmen im Sommer 1993 außer mir der Geologiestudent Thomas Herzog und mein Kollege Dipl.-Geol. Dr. Jürgen Froh teil. Schon vor der Fahrt nach Grönland waren 4 Gebiete mit instabilen Eisrandstauseen am Ran-

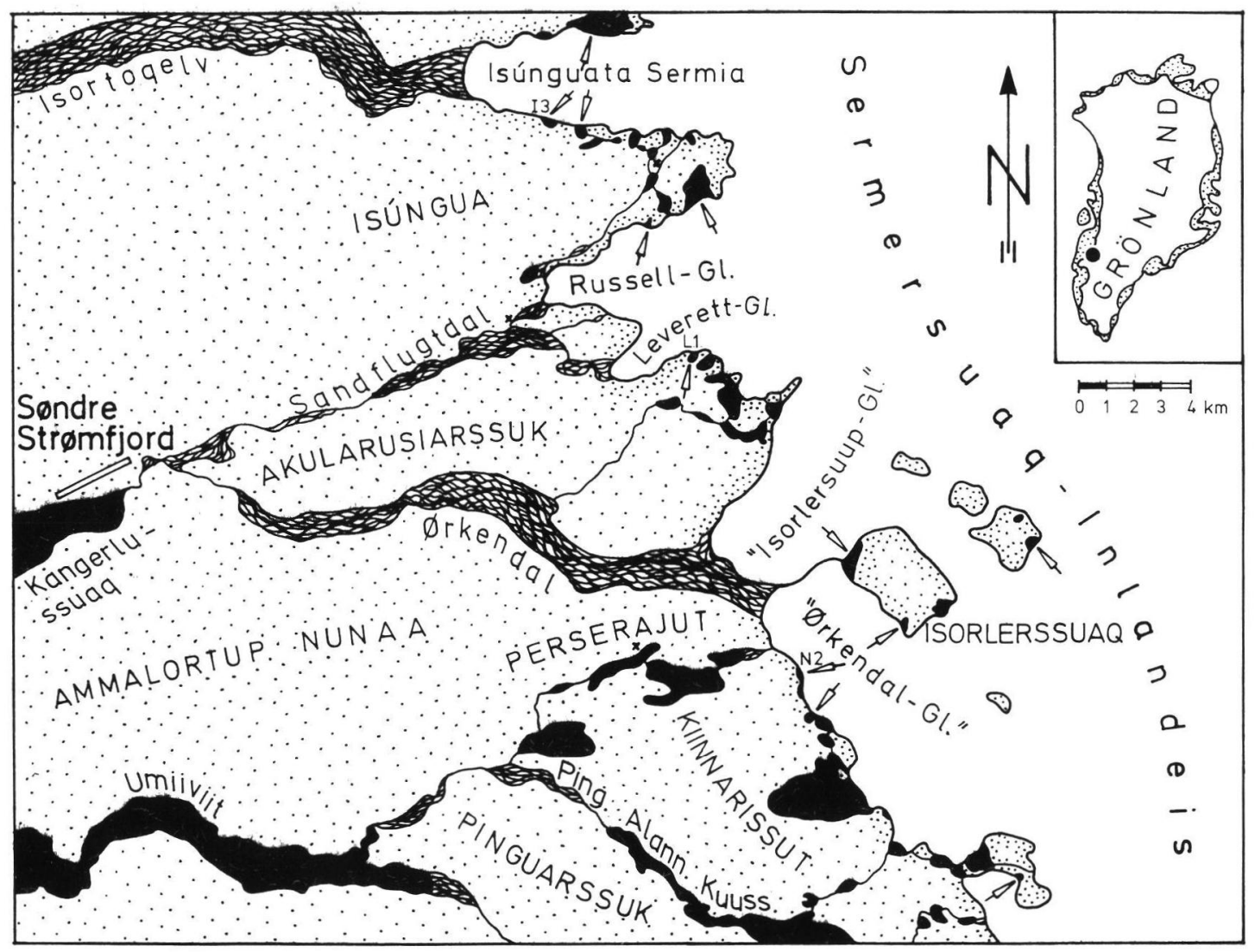

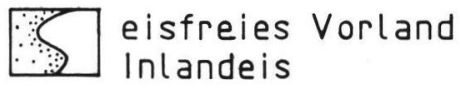

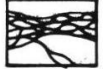

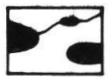

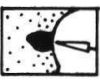

instabile
Schmelzwasserseen

Eisrandstauseen
I3 Isunguata 3

L1 Leverett 1

N2 Nys $\varnothing 2$

Abb. 1: Übersichtskarte des Arbeitsgebietes in Westgrönland, auf der die wichtigsten Schmelzwasserseen und -flüsse sowie alle in dieser Gegend bisher sicher identifizierbaren instabilen Eisrandstauseen verzeichnet sind. Der Übersichtlichkeit halber sind die unzähligen größeren und kleineren periglaziären Seen nicht eingezeichnet. Mit Kreuzen sind die Punkte markiert, wo während unseres Aufenthaltes Lager aufgeschlagen wurden.

Fig. 1: Outline map of the investigated area in West Greenland, showing the most important meltwater lakes und rivers, as well as all the unstable ice-dammed lakes identified in this region with certainty so far. For clearness the innumerable small and large periglacial lakes are not shown here. Sites of basecamps used for the investigations are marked by crosses. 
de des Inlandeises östlich des Flughafens Søndre Strømfjord ausgewählt worden, die als Untersuchungsobjekte besonders geeignet schienen - vorausgesetzt die Seebecken waren zum Zeitpunkt unseres Aufenthaltes tatsächlich leer.

Es blieb nichts anderes übrig, als den gesamten Eisrand abzulaufen und die Seen der Reihe nach anzuschauen. Das ist aber ein äußerst zeitraubendes und mühseliges Unterfangen. Die entferntesten Teile des Eisrandes, die hier ohne größeren technischen Aufwand erreicht werden können, liegen mehr als $40 \mathrm{~km}$ nordöstlich bzw. südöstlich des Flughafens. Bis auf eine einzige kurze Piste gibt es keine Straßen; das Gelände ist streckenweise unwegsam und nur mit großen Anstrengungen begehbar. Außerdem kann man nicht einfach den gesamten Rand des Inlandeises in einem Stück ablaufen, bis man einen geeigneten See gefunden hat. Das scheitert schon am Transport der dafür notwendigen Menge an Verpflegung. Zudem versperren zwei extrem wasserreiche und breite Schmelzwasserflüsse den Weg und zwingen einen jedesmal, ein Schlauchboot zu benutzen bzw. zum Flughafen zurückzulaufen, wo es eine Brücke gibt (Abb. 1). Mit einem Hubschrauber hätte sich die Sache zweifellos vereinfachen und beschleunigen lassen, wäre aber dadurch auch extrem verteuert worden. Ergänzt werden muß noch, daß ich mich im Sommer 1996 während einer privaten Grönlandreise nochmals einige Tage im Untersuchungsgebiet aufgehalten habe und hier einige ergänzende Beobachtungen machen konnte.

Die amtlichen Karten Grönlands im Maßstab 1:250 000 (für manche Gegenden auch in Vergrößerungen im Maßstab 1:100 000 erhältlich), die vom Geodätischen Institut in Kopenhagen herausgegeben werden, hatten sich schon bei früheren Unternehmungen in Westgrönland als äußerst grob und extrem unzuverlässig erwiesen. Brauchbare Spezialkarten in günstigeren Maßstäben sind vorläufig nur für die dichter besiedelten oder wirtschaftlich interessanten Teile Grönlands verfügbar - und zu diesen zählt das Untersuchungsgebiet nicht. Die topographischen Kartengrundlagen, die für die Kartierung der Seen notwendig waren, mußten folglich selbst hergestellt werden.

Seit einem gleichfalls von der DFG geförderten Projekt, das ich 1986 im südlichen Teil des Untersuchungsgebietes durchgeführt hatte (ScHOlz, 1986 b und 1987), war klar, daß sich Ortholuftbildkarten nicht ohne weiteres herstellen lassen, da sich in der weiteren Umgebung kein einziger Paßpunkt findet. So blieb nichts anderes übrig, als die schlechten amtlichen Karten mit der Hilfe von Luftbildern so weit zu verbessern, daß sie als halbwegs brauch- bare Kartierunterlagen dienen konnten. Auf Vergrößerungen der Luftbilder, die den mittleren Maßstab 1:25000 bzw. 1:10000 aufwiesen, wurden die auf der topographischen Karte von Søndre Strømfjord im Maßstab 1:100 000 (Udvalget for vandreturisme i Grønland 1978, vergrößerter Auszug aus Karten im Maßstab 1:250 000, Geodætisk Institut 1977) eingezeichneten Höhenkoten (Äquidistanz $50 \mathrm{~m}$ ) übertragen und unter Stereoskopen den tatsächlichen Geländeformen angepaßt. Dabei war freilich davon ausgegangen worden, daß die auf der amtlichen Karte dargestellten Höhenlinien und Höhenangaben im Prinzip nicht falsch sind.

Diese provisorischen Karten (Abb. 3 und 6) haben sich - trotz ihrer wenig befriedigenden Herstellungsweise - im Gelände ausgezeichnet bewährt. Sie haben sogar den Vorteil, daß transparente Abzüge jederzeit mit den Luftbildern exakt zur Deckung gebracht werden können, was die Arbeit mit ihnen entscheidend erleichtert. Durch zahlreiche Korrekturen der Höhenlinien während der Arbeiten im Gelände konnten sie weiter verbessert werden. Die vorliegenden Karten weisen zwar geringfügige Verzerrungen auf, zeigen aber ein ziemlich realistisches Modell der Geländeoberfläche und sind als Orientierungshilfe ausgezeichnet geeignet.

Ein wesentliches Problem besteht allerdings darin, daß die aus den amtlichen Karten übernommenen Höhenkoten und Höhenpunkte stellenweise nicht einmal annähernd zu stimmen scheinen. Das ergab sich aus einigen barometrischen Kontrollmessungen, die wir hier durchgeführt haben. Die von uns gemessenen und die aus der amtlichen Karte entnommenen Höhen wichen mitunter um mehr als $100 \mathrm{~m}$ voneinander $\mathrm{ab}$. Da wir aber weder gerätemäßig noch von der zur Verfügung stehenden Zeit her in der Lage waren, diese Fehler zu korrigieren, haben die Höhenlinien auf unseren provisorischen Karten eher den Charakter von Konturlinien. Trotzdem sind sie allen amtlichen Karten dieser Gegend haushoch überlegen.

Es sei außerdem noch darauf hingewiesen, daß im vorliegenden Text und auf den Kartenbeilagen Namen auftauchen, die konsequent in Anführungszeichen geschrieben werden. Diese Begriffe sind nicht den amtlichen Karten entnommen, sondern im Rahmen der vorliegenden Untersuchungen als Arbeitsbegriffe eingeführt worden. Eine offizielle Namensgebung ist damit nicht beabsichtigt.

\section{Das Untersuchungsgebiet in Westgrönland}

Das hier vorgestellte Untersuchungsgebiet ist vergleichsweise einfach zugänglich, da es vom Inter- 
nationalen Flughafen Søndre Strømfjord (Kangerlussuaq) aus zu Fuß erreicht werden kann. Der hier vorgestellte Abschnitt des Eisrandes (Nr. 33 nach WEIDICK, 1968: Taf. 1) liegt im mittleren Westgrönland, etwas nördlich des Polarkreises (Abb. 1). Zwischen dem Sukkertoppengebiet im S und der Diskobucht im $\mathrm{N}$ reicht das Inlandeis nicht, wie sonst fast überall in Grönland, nahe an die Küste heran, sondern grenzt in Form flacher Eiszungen an ein niedriges Bergland. Der eisfreie Landstreifen wird stellenweise bis zu $180 \mathrm{~km}$ breit. Vom Rande des Eises fließen wasserreiche Schmelzwasserflüsse auf breiten Sanderflächen nach $\mathrm{W}$, wo sich ihre Wassermassen in die Enden weit ins Landesinnere hineinreichender Fjorde ergießen. Die breiten Zungenenden liegen in Höhen von etwa 100 bis $300 \mathrm{~m}$ über dem Meer. Von hier aus steigt die Oberfläche des Inlandeises langsam an und erreicht schon in einer Entfernung von etwa $100 \mathrm{~km}$ vom Eisrand Höhen von über $2000 \mathrm{~m}$.

\subsection{Zur Geologie des Untersuchungsgebietes}

Das Untersuchungsgebiet liegt im Bereich hochmetamorpher, präkambrischer Gesteine, die im Süden dem Archäischen Block, im Norden der Mobilzone der Nagssugtoqiden angehören. Die radiometrischen Alter dieser Metamorphite schwanken zwischen 1,7 und mehr als 3 Mia. Jahren. Der Archäische Block wird im Arbeitsgebiet von Tiefengesteinen und Migmatiten (Quarzsyenite mit mafischen Restbeständen) aufgebaut, die von mächtigen, N-S-streichenden Lamprophyrgängen (Kangamiut-Gangschwarm, Amphibolite) diskordant durchschlagen werden. Die im Norden anschließende Mobilzone der Nagssugtoqiden besteht im wesentlichen aus sauren, teilweise mylonitischen Gneisen, in die - konkordant zu ihrem E-W-streichenden Parallelgefüge - gangförmige, 50 bis $100 \mathrm{~m}$ mächtige, oft boudinierte Amphibolit-, Granatamphibolit- und Ultrabasitkörper eingelagert sind. Sie werden als prätektonisch in einen archäischen Gneiskomplex intrudierte basische Gänge (Kangamiut-Dykes) gedeutet, die im Laufe einer jüngeren Durchbewegung entlang E-W-laufender Scherzonen umorientiert wurden (EsCHER et al., 1976). Die Beobachtung allerdings, daß in die Amphibolite gelegentlich auch gebänderte Marmorkörper eingelagert sein können, lassen dieses genetische Modell zweifelhaft erscheinen und legen eher eine suprakrustale Entstehung zumindest von Teilen des Komplexes nahe. Die mächtigen, steil nach $\mathrm{N}$ einfallenden Amphibolitkörper stecken jedenfalls heute vielfach im Kern von E-W-verlaufenden Bergrücken. Alle Gesteine sind während des Hochglazials vom Inlandeis überfahren und im Laufe des Holozäns wieder freigegeben worden. Große Flächen sind deshalb von pleistozänen Grundmoränén bedeckt, die dem eisüberschliffenen und geschrammten Untergrund auflagern. Vom Eisrürckzug zeugen zahlreiche Wallsysteme zwischen der Küste und dem heutigen Rand des Inlandeises (TEN. BrinK, 1975; Weidick, 1972; Stäblein, 1975; Scholz \& GrottenTHALER, 1988). Auch die innersten und damit jüngsten Rückzugsmoränen, die sich in der weiteren Umgebung der Gletscherzungen finden (Vorfeldstadien), scheinen mehrere tausend Jahre alt zu sein (TEN BRINK, 1975). Nur einige weitgehend vegetationsfreie Wälle, die stellenweise in der unmittelbaren Nähe des Eisrandes zu beobachten sind, dürften vergleichsweise jung sein und wohl größtenteils vom Ende des letzten und Anfang dieses Jahrhunderts stammen (Historische Stadien). ZWischen der Bildung der Historischen und der Vorfeldstadien scheint dieser Abschnitt des Ëisrandes bedeutend weiter im E gelegen zu haben als heute. In dieser Zeit scheint die Hauptmasse der weit verbreiteten, dezimeter- bis metermächtigen, schluffig-feinsandigen Lößdecken entstanden zu śein, die alle älteren Bildungen im Vorfeld des Inlandeises überlagern können (Scholz \& GrotTENTHaler, 1988). Diese feinkörnigen äolischen Deckschichten, die heute wieder vielfach durch Deflation abgetragen werden, fehlen auf den Wällen der Historischen Stadien. Der große Altersunterschied zwischen den Moränenwällen der Jahrtausende alten Vorfeldstadien und der Historischen Stadien ist auch lichenometrisch nachweisbar (vergl. Beschel, 1961).

Gröberkörnige Flugsandfelder, die unmittelbar am Eisrand und vor allem auf der Nordseite der großen Sanderflächen liegen, sind heute noch in Bildung begriffen. Sie sind vor allern durch Buschdünen charakterisiert, kleine, in Windrichtung gestreckte Dünen, die von Büschen der Weide Salix glauca gekrönt werden. Sie entstehen durch Starkwinde in der unmittelbaren Umgebung des Eises. Wie man an der Ausrichtung von Lineardünen und Deflationswannen, der Orientierung von Windkantern oder an der Lage der Dünenfelder bezüglich der Ausblasungsgebiete ablesen kann, kommen die Starkwinde vornehmlich aus südöstlicher Richtung. Es sind katabatische Fallwinde oder Föhne, die durch die Erddrehung antizyklonisch abgelenkt werden. Allerdings hat auch das Relief im Vorfeld des Eises einen erheblichen Einfluß auf die Windrichtung.

\subsection{Zum Klima und zu den Frost- erscheinungen im Untersuchungsgeblet}

Während das eisrandnahe Bergland nur an wenigen Stellen mehr als 400 bis $500 \mathrm{~m}$ hoch wird, fin- 
den sich in Küstennähe lokal vergletscherte Gebirge mit mehr als 1800 m Höhe. Diese Gebirge schirmen die regenbringenden Westwinde weitgehend ab. Zusammen mit der relativ großen Entfernung zum offenen Meer führt das zu einer ausgeprägten Kontinentalität des Klimas im Landesinneren - mit sehr niedrigen Jahresmitteltemperaturen $\left(-4,8{ }^{\circ} \mathrm{C}\right.$; ETAC 1970), besonders warmen Sommern (Julimittel $10,5^{\circ} \mathrm{C}$ ) und großer Trockenheit (Jahresmittel 150-200 mm; HẢrLøv \& al. in MINISTERIET FOR GRØNLAND, 1980 und ERICSON, 1987). Zudem trocknen Föhn und katabatische Eisfallwinde (PutNins, 1970) das Gletschervorfeld so stark aus, daß die Landschaft einen steppenartigen, stellenweise sogar wüstenhaften Charakter besitzt (BELKNAP, 1941 und HoBBs, 1931).

Folglich läßt sich überall im Arbeitsgebiet, wo porenreiche Sedimente im Untergrund zu finden sind, Permafrost nachweisen. An Nordhängen kann die sommerliche Permafrosttafel häufig nur $10 \mathrm{~cm}$ unter der Vegetationsdecke ergraben werden. Auf inaktiven, vegetationslosen Flußterrassen beginnt der Permafrost dagegen oft erst in 2 bis $3 \mathrm{~m}$ Tiefe. Wo die Durchfeuchtung des Untergrundes genügend gut ist, lassen sich Frostmusterböden nachweisen. Besonders auffällig sind palsaartige Beulen, die einen Eiskern besitzen und gelegentlich auf älteren Flußterrassen zu finden sind (Dijkmans, 1989). Hier, an nordexponierten Hängen wie in feuchten Senken, sind auch Eiskeilpolygone (DIJkMANs \& TÖRNQUIST,1990), an nord- und ostexponierten Hängen Erdbülten und Fließerdeloben verbreitet. Die Fließerden (gebundene Solifluktion), die zum großen Teil aus gelifluidal umgelagerten äolischen Deckschichten bestehen, sind leicht bräunlich gefärbt, gelegentlich gebändert, haben streifenweise hohe organische Gehalte und können sich in Senken zu beträchtlichen Mächtigkeiten akkumulieren. Obwohl im Sommer noch die ergiebigsten Niederschläge fallen (STÄBLEIN, 1977b), gibt es nach der Schneeschmelze - abgesehen von den Schmelzwassersystemen - in tieferen Lagen kaum dauernd fließende Gewässer. Die Verdunstung ist so hoch, daß die meisten der zahlreichen periglaziären Seen ohne Abfluß sind und teilweise erhöhte Salzgehalte aufweisen. Während die Gletscher im Winter kaum Schmelzwasser spenden, die Sanderflächen weitgehend ausgetrocknet sind und - nach Angaben der Bevölkerung in Søndre Strømfjord - ohne Schwierigkeit mit einem Landrover überquert werden können, fallen im Sommer auch nach der Schneeschmelze gewaltige Schmelzwassermassen an. Die anastomisierenden Flußsysteme auf den Sanderflächen im Sandflugtdal oder Ørkendal schütten im Sommer schon normalerweise jeweils 150 bis
$300 \mathrm{~m}^{3}$ Wasser pro Sekunde (Wert geschätzt). An den Schmelzwasserflüssen sind auch im Sommer erhebliche Wasserstandsschwankungen zu beobachten. Proportional zum täglichen Temperaturgang lassen sich den Temperaturmaxima und -minima nachhinkende Pegeländerungen von mehr als $40 \mathrm{~cm}$ beobachten - wobei die höchsten Pegelstände im Mittel um 16.00 Uhr, die niedrigsten um 10.00 Uhr erreicht werden. Schönwetterperioden und Föhnlagen machen sich durch ungewöhnlich hohe Pegelstände bemerkbar, die mehrere Dezimeter über dem sommerlichen Normalstand liegen können.

\subsection{Zur Vegetation des Untersuchungsgebietes}

Bei der Vegetation gibt es deutliche Unterschiede zwischen dem kontinentalen Landesinneren und den ozeanischen Küstengebieten auf der einen, den niedrigen Hügelländern und den höheren Bergen auf der anderen Seite. Während an den Küsten Zwergstrauchheiden, kräuterreiche Gras- und Sumpfgesellschaften dominieren, wird die Landschaft im Landesinneren eher durch trockene Steppen und Dünengesellschaften geprägt. Zwergstrauchheiden sind hier vor allem auf den besser durchfeuchteten Nordhängen zu finden. Die relativ hohen Durchschnittstemperaturen der Sommermonate ermöglichen das Wachstum von mehr als mannshohen Weiden - an gut mit Wasser versorgten und windgeschützten Standorten (BøснER, 1959 und 1975, Bøcher et al. 1968).

Vor allem in den höheren Lagen und in der unmittelbaren Umgebung des Eisrandes treten vermehrt "offene" Vegetationstypen auf, bei denen der Untergrund nur schütter bewachsen bzw. die geschlossene Vegetationsdecke mosaikartig mit völlig vegetationsfreien Flecken durchsetzt ist. Die Entstehung dieser offenen Pflanzengesellschaften ist teilweise auf periglaziäre Prozesse (Bodenfließen, Kryoturbation), in Eisrandnähe vor allem aber auf Erosionsschäden durch die heftigen Fallwinde zurückzuführen (FeILBerg et al. 1984).

Die im Arbeitsgebiet auftretenden Pflanzengesellschaften sind zuerst von Bøcher (z. B. 1959, 1968 und 1975), später durch GILCK (in ScHOLz, 1987) ausfühfllich definiert und beschrieben worden. Weit verbreitet sind arktische Steppen ("short grass prairie“, BøCHER, 1954), mit einem deutlichen Überwiegen von Cyperaceen (Sauergräser). Daneben kommen, vor allem in Talgründen und Mulden in tieferen Lagen mit besser durchfeuchteten Böden, gramineenreiche Pflanzengesellschaften vor, die als "Großgraswiese“ („tall grass prairie“, ВøсHER, 1954) bezeichnet werden. Charakterpflanze ist ein Reitgras, 
das bis hüfthoch wachsende Calamagrostis purpurescens. In tieferen Lagen findet sich an windgeschützten und genügend feuchten Standorten - dort auch an Südseiten - mannshohes, dichtes Gebüsch der Weide Salix glauca, ein Vegetationstyp, der als „Salix-glauca-Gebüsch“ bezeichnet wird. Besonders weit verbreitet sind nahezu reine Bestände der Zwergbirke Betula nana. Diese „Betula-nanaZwergstrauchheide" findet sich in tieferen Lagen auf mäßig geneigten Nordhängen an Stellen, wo die Permafrosttafel in nur wenigen Dezimetern Tiefe zu erbohren ist. Recht ausgedehnte Dünenfelder sind vor allem auf den Nordseiten der großen Sanderflächen und unmittelbar am Eisrand zu finden. Auf ebenen Flächen zwischen „Buschdünen“, die von der Weide Salix glauca dominiert werden, seltener aber auch auf kleinen, hügelförmigen Dünen und auf südseitigen, mit Flugsand bedeckten Hängen am Rande der Dünenfelder, wachsen dichte Bestände des Strandroggen (Elymus arenarius).

\subsection{Beschreibung der instabilen Eisrandstauseen}

Terminoglaziäre Seen (sensu Ashley et al., 1985), die unmittelbar an den Eisrand grenzen (,ice-contact lakes“ sensu Church \& Gilbert, 1975), sind am Rand des Inlandeises in Westgrönland ungemein verbreitet (SCHOlz et al., 1988; WEIDICK, 1988). An einigen Stellen grenzt der Eisrand mit senkrechten Kalbungsfronten an Schmelzwasserseen, die vielfach von Eisbergen bedeckt sind. Der größte von ihnen ist der mehr als $3 \mathrm{~km}$ lange Iluliartooq im Kiinarissut-Bergland (Abb.1), südöstlich von Søndre Strømfjord. Einige dieser Seen besitzen einen Ausfluß, der in Funktion ist, wenn sie ihre maximale Stauhöhe erreicht haben, andere dagegen scheinen überhaupt nur subglaziär zu entwässern. Manche dieser Seen zeigen beim Vergleich unterschiedlich alter Luftbilder gewaltige Wasserstandsänderungen. Über eine Kombination von direkter Beobachtung und der Auswertung von Luftbildern lassen sich am Eisrand zwischen Isúnguata Sermia im Norden und dem Pinguarsuup Alannguata Kuussua mindestens 12 Seen ermitteln, die sich in gewissen, vielleicht unregelmäßigen Abständen zu entleeren scheinen (Abb. 1). Es wäre aber durchaus möglich, daß auch benachbarte Eisrandstauseen instabil sind und zum Zeitpunkt der Befliegungen nur zufällig gerade voll waren.

Von diesen instabilen Seen schienen 4 sich besonders regelmäßig zu entleeren und wir hofften, wenigstens 2 davon während unseres Aufenthaltes untersuchen zu können. Der eine See liegt am Westrand des „Ørkendal-Gletschers" (,Iluliartununnguaq $2^{\star}$ ), der zweite am Südrand des Leverett-
Gletschers („Leverett 1“), der dritte am Nordrand des Russell-Gletschers („Oberer Russellsee“ oder „Russell 1") und der vierte am Südrand des Isúnguata Sermia („Isunguata 3“) (Abb. 1). „Iluliartununnguaq 2“ und „Russell 1“, von denen ich mir besonders interessante Ergebnisse erhofft hatte, blieben leider, solange wir uns in der Nähe aufhielten, bis zum Rand mit Wasser gefüllt. Sie waren noch immer nicht ausgelaufen, als wir beim Rückflug das Gebiet überquerten. „Leverett 1“ und „Isunguata 3" dagegen waren im Sommer 1993 entsprechend unseren Erwartungen tatsächlich ausgelaufen und konnten untersucht werden (Abb. 1). Zusätzlich fanden wir etwas nördlich des Iluliartununnguaq ein sehr schmales, langgestrecktes Seebecken („Nysø 2"), das sich offenbar erst kurz vor unserer Ankunft entleert hatte (Abb. 1). Bei einer ergänzenden Begehung des Eisrandes im August 1996 wurde zusätzlich noch der „Isunguata $2 "$ in ausgelaufenem Zustand angetroffen.

Die unmittelbare Umgebung der Seen sowie die trockengefallenen Teile des Seebodens wurden, soweit sie zugänglich waren, geologisch kartiert. An zahlreichen Stellen der trockengefallenen Seeböden (vor allem von „Isunguata 3“ und von „Leverett 1“) wurden Profile aufgegraben, untersucht und dokumentiert. Die Profile wurden fotografisch und zeichnerisch festgehalten. Neben gestörten wurden auch ungestörte Sedimentproben gewonnen. An einigen Stellen von „Isunguata 3" wurden Stechkastenprofile präpariert und die Präparate mitgenommen. In 3 Fällen gelang es, kurze Kerne (der längste ist $1 \mathrm{~m}$ lang) mit Hilfe von mitgebrachten Kunststoff-Kernrohren herauszustechen und mitzunehmen. Die tatsächlich mitgebrachte Probenzahl blieb - durch unsere begrenzte Transportkapazität bedingt - relativ bescheiden.

\subsubsection{Iluliartununnguaq 2 (Q2)}

Der etwa $1500 \mathrm{~m}$ lange und $500 \mathrm{~m}$ breite See „Iluliartununnguaq" (Abb. 1) ist durch eine weit vorspringende Landzunge (Taf. 1a), die sich unter dem Wasserspiegel als Untiefe fortsetzt, in zwei tiefere Seebecken unterteilt (Abb. 2). Auch dieser etwa $400 \mathrm{~m}$ über dem Meer gelegene Doppelsee grenzt im $\mathrm{NE}$ direkt ans Inlandeis, wo eine fast $1 \mathrm{~km}$ lange Kalbungsfront ausgebildet ist (Taf. 1a). Schmelzwasser, das am Nordwestende dieses Sees überläuft, fließt in einer peripheren Rinne am Eisrand entlang und verschwindet nach kaum $100 \mathrm{~m}$ in einem Eistunnel.

Auf Luftbildern des Geodätischen Institutes in Kopenhagen, die von einer Befliegung Mitte August 1968 stammen (FS. Nr. 850780), ist das nordwestliche, kleinere Teilbecken („Iluliartununnguaq 2“) völ- 
lig wasserleer (Abb. 2). Auf Luftbildern von einer Befliegung Anfang September 1985 (FS. Nr. 860957) ist er dagegen wassergefüllt. Wie auf der älteren Aufnahme zu sehen war, wird er in entleertem $\mathrm{Zu}$ stand von einem breiten Schmelzwasserbach durchflossen, dem Überlauf des südöstlichen Teilbeckens („Iluliartununnguaq 1“), dessen Wasserspiegel nur etwas abgesenkt ist. Der Bach mündet im Profundal des Beckens in einen kaum 100 m großen Restsee, dessen Überlauf wiederum nach einer Laufstrecke von etwa $200 \mathrm{~m}$ unter dem Eis verschwindet (Abb. 2). Das Profundal scheint mit feinkörnigen Sedimenten aufgefüllt zu sein. Auf der westlichen Innenseite des leeren Seebeckens sind teilweise die nackten Felsen entblößt. Die Flanken auf der Ostseite bestehen aus grobblockigen Eisrandablagerungen. Gestrandete Eisberge lassen sich auf dem Luftbild nicht erkennen, vielleicht ein Hinweis auf einen längeren Zeitraum, der zwischen dem Auslaufen des Sees und der Aufnahme verstrichen sein muß.

Die Pflanzendecke auf diesem Luftbild hört offenbar im Bereich der jetzigen Hochwasserlinie auf. Deswegen ist anzunehmen, daß das Teilbecken garnicht lange vorher noch mit Wasser gefüllt war. Auf dem Luftbild von 1968 ist das ausgelaufene Teilbecken des „Iluliartununnguaq 2“ ca. $450 \mathrm{~m}$ breit; auf dem Luftbild von 1985 ist es deutlich schmäler - ein beredter Hinweis auf das augenblickliche Vorrücken des Inlandeises, das in den letzten 10 Jahren überall östlich von Søndre Strømfjord zu beobachten war (SCHOLZ, 1991).

Beim Auslaufen dieses vermutlich etwa 20 bis $30 \mathrm{~m}$ tiefen Beckens dürfte ein Wasservolumen unter dem Eis verschwunden und vermutlich im Ørkendal (?) als Gletscherlauf wieder zutage getreten sein, das in der Größenordnung von etwa 3000000 bis $4000000 \mathrm{~m}^{3}$ liegt.

Am Südende des Ørkendals, der terminalen Sanderfläche, die etwa $4 \mathrm{~km}$ weiter im $\mathrm{N}$ ansetzt (Abb. 2), sind relativ frische Hochwassermarken zu entdecken, kaum $1 \mathrm{~m}$ über dem sommerlichen Normalwasserstand. Zudem gibt es hier - etwa 300 bis $1000 \mathrm{~m}$ vom Eisrand entfernt - winzige, kaum bewachsene Terrassen aus Grobsanden und Feinkiesen, die sogar 2 bis $3 \mathrm{~m}$ höher liegende Hochwasserstände anzeigen. Sie könnten von Gletscherläufen herrühren, die mit dem Auslaufen des „Iluliartununnguaq 2“ (oder gar des Iluliartooq?) zusammenhängen. Im Sommer 1986 konnten diese Seen über viele Wochen hinweg beobachtet werden, waren in dieser Zeit aber leider ständig voll mit Wasser. Auch 1993 blieben sie - während unseres ganzen Aufenthaltes - enttäuschenderweise mit Wasser gefüllt.

\subsubsection{Nysø 2 (N2)}

Kaum 100 m nördlich des „Iluliartununnguaq 2“ liegt das Inlandeis direkt den eisüberschliffenen Felsen eines Höhenrückens auf, der vom Kiinarissut-Bergland herunterzieht und an dieser Stelle unter dem Eis verschwindet. Zwischen hier und felsigen Steilwänden $1200 \mathrm{~m}$ weiter im N, an die sich das Eis besonders eng anschmiegt, ist eine ziemlich breite periphere Rinne ausgebildet, die etwas unter $400 \mathrm{~m}$ über dem Meer liegt (Abb. 2). Auf den Luftbildern des Geodätischen Institutes in Kopenhagen von 1968 (FS. Nr. 850780) sind hier keine Schmelzwasserseen zu erkennen. Auf den jüngeren Flugaufnahmen von 1985 ist ungefähr in der Mitte zwischen beiden Felsriegeln ein etwa $500 \mathrm{~m}$ langer, ganz schmaler Stausee zu sehen („Nysø 1“), der hier seitdem entstanden war und weitgehend unverändert auch noch 1986 existierte. Der Eisrand war im Vergleich zu 1968 deutlich nach W vorgerückt (ScHOlz, 1991).

Bei unserer Begehung 1993 war der Eisspiegel gegenüber 1997 nochmals deutlich angestiegen und die etwa 500 m nördlich des „Nysø 1“ gelegene Engstelle zwischen Eisrand und Fels dadurch fast unpassierbar geworden. Der Wasserspiegel des „Nysø 1" lag jetzt um mehrere Meter höher als 1986. Das war u.a. daran zu erkennen, daß markante Moränenwälle (der historischen Stadien), die 1986 noch am Rand des „Nys $\varnothing$ 1" gelegen hatten, jetzt als Inseln mitten im See herauskamen. In der peripheren Rinne zwischen „Nysø 1“ und der nördlich davon liegenden Engstelle hatten sich mehrere schmale Schmelzwasserseen gestaut. Sie standen durch Schmelzwasserrinnen miteinander in Verbindung, die zwischen den einzelnen Seen Höhen von jeweils wenigen Metern zu überwinden hatten. Das aus dem nördlichsten dieser Seen überlaufende Schmelzwasser verschwand kurz vor der Engstelle in einem Eistunnel. Die westlichen Ufer dieser nur wenige Dekameter breiten Seen waren bis zur Wasserlinie von Zwergstrauchheiden bewachsen. Das Gegenufer wurde abschnittsweise vom blanken Eis mit senkrechten Kalbungsfronten gebildet. Teilweise wurden die Seen auf der Ostseite auch von blockreichen Eisrandablagerungen begrenzt.

Auf den Flanken dieser Moränen waren am Nordende der Seenkette Hochwassermarken zu sehen, die anzeigten, daß der nördlichste der Seen vorher einen bis zu $6 \mathrm{~m}$ höheren Wasserstand gehabt haben muß. Weitere Hochwassermarken, die sich bei näherem Hinschauen überall entlang des Ostufers der Seenkette fanden, machten deutlich, daß es sich bei der Seenkette nur um Reste eines inzwischen ausgelaufenen, schmalen, größeren Eisrandstausees gehandelt haben muß. Deutliche Wasserstandsmar- 

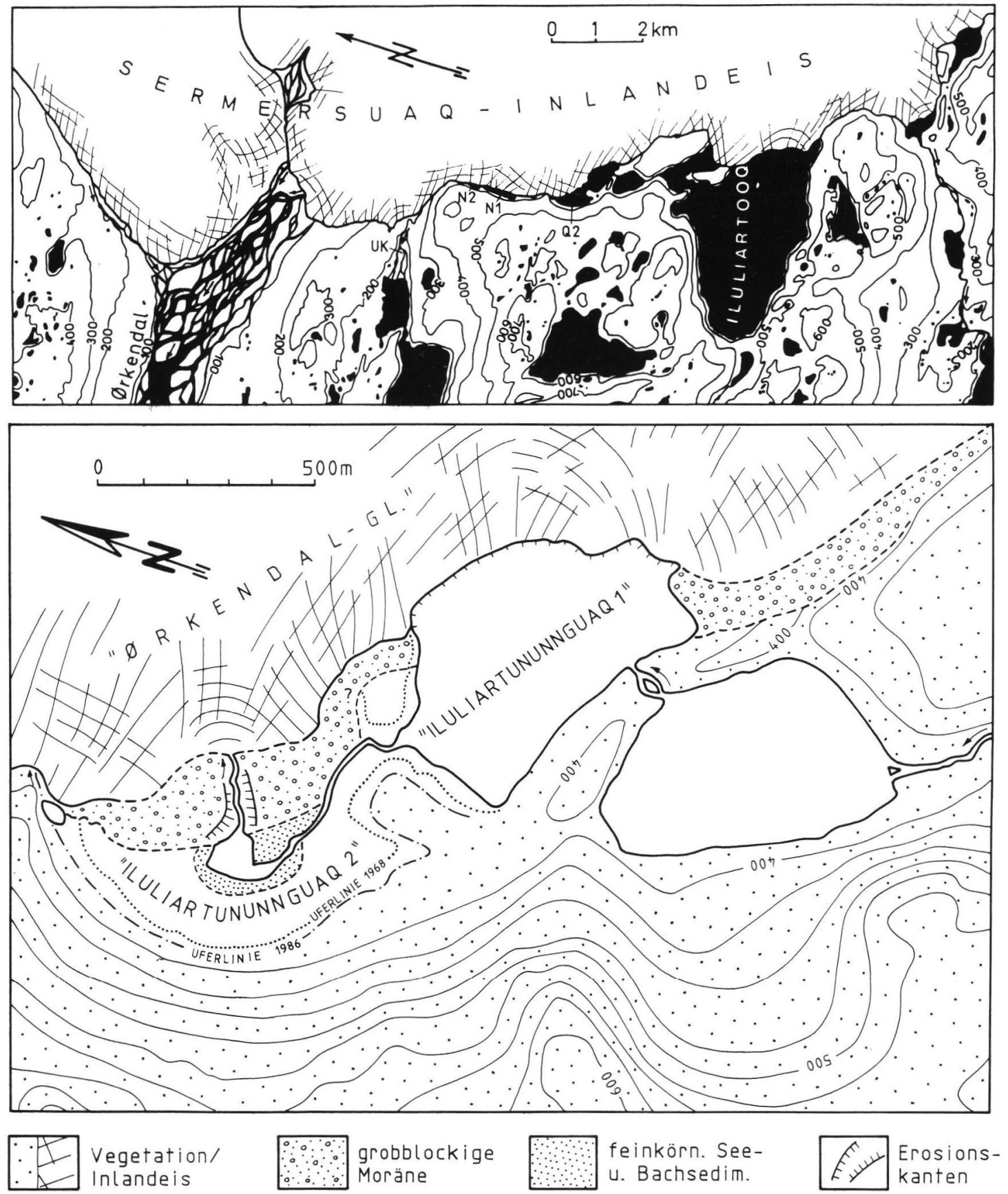

Abb. 2: Die beiden topographischen Kärtchen sind auf der Grundlage der amtlichen Karte 1:100000 und der von Luftbildern hergestellt. Unter Verwendung der Karten bei ScHOLz (1987), verändert. Hier finden sich auch eine geologische und eine pflanzensoziologische Detailkarte des Gebietes. Oben: Topographisches Übersichtskärtchen des Gebietes zwischen dem riesigen Ørkendal-Sander und dem Iluliartooq, mit der südlich anschließenden kleinen Sanderfläche „Umimmalissuup Kunungua“ (UK), dem „Nys $\varnothing$ 1“ (N1), dem „Nysø 2“ (N2) und dem „Iluliartununnguaq“. Die Flüsse und Seen sind schwarz dargestellt. Unten: Detailkärtchen mit dem instabilen Eisrandstausee „Iluliartununnguaq“. Der See besteht aus 2 Teilbecken, von denen sich das nördlichere (Q2) gelegentlich entleert.

Fig 2: Both topographic maps were made on base of the official map 1:100000 and by use of aerial photographs, using the maps given in Scholz (1987), corrected. In Scholz (1987) geological as well as botanical maps of the region are to be found. Above: Topographic map giving an overview of the area between the large sandur of Ørkendal and the lake Iluliartooq, together with the smal sandur plain "Umimmalissuup Kunungua“" (UK) to the South and the lakes "Nysø 1" (N1), "Nysø 2" (N2), and "Iluliartununnguaq." All rivers and lakes are symbolised with black signatures. Below: Special map showing the unstable ice-dammed lake „Iluliartununnguaq". The lake consists of 2 separate basins. The northern one (Q2) empties from time to time. 
ken waren am Eisrand selbst und auf Moränen der Historischen Stadien zu erkennen, die hier der Gletscherfront unmittelbar vorgelagert sind. Hochwassermarken, die allerdings weniger deutlich waren, fanden sich auch am dicht mit Vegetation bewachsenen Gegenufer (Taf. 1b). Hier war die Vegetation teilweise mit feinkörnigen Sedimenten überdeckt, die in einem Stausee abgelagert worden sein mußten.

Da diese Sedimente größtenteils noch feucht waren, muß der Wasserspiegel noch kurz vor unserer Ankunft am 11. 7. 1995 deutlich höher gelegen haben. Tatsächlich gab es Hinweise, daß dieser See am Vortag ausgelaufen war. Die terminale Schmelzwasserrinne des „Umimmalissuup Kunungua“, die $1 \mathrm{~km}$ weiter im $\mathrm{N}$ den Eisrand entwässert (Abb. 2), führt gewöhnlich so wenig Wasser, daß sie in einiger Entfernung vom Eis normalerweise überquerbar ist, ohne daß man die Schuhe ausziehen muß. Am 10.7.1995, am Tag bevor wir den „Nysø 2“ das erste Mal zu Gesicht bekamen, führte das verflochtene Flußsystem dieser Sanderfläche so viel Wasser, daß man in einigen Rinnen bis zur Hüfte im Schmelzwasser stand. Die Hauptmasse des Wassers schoß mit Getöse als meterdicker Strahl aus einem fast mannshohen Loch, das sich im Bereich vom „dirty basal ice" etwa in der Mitte der steilen Eisfront befand. Schon am darauffolgenden Tag hatte die Schüttung deutlich nachgelassen. Die Sanderfläche war an diesem und den restlichen Tagen unseres Aufenthaltes wieder ziemlich einfach zu überqueren. Ich vermute, daß das von uns beobachtete Hochwasser mit dem Auslaufen des "Nysø 2" in Verbindung stand. Das Wasservolumen, das bei diesem kleinen Gletscherlauf freigesetzt worden ist, dürfte in der Größenordnung von etwa $30000 \mathrm{~m}^{3}$ gelegen haben. Der tiefere Teil des rinnenförmigen „Nysø 2“ wurde im Sommer 1993 auf seiner ganzen Länge von einem breiten Bach durchflossen, dem Überlauf von „Nysø 1", der sich stellenweise zu einem schmalen Restsee erweiterte. Wo das Gewässer seicht war, konnte man den steinigen Boden der Rinne erkennen. Bis zu 6 m über dem Niedrigwasserniveau waren die Zwergsträucher mit eingetrocknetem Schluff überzuckert und staubten beim Darüberlaufen (Taf. 1b). Stellenweise fanden sich auf den Zwergsträuchern liegende Häufchen von Sand und Geröllen. Ähnliche Erscheinungen habe ich 1987 im Becken des damals eben ausgelaufenen "Oberen Russellsees“ (,Russell 1“) beobachten können. Bei ihnen handelte es sich um die Sedimentfracht bzw. die Liegemarken von gestrandeten und inzwischen abgeschmolzenen Drifteisblöcken. Am „Nysø 2“ trugen die teils lebenden, teils abgestorbenen Pflanzen - etwa 1 bis $2 \mathrm{~m}$ über dem Niedrigwasserstand - zentimeter-, weiter unten auch dezimeterdicke, undeutlich geschichtete Hauben aus schluffigen, feinbis mittelkörnigen Sanden (n21). Unter diesen Hauben gab es weiterhin zahlreiche luftgefüllte Hohlräume. Die Schichtungsgefüge waren vielfach gestört, was auf Sackungsvorgänge zurückzuführen sein dürfte.

All diese Beobachtungen sprechen dafür, daß sich anstelle des Baches noch kurz vor unserem Eintreffen ein see befunden haben muß, der inzwischen ausgelaufen war. Der See muß an seinem Westufer die hier wachsenden Pflanzengesellschaften überflutet haben, während sein Ostufer an den aktiven Eisrand grenzte. Stellenweise muß er direkten Kontakt mit dem Eis gehabt haben, da Spuren des Drifteises nachweisbar waren. Aus der nach unten zunchmenden Mächtigkeit der sandig-schluffigen Stillwasserablagerungen muß geschlossen werden, daß die tieferen Teile des Seebeckens länger unter Wasser waren als die höheren. Die maximale Stauhöhe wird wohl nur ganz kurze Zeit erreicht worden sein, da in den obersten Metern, abgesehen von einer dünnen Schluffhaut auf den Pflanzen, keine Seesedimente nachweisbar sind.

Im Bereich der höchsten Wasserstandsmarken konnten an einigen Stellen charakteristische Schäden an der Vegetation beobachtet werden. Seewärts war auf quadratmetergroßen Flächen der nackte Boden freigelegt, hangwärts war die hier fehlende Vegetationsdecke wie ein Tischtuch zusammengestaucht. Ähnliche Vegetationsschäden habe ich 1987 auch im Bereich der maximalen Wasserstandsmarken des ausgelaufenen „Russell 1“ beobachten können, wo sie offensichtlich in Zusammenhang mit einer Seegefrornis standen. Zerbrochene Reste der Eisplatten, die diese Schäden offenbar verursacht hatten, lagen hier am R1 noch an Ort und Stelle.

\subsubsection{Leverett 1 (L1)}

Der instabile Eisrandstausee „Leverett 1“ liegt genau im Zwickel zwischen den beiden Inlandeiszungen des Leverett-Gletschers und des „Isorlersuup-Gletschers", der amtlichen Karte nach in einer Höhe von etwas über $500 \mathrm{~m}$ über dem Meer. Es ist der nordwestlichste dieser Seen und liegt dem Leverett-Gletscher am nächsten. Auf Luftbildern des Geodätischen Instituts in Kopenhagen, die von einer Befliegung Anfang September 1985 stammen (FS. Nr. 860957), ist der „Leverett 1“ in leerem Zustand zu sehen, genauso wie auf Luftbildern von einer Befliegung von Mitte August 1968 (FS. Nr. 850780). Auf den älteren Aufnahmen sind zahlreiche gestrandete Eisberge zu erkennen, die auf der Schlammkrawatte des Stausees liegen. Er scheint al- 


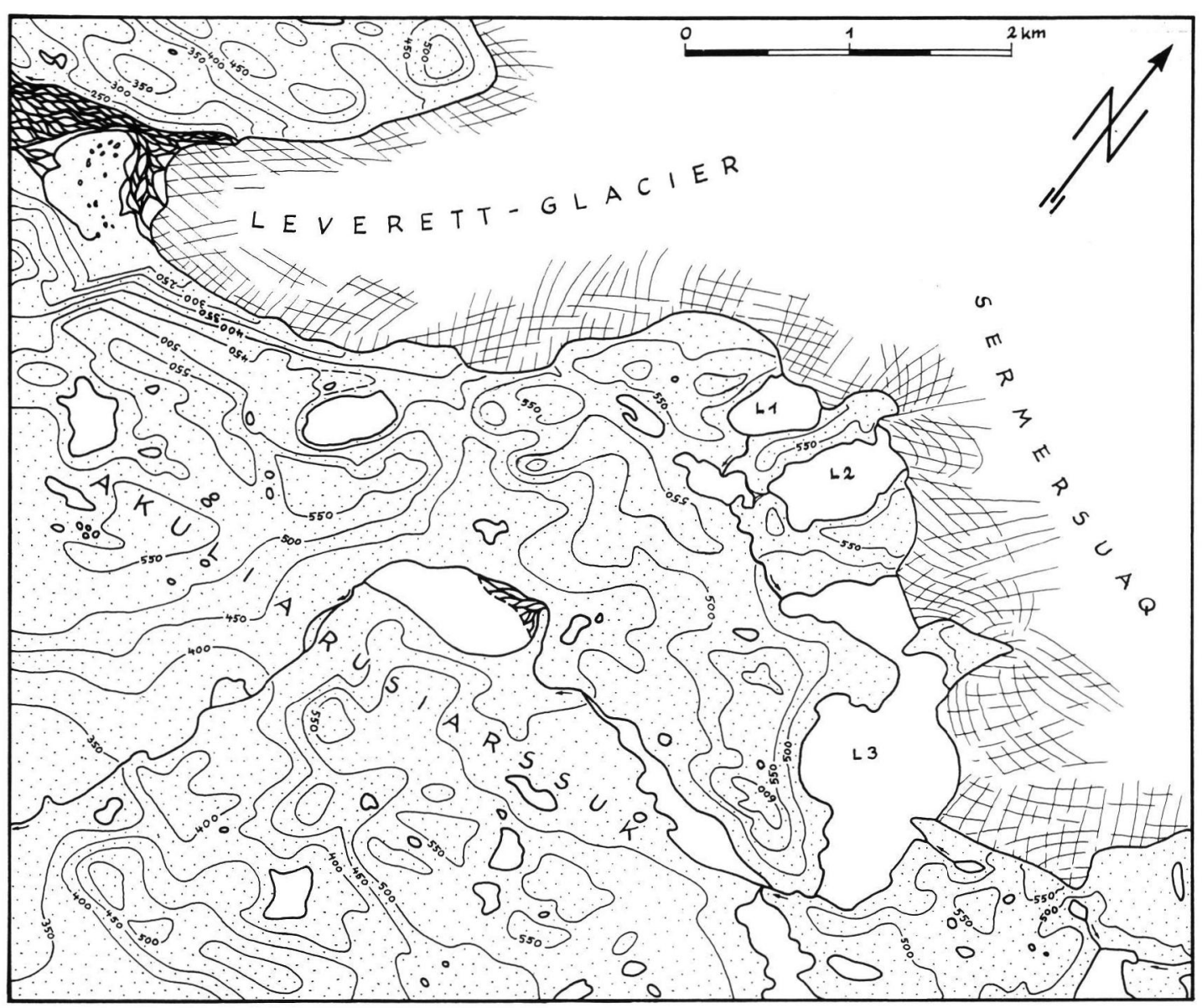

Abb. 3: Topographische Übersichtskarte des Gebietes südlich des Leverettgletschers, um die Lage und die hydrographischen Verhältnisse des instabilen Eisrandstausees „Leverett 1“ (L1) zu verdeutlichen. Das Festland ist gepunktet, die Seen sind weiß, die Gletscher mit einer Spaltensignatur dargestellt.

Fig. 3: Topographic map giving an overview of the region south of the Leverett Glacier, in order to show the situation and the hydrographical conditions of the unstable ice-dammed lake „Leverett 1“ (L1). Land is dotted, lakes are white, glacier tongues symbolised with a crevasse signature.

so, kurz bevor die Aufnahme gemacht wurde, ausgelaufen zu sein. Im Gegensatz dazu konnte im Sommer 1987 vom Flugzeug aus beobachtet werden, daß der „Leverett 1“ mit Schmelzwasser gefüllt war. Bei unserer Ankunft am 1. August 1993 war der See jedoch leer (Taf. 2a und 2b).

Das etwa $550 \mathrm{~m}$ lange, $400 \mathrm{~m}$ breite und über $40 \mathrm{~m}$ tiefe Seebecken wird im NW und SE von niedrigen Felsrücken begleitet, auf der nordöstlichen Schmalseite vom Inlandeis abgedämmt und auf der Südwestseite durch einen niedrigen Hügel abgeriegelt (Abb. 3, 4). Zwei Flanken der länglichen Hohlform sind relativ steil, während der Boden zum Eis hin, in NNE' Richtung, allmählich abfällt. Im Profundal am Nordostende des vegetationslosen Beckens befand sich 1993 ein Restsee von etwa 200 m Durchmesser (Taf. 3a und Abb. 5). An seinen Ufern, vor allem am Südende, lagen große Mengen teilweise riesiger gestrandeter Eisberge. Vereinzelt fanden sich noch tauende Reste gestrandeten Drifteises nur wenige Meter unterhalb der Hochwasserlinie des Beckens. Die ehemals vertikale Kalbungsfront der am Nordende des Sees liegenden Gletscherzunge war schon bei unserer Ankunft teilweise zusammengebrochen.

Der Maximalstand des Wassers wird durch ein kleines Kliff nachgezeichnet, das sich auf 3 Seiten des Seebeckens verfolgen läßt (Taf. $2 a$ und $2 b$ ). Knapp unterhalb dieser Uferlinie lagen z.Z. unserer Ankunft die ersten im Abschmelzen begriffenen Drifteisblöcke. Am Südende des Sees setzt eine mehrere Meter in die Umgebung eingeschnittene Rinne an, die sich außerhalb des Seebeckens nach $\mathrm{S}$ zu in ein ca. $300 \mathrm{~m}$ langes, ganz flaches Trockentälchen fortsetzt (Abb. 4 und Taf. 2b). Das Gefälle dieses Tales ist nach S gerichtet. Der weitgehend ebene, ve- 

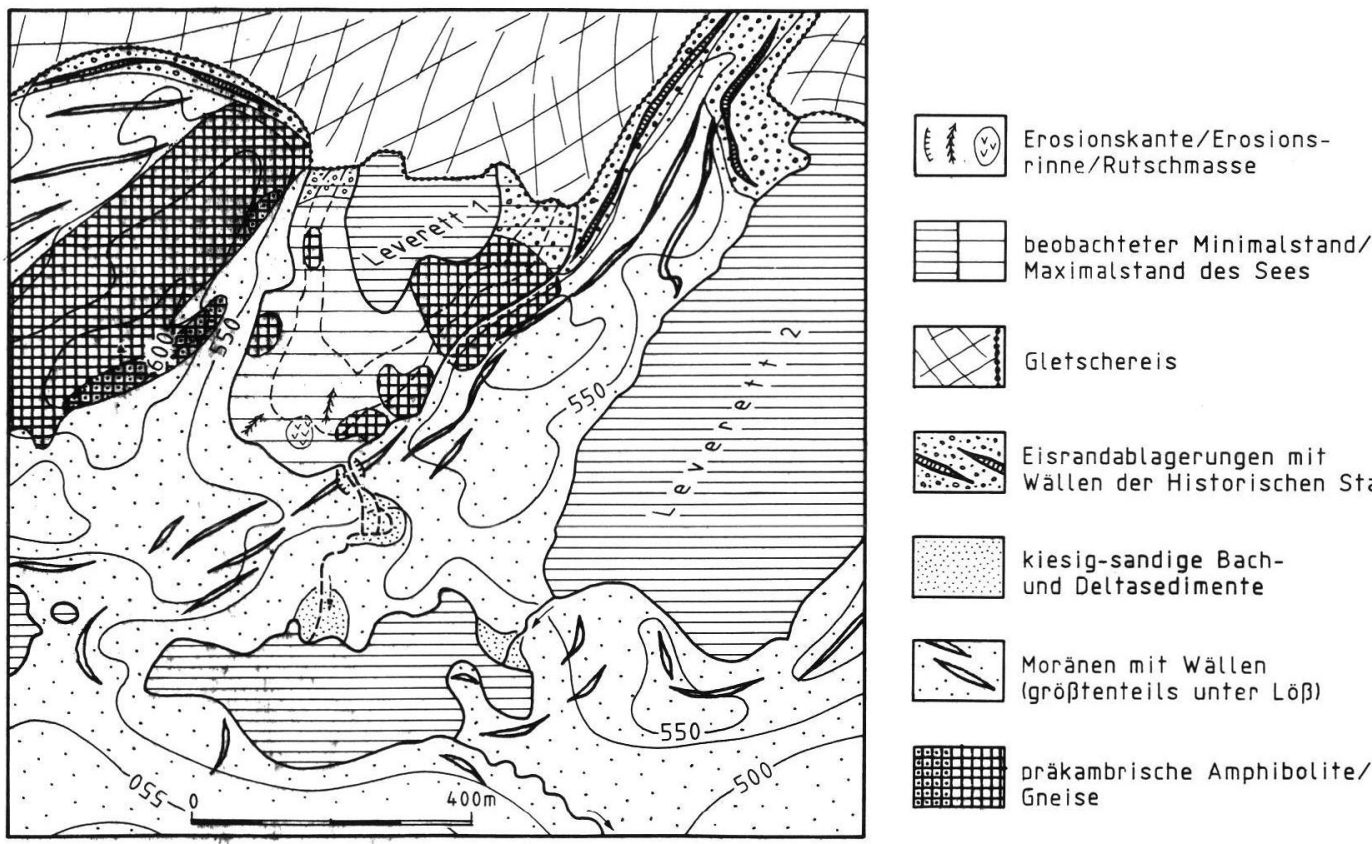

Gletschereis

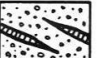

Eisrandablagerungen mit

Wällen der Historischen Stadien
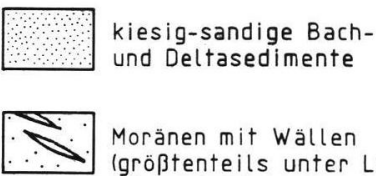

Moränen mit Wällen

(größtenteils unter Löß)

Dräkambrische Amphibolite/

Gneise

Abb. 4: Geologisches Kärtchen der unmittelbaren Umgebung des instabilen Eisrandstausees „Leverett 1“. Aufgenommen auf der Grundlage einer verbesserten Version der Karte von Abb. 3. Der nur periodisch wasserführende Überlauf des Sees ist gestrichelt dargestellt.

Fig. 4: Geological map showing the vicinity of the unstable ice-dammed lake "Leverett 1". It was produced on base of a corrected version of the map given in fig. 3. The lake outlet supplied periodically with water only, is marked with a dotted line.

getationslose Boden des stellenweise in mehrere Rinnen aufgespaltenen Tälchens ist teils von Geröllen, teils von Sand bedeckt. Diese Rinne dient dem See in den Zeiten, in der er gefüllt ist, offensichtlich als Überlauf. Das hier überfließende Schmelzwasser mündet in einen kleinen, südlich anschließenden See, wo sich augenscheinlich ein weitgehend bewachsenes, sandiges Delta gebildet hat (Abb. 4). Der Überlauf dieses Sees wiederum, der auch mit Schmelzwasser versorgt wird, das aus dem benachbarten See „Leverett 2" überläuft, mündet nach weniger als $1 \mathrm{~km}$ Fließstrecke in den größten dieser Eisrandstauseen, den "Leverett 3“ (Abb. 3). Der Zustand, in dem der See 1993 angetroffen wurde, stimmt weitgehend mit demjenigen überein, der auch auf den untersuchten Luftbildern von 1968 und 1985 zu erkennen war. Aus den geschilderten Beobachtungen muß geschlossen werden, daß der See wohl noch wenige Wochen vor unserer Ankunft mit Schmelzwasser gefüllt war.

Der trockengefallene, schüsselförmige Seeboden war im Sommer 1993 nicht überall zugänglich. Im Profundal des Beckens befand sich ein etwa 200 mal $200 \mathrm{~m}$ großer Restsee, der dicht mit schwimmenden, großen Eisblöcken bedeckt war (Taf. 3a).
Trotz einiger Versuche gelang es nicht, näher als 50 $m$ an diesen Restsee heranzukommen und Proben zu sammeln. In seiner unmittelbaren Umgebung liegen die gestrandeten Eisberge so dicht, daß zwischen ihnen nur noch schmale Gassen frei sind (Abb. 5). Einige der am Rand des Beckentiefsten liegenden Eisblöcke sind so groß, daß sie noch über den Beckenrand hinausragen. Zudem hört und sieht man ständig, wie kilo- bis tonnenschwere Eisblöcke krachend herunterbrechen. Selbst mit Helmen bewehrt wäre es zu gefährlich gewesen, zwischen die riesigen Eisblöcke vorzudringen. So kann über die Sedimente im Profundal nichts ausgesagt werden. Die Beobachtungen, die sich an den unmittelbar angrenzenden, mäßig geböschten Teilen des schüsselförmigen Seebeckens machen lassen, sind wohl auch auf das Profundal übertragbar.

Das Substrat der Zwergstrauchheiden, die die Hänge am Südende des Seebeckens bedecken, bilden kryoturbat gestörte äolische Sedimente. Sie sind durch Gelifluktion mit organischem Material vermischt und dadurch sowie durch Verwitterung bräunlich gefärbt. Der Hang ist fast lückenlos mit Erdbülten (Hummocks) bedeckt. Der gleiche Vegetationstyp findet sich auch innerhalb des Seebeckens 

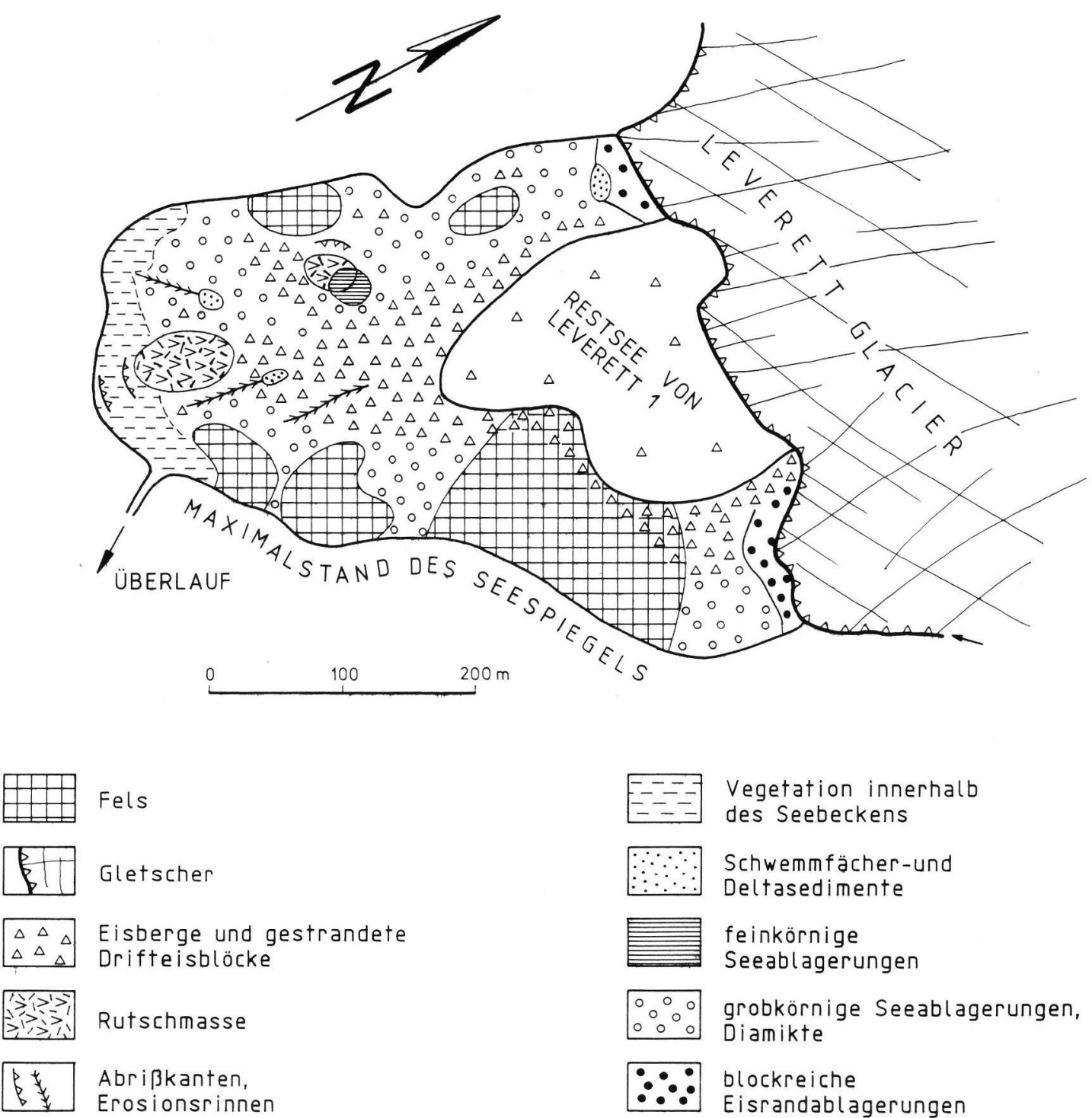

Fels

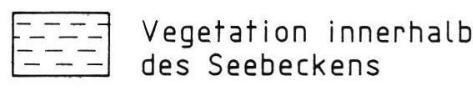

Gletscher

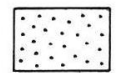

\section{Schwemmfächer-und Deltasedimente}

\section{Eisberge und gestrandete}

Drifteisblöcke

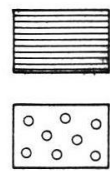

\section{feinkörnige \\ Seeablagerungen}

\section{Rutschmasse}

\section{grobkörnige Seeablagerungen, Diamikte}

\section{Abrißkanten,} Erosionsrinnen

Abb. 5: Die Gliederung des weitgehend wasserleeren Beckens von „Leverett 1“, wie es im Sommer 1993 ausgesehen hat. Die Bereiche außerhalb des maximalen Wasserstandes sind nicht dargestellt. Aufgenommen auf der Grundlage einer verbesserten Version der Karte von Abb. 3.

Fig. 5: Morphologic pattern of the rather empty basin of „Leverett $1^{\prime \prime}$, as it appeared in summer 1993. The area above the maxi mum water level is ignored here. This map was produced on base of a corrected version of the map given in fig. 3.

unterhalb der Hochwasserlinie, aber nur am relativ flach geböschten Südwestende des Beckens, wo die Hänge $15^{\circ}$ Neigung kaum übersteigen (Taf. 2a und b). Nur die Erdbülten fehlen hier weitgehend oder sind zumindest schwächer entwickelt, die Bodendeckung ist deutlich geringer und es tritt hier eine Anzahl flacher Erosionsrinnen auf, die alle knapp unterhalb der deutlichen Uferlinie beginnen (Taf. 2b). Die Zwergsträucher sind hier von einer dünnen Schluffschicht überzogen, gleichwohl aber in den obersten 6 bis $8 \mathrm{~m}$ größtenteils noch am Leben und grün. Zudem liegen auf der Vegetationsdecke einzelne Blöcke und kleine Häufchen von Sand und Geröll herum. Es muß sich dabei um Material handeln, das von gestrandeten und inzwischen abgetauten Drifteisblöcken stammt.

Ab etwa $8 \mathrm{~m}$ unterhalb des Überlaufes gibt es auch am Südende des Seebeckens weder tote noch lebende Zwergsträucher. Hier kommen dafür bräunlich gefärbte, schluffige Sedimente heraus, die den 
kryoturbat gestörten äolischen Sedimenten ähneln, dem Substrat der Vegetation außerhalb des Beckens (112, 115). In diesem Bereich ist das Relief des Hanges sehr unruhig. Hier treten unregelmäßige Wülste, Versteilungen und Spalten im Boden auf, die darauf hinweisen, daß hier der ganze Hang in Bewegung ist (Taf. 2b).

Gegen die Hänge der Umgebung ist das Seebecken überall mit einer kliffartigen Versteilung abgesetzt. Diese Uferlinie, die den maximalen Seespiegel nachzeichnet, ist als messerscharfe Grenze auf 3 Seiten des Seebeckens zu verfolgen. Am NW- und am SEUfer trennt diese Grenze die bewachsenen Hänge vom vegetationslosen Becken ab. Am flacheren SWUfer, wo auch Teile des Seebeckens selbst bewachsen sind, ist unterhalb dieser kaum $1 / 2 \mathrm{~m}$ hohen Stufe eine mehrere Meter breite, bewachsene Verebnungsfläche ausgebildet, deren Vegetation sich von der Umgebung deutlich unterscheidet (Taf. 2a). Auf dieser Schorre dominieren Moose, während Zwergsträucher, abgesehen von Salix herbacea, völlig fehlen. Dieser Vegetationstyp erinnert stark an eine „Schneetälchen-Vegetation“, die sich an Stellen mit extrem kurzer Vegetationsperiode ausbildet. Auch die Pflanzen auf diesem Uferstreifen sind mit Schluff überpudert. Stellenweise sind hier auch trockene, papierartig dünne Krusten zu finden, die im wesentlichen aus eingetrockneten Algen zu bestehen scheinen (116).

Der Seeboden ist aber nicht überall gleich aufgebaut (Abb. 5). An der NW-, vor allem aber an der SE-Flanke des Beckens kommen in steilen Lagen die eisüberschliffenen Felsen des Grundgebirges heraus. Sie haben eine hellgraue Farbe, da die Oberfläche mit einer dünnen, eingetrockneten Schluffhaut überzogen ist. An weniger stark geböschten Stellen liegen etwas Sand und lose Blöcke auf den Felsen herum. Der weitaus größte Teil des trockenen Seebeckens wird aber von lockeren, blockigsandigen, schwach schluffigen Sedimenten eingenommen. Diese Ablagerungen sind ungeschichtet und weitgehend unsortiert. An den Beckenflanken ist schon von weitem auf diesen Ablagerungen eine deutliche horizontale Bänderung zu erkennen. Dabei handelt es sich um horizontale Streifen aus hangparallel geschichteten, relativ schlecht sortierten, grobkörnigen Sanden, die kleine Geröllchen enthalten (114). Gegen die blockig-sandigen Sedimente sind sie schwierig abzugrenzen. Die Mächtigkeit dieser Sandkörper, die den unsortierten Sedimenten auflagern, liegt im $\mathrm{cm}-$, maximal im dmBereich. Es handelt sich hier offensichtlich um Wasserstandsmarken, um Strandbildungen, die bei absinkendem, vielleicht auch bei steigendem Seespiegel entstanden sind.
Größere Sandkörper finden sich nur in der Nordostecke des Seebeckens, wenige Dekameter vom Eisrand entfernt. Sie sind an die Umgebung einer Rinne gebunden, in der sich zeitweise vom Eisrand ablaufende Schmelzwässer sammeln und eisrandparallel dem Restsee zulaufen. Am Ende von einigen kleinen Erosionsrinnen, die das Schmelzwasser von am Hang liegenden, gestrandeten Eisbergen aufnahmen, entstanden gleichfalls sandige Schwemmfächer (113). Feinkörnige Seesedimente, mittel- bis grobkörnige Schluffe mit relativ geringen Feinschluff- und Tongehalten, sind im Seebecken sehr selten anzutreffen und konnten im wesentlichen nur auf einer größeren Hangverflachung im SW des Beckens entdeckt werden, etwa 15 bis 20 m unterhalb der Uferlinie $(111,117)$. Diese wiesen teilweise sogar eine überaus deutlich sichtbare, mm-dünne Laminierung auf. Sie erreichten hier eine Mächtigkeit von kaum mehr als $5 \mathrm{~cm}$ und überlagerten grobblockige, kiesig-sandige Sedimente des Typs, wie sie oben schon beschrieben worden sind. Seitlich scheinen sie in die gleichen grobblockigen Sedimente überzugehen. Allerdings war der Bereich, in dem sie gefunden wurden, durch Hangbewegungen beeinflußt. Der größte Teil des Seebeckens aber wird von ungeschichteten, schluffig-sandig-blockigen Ablagerungen eingenommen (Abb. 5).

\subsubsection{Russell 1 (Oberer Russell-See, R1)}

Der „Russell 1“ wurde in früheren Arbeiten (ScHolz et al., 1988) „Oberer Russell-See“ genannt. Dieser im gefüllten Zustand etwa 1,5 km lange, $1 \mathrm{~km}$ breite und über $50 \mathrm{~m}$ tiefe See befindet sich, in niedrige Berge eingebettet, im Zwickel zwischen RussellGletscher und Isúnguata Sermia (Abb. 6). Der See liegt nach der Karte etwas unter 500 m hoch, nach unseren barometrischen Höhenmessungen aber nur ca. 300-400 m hoch. Er ist auf einer Seite durch eine senkrechte Kalbungsfront begrenzt und speist ein großes, peripheres Flußsystem (Abb. 1), das die Nordflanke des Russell-Gletschers entwässert und Zuschüsse auch vom weiter im N liegenden Isúnguata Sermia erhält (Sugden et al., 1985). Während des Sommers schüttet es nach Russel. (1989) zwischen 13 und $37 \mathrm{~m}^{3}$ Wasser pro Sekunde. Die Schmelzwässer durchfließen eine Reihe von Sanderflächen und Seen, die teilweise durch Stromschnellen und Wasserfälle miteinander verbunden sind. An Stellen, wo er zum Eis hin abgedrängt wird, erodiert der Fluß den Gletscher in senkrechten Wänden an, verschwindet am Zungenende sogar auf einer Strecke von $500 \mathrm{~m}$ Länge in einem weiteren subglaziären Tunnel, bevor er über den anschließenden „RussellSander" den Eisrand endgültig verlassen kann. 
Auf den amtlichen Luftbildern des Geodätischen Instituts in Kopenhagen, die von von Befliegungen von Anfang September 1985 (FS. Nr. 860957) und von Mitte August 1968 (FS. Nr. 850780) stammen, sowie auf den selbstgemachten Schrägaufnahmen, die jeweils beim Überfliegen des Gebietes mit dem Linienflugzeug in den Jahren 1982, 1986, 1987 und 1993 aufgenommen wurden, ist der „Russell 1“ manchmal in gefülltem, in teilweise gefülltem oder in entleertem Zustand zu erkennen. Im sommerlichen Normalzustand scheint der See mehr oder weniger gefüllt und mit schwimmenden Eisbergen bedeckt zu sein. Gelegentlich ist er, wie im Juli 1993 beobachtet werden konnte, so voll, daß das Schmelzwasser über einen kleinen See und Wasserfälle nach W zum „outlet lake 1" hin abfließt (Abb. 6). Diese höchsten Wasserstandsmarken werden durch ein niedriges Kliff mit vorgelagertem Geröllstrand nachgezeichnet. Diese höchsten Wasserstände scheinen aber nur gelegentlich erreicht zu werden. Dafür spricht die Beobachtung von 1987 , daß die Uferbereiche noch etwa 10 bis $15 \mathrm{~m}$ unterhalb dieser höchsten Wasserstandsmarken von lebenden Zwergstrauchheiden bewachsen sind. Nach dem Bewuchs auf dem Strand und auf dem Geröll im Bett des Überlaufes zu urteilen, war diese maximale Füllung damals schon mehrere Jahre nicht mehr erreicht worden.

Nach dem Auslaufen des „Russell 1“ im Juli 1987 blieb ein dicht mit schwimmenden Eisbergen bedeckter, immer noch vom Eis abgedämmter Restsee von etwa 800 m Länge zurück, dessen Wasserspiegel $48 \mathrm{~m}$ tiefer als die frischen Hochwassermarken lag, die wiederum etwa $3 \mathrm{~m}$ unter den höchsten Wasserstandsmarken blieben (Russelt, 1989). Die Höchstwasserstände von 1987 wurden von großen Eisplatten - den Resten einer Seegefrornis - nachgezeichnet. Darunter lagen auf den breiten Schlammkrawatten zahlreiche gestrandete Eisberge, die mitunter die Größe eines Einfamilienhauses erreichten (Taf. 3b). An Stellen, wo sie schon weggetaut waren, fanden sich ihre Spuren in Form von kleinen Haufen ausgeschmolzenen Schuttes und großen Liegemarken im weichen Untergrund. Die hier wachsenden, grünen Zwergbirken waren mit einer teilweise zentimenter- bis dezimeterdicken Schlammschicht bedeckt. Unter der deutlich über $50 \mathrm{~m}$ hohen, teilweise zusammengebrochenen Kalbungsfront am Südufer des Sees waren große Schutthalden aus Eisblöcken entstanden.

Mitte Juli 1987 entleerte sich der „Russell 1“ innerhalb von 36 Stunden und erzeugte eine Hochwasserwelle, die sich im Bereich der peripheren Rinnen und auf den terminalen Sanderflächen als dramatischer Anstieg der Wasserstände zu erkennen gab. Die Auswirkung dieses Ereignisses auf die Sanderflächen wurde damals verfolgt und dokumentiert (Scholz et al., 1988; RusselL, 1989). Vermessungen des Seebeckens sowie die Auswertung automatisch arbeitender Pegel, die von Geographen der Universität Aberdeen im Oberlauf des peripheren Entwässerungssystems installiert worden waren, lassen darauf schließen, daß der See damals zwischen 32 und $36 \cdot 10^{6} \mathrm{~m}^{3}$ Wasser verlor (Russell, 1989).

Es ist unbekannt, wann genau das Auslaufen des Sees am 17. Juli 1987 einsetzte. Mit zunehmender Entfernung von ihrem Ursprungsort dürfte die Flutwelle mit wachsender zeitlicher Verzögerung, von den durchflossenen Seen gedämpft und auseinandergezogen, mit abnehmender Amplitude angekommen sein. Erst als die Flutwelle gegen 23.00 Uhr das Zungenende des Russell-Gletschers - etwa 10 $\mathrm{km}$ unterhalb des auslaufenden Sees - erreicht hatte, sprachen die hier installierten Pegel an. Gleichzeitig war ein lang anhaltendes Donnern von der Kalbungsfront am Gletscherende zu hören. Dieses Donnern zeigte wohl eine verstärkte Erosion der Eiswände durch den anschwellenden Fluß an.

Das Donnern hörte nicht mehr auf, während das Wasser die ganze Nacht über stetig anstieg. Noch in der Nacht vom 17. zum 18. Juli waren die Eisbreccien am Fuße der Eiswände fortgespült worden. Hausgroße Gletscherteile wurden mitgerissen, in kubikmetergroße Eisblöcke zerlegt und polternd über den fast völlig überfluteten „Russell-Sander“ gewälzt. Am Eisrand erreichte die Hochwassermarke mehr als $10 \mathrm{~m}$ über der Niedrigwasserlinie. Auf der Sanderfläche selbst stieg das Wasser immerhin noch stellenweise etwa $3 \mathrm{~m}$ an, vor allem vor Engstellen. Das Treibeis wurde über die gesamte Breite des Flußsystems verteilt und bis zum ca. $25 \mathrm{~km}$ entfernten Flughafen Søndre Strømfjord mitgeschleppt (Abb. 1). Selbst das Fjordende des Kangerlussuaq war am Flughafen Søndre Strømfjord mit schwimmenden Eisblöcken bedeckt. Die höchsten Pegelstände am „Russell-Sander“ wurden erst am 18. Juli gegen 16.00 Uhr erreicht. Von da an fiel das Wasser stetig und hatte spätestens am 19. Juli gegen 11 Uhr wieder seinen normalen sommerlichen Pegelstand. Ein ähnlich ablaufender Gletscherlauf des gleichen Sees ist auch für den 19. und 20. August 1984 dokumentiert, bei dem er allerdings nur $22 \cdot 10^{6} \mathrm{~m}^{3}$ Wasser verloren hat (Sugden et al., 1985). Der See hatte allerdings vorher eine deutlich geringere Stauhöhe erreicht, während am Ende zudem ein etwas größerer Restsee zurückblieb.

Auslösende Ursache des Gletscherlaufes im Sommer 1987 dürfte, ähnlich wie in den vorangegangenen Jahren, der in der wärmsten Jahreszeit verstärkte Schmelzwassereintrag sein. Wenig ergiebige Nie- 


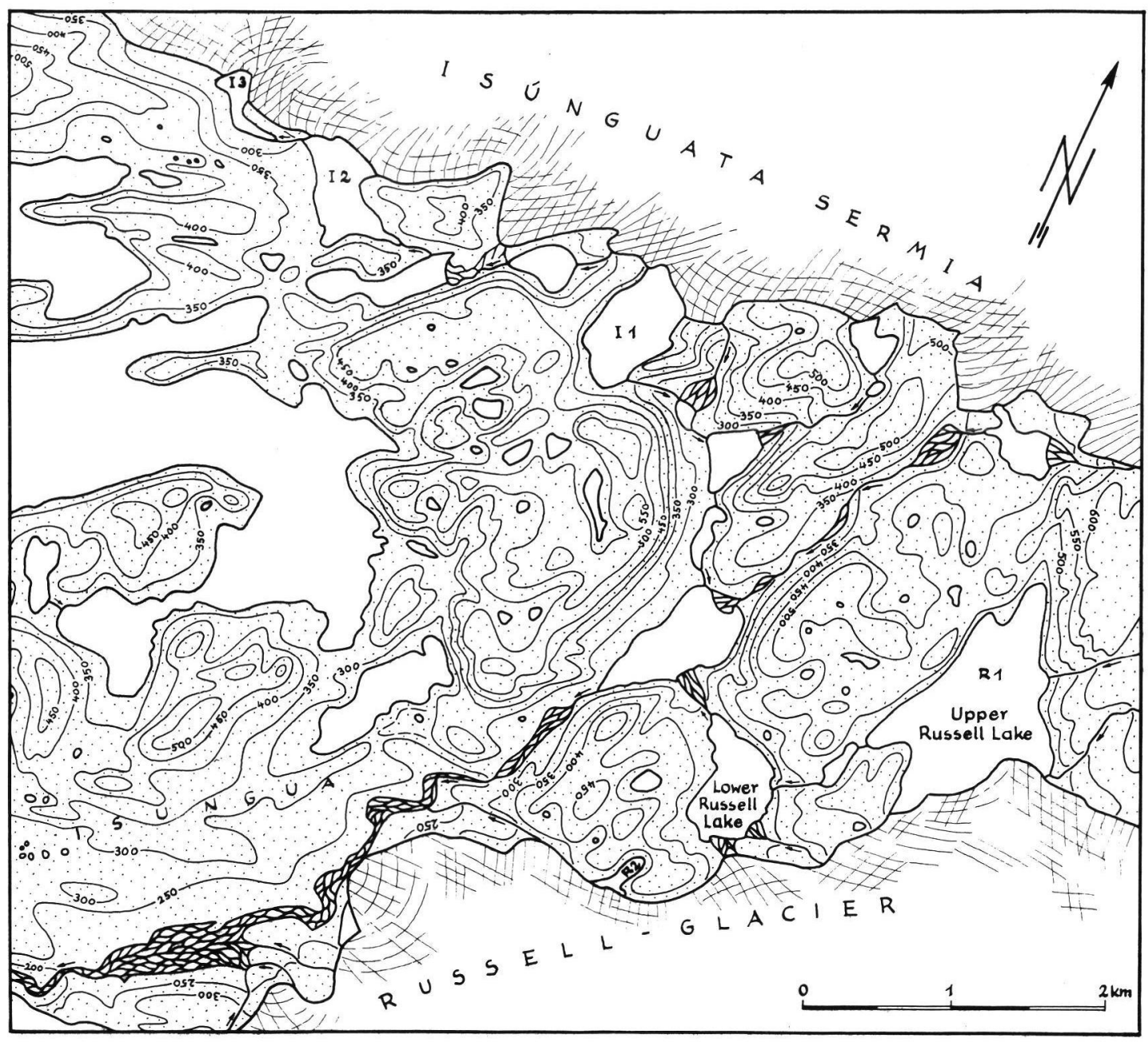

Abb. 6: Topographische Übersichtskarte des eisfreien Gebietes zwischen dem Russell-Gletscher und dem Isúnguata Sermia, um die Lage und die hydrographischen Verhältnisse der instabilen Eisrandstauseen „Russell 1“ (R1), „Russell 2“ (R2), „Isunguata 2" (I2) und „Isunguata 3" (I3) zu verdeutlichen. Das Festland ist gepunktet, die Seen sind weiß, die Gletscher mit einer Spaltensignatur dargestellt.

Fig. 6: Topographic map giving an overview of the non-glaciated areas between Russel Glacier und Isunguata Sermia, in order to demonstrate the situation and the hydrographical conditions of the unstable ice-dammed lakes „Russel 1“ (R1), „Russel 2“ (R2), „Isunguata 2" (I2) und „Isunguata 3" (I3). Land is dotted, lakes are white, glacier tongues symbolised with a crevasse signature.

derschläge, die im gleichen Zeitraum (17. und 18. Juli 1987) in den eisrandnahen Gebieten zu beobachten waren, kommen dagegen als Auslöser wohl kaum in Frage, da der Regen erst um etwa 22.00 Uhr einsetzte - kurz bevor die Flutwelle am Gletscherende ankam. Der Abfluß des „Russell 1“ läuft normalerweise über den oben beschriebenen Überlauf bzw. über Eistunnel am Westende der Kalbungsfront (SUGDEN et al., 1985). Etwa $1 \mathrm{~km}$ unterhalb des Sees tritt das Wasser wieder zutage und wird über ein grobblockiges Delta in einen mehr als $50 \mathrm{~m}$ tiefer liegenden See eingespeist, den „outlet lake 1“ („Unterer Russellsee“). Über eine Felsrinne ist dieser See mit einer Kette von weiteren
Seen und Sanderflächen des peripheren Entwässerungssystems am Nordrand des Russellgletschers verbunden (Abb. 6).

So lange die subglaziäre Entwässerung über die Eistunnel funktioniert, kann der See nicht über dessen Höhenlage hinaus ansteigen. Der Eingang des Tunnels, der zwischen Eis und Felsuntergrund liegt, hat ein Niveau, das in etwa einer 3/4-Füllung des Sees entspricht. Erst wenn er für die im Sommer zufließenden Schmelzwassermassen offensichtlich zu eng wird, steigt der Seespiegel weiter an, bis der Punkt erreicht ist, wo randliche Teile des Inlandeises unter Auftrieb geraten. Dieser Punkt wird aber im Abstand von 1 bis 3 Jahren bei ganz unter- 
schiedlichen Stauhöhen erreicht. Es ist bisher nicht bekannt, von welchen Faktoren das abhängt. Was genau unter dem Eis passiert, bleibt vorerst im Dunkeln. Wenn der Gletscherlauf aber einmal begonnen hat, läuft das Wasser jedenfalls, wie bei einer WC-Spülung, so lange aus dem See, bis er weitgehend entleert ist. Dann kann der Prozeß wieder von neuem beginnen.

\subsubsection{Russell 2 (R2)}

Auch der sehr viel kleinere Eisrandstausee „Russell 2“, der westlich des „outlet lake 1“ liegt (Abb. 6), entleert sich periodisch. In gefülltem Zustand ist er etwa $250 \mathrm{~m}$ lang, $100 \mathrm{~m}$ breit, $22 \mathrm{~m}$ tief und grenzt im S auf einer Strecke von $250 \mathrm{~m}$ direkt ans Eis. Nach seinem Auslaufen, das durch die oben genannte Arbeitsgruppe aus Aberdeen am 15. Juli 1988 beobachtet wurde (Russell et al., 1990), blieb in einem nördlichen Teilbecken ein knapp $100 \mathrm{~m}$ langer, weitgehend eisfreier Restsee zurück („upper ba$\left.\sin ^{\prime \prime}\right)$, an dessen Ufer einige gestrandete Drifteisblöcke lagen. Zwischen diesem Teilbecken und dem Eisrand waren, entsprechend den Angaben von RusSELL et al. (1990), bei sinkendem Wasserstand Moränenwälle sichtbar geworden, die vorher unter dem Seespiegel des gefüllten Stausees verborgen waren. Ein Überlauf dieses Restsees hatte sich während des Auslaufens erosiv in die Moränenwälle eingeschnitten, bevor er in einem Tunnel unter dem Eis verschwand („lower basin“). Das unter dem Eis verschwundene Schmelzwasser, etwa $330000 \mathrm{~m}^{3}$, dürfte kaum $500 \mathrm{~m}$ weiter im W als Gletscherlauf wieder zutage gekommen sein, und nach weiteren $700 \mathrm{~m}$ das periphere Entwässerungssystem erreicht haben. Der „Russell 2" ist nur erreichbar, wenn man das periphere Rinnensystem unterhalb des "Russell 1 " überquert (Abb. 6). Das erschien aber 1993 angesichts eines vom „Russell 1" verursachten drohenden Gletscherlaufes zu gefährlich. Deshalb wurde er im Rahmen des Projektes nicht näher untersucht.

\subsubsection{Isunguata 2 (I2)}

Der „Isunguata 2 " hat die Form eines etwas verbeulten Rechteckes, das etwa 600 auf $350 \mathrm{~m}$ mißt (Abb. 6). Er war auf den amtlichen Luftbildern des Geodätischen Instituts in Kopenhagen, die von einer Befliegung Mitte August 1968 (FS. Nr. 850780) stammen, in halb entleertem Zustand zu sehen (Abb. 7). Der von einer breiten Schlammkrawatte umgebene Restsee nahm ungefähr noch die Hälfte der Fläche des gefüllten Stausees ein. Daher war von vornherein klar, daß dieser Eisrandstausee instabil sein muß. Während er sowohl bei den Aufenthalten im Juli 1982 als auch im Juli 1993 mit Schmelzwasser gefüllt blieb, war er bei meiner Ankunft am 10. August 1996 bereits ausgelaufen. Während 1993 die hohe Kalbungsfront, die den See im N abdämmt, sehr aktiv war, und überall kleinere Eisberge herumschwammen, ist auf den oben erwähnten Luftbildern kein Drifteis zu entdecken, wohl ein Hinweis darauf, daß das Ereignis schon mindestens einige Wochen her war. Das gleiche muß für den Zeitpunkt meiner Ankunft im Sommer 1996 angenommen werden. Die Kalbungsfront lag 1993 und 1996 um einige Dekameter weiter im S als 1968. Der Überlauf, über den Schmelzwasser aus dem "Isunguata 2 " in den rund $40 \mathrm{~m}$ tiefer gelegenen „Isunguata 3" nach W überfloß, war auf der Aufnahme von 1968 und bei unserem Aufenthalt 1996 zwar sichtbar, aber trocken.

Das im gefüllten Zustand ungegliedert erscheinende Seebecken ist im entleerten Zustand durch Schwellen in drei Teilbecken geteilt, von denen das mittlere und größte 1968 und 1996 einen Restsee enthielt. Der Spiegel dieses Restsees liegt etwa $15 \mathrm{~m}$ unter der maximalen Stauhöhe. Er wird von SE her durch einen Schmelzwasserzulauf genährt, der seinerseits den Überlauf eines im E anschließenden Sees darstellt. Der eigene Überlauf des Restsees hatte sich 1996 tief in einen mehr als $10 \mathrm{~m}$ hohen Moränenwall eingeschnitten, der sich unmittelbar vor der Kalbungsfront auf der Schwelle gebildet hatte, die auf dem Luftbild von 1968 noch ein gletscherwärts gelegenes drittes Teilbecken abtrennte. Dieser Schmelzwasserbach verschwand am Grund des dritten, 1996 trockenen Teilbeckens in einem trichterförmigen Tunneleingang unter dem Eis. Während die Flanken der dem Eisrand näher liegenden Teile des Seebeckens vor allem mit sandigen sowie schluffig-sandig-blockigen Sedimenten bedeckt sind, dominieren in den distalen Bereichen des Beckens vor allem schluffige, vielfach gebänderte Ablagerungen.

\subsubsection{Isunguata 3 (I3)}

Auf den mir zur Verfügung stehenden amtlichen Luftbildern des Geodätischen Instituts in Kopenhagen, die von einer Befliegung Mitte August 1968 (FS. Nr. 850780) stammen, war das etwa $600 \mathrm{~m}$ lange und $100 \mathrm{~m}$ breite, ziemlich kompliziert geformte Seebecken des "Isunguata 3“ in nicht ganz vollem Zustand (ziemlich schlecht) zu erkennen. Auf einer Aufnahme, die ich während einer Wanderung in dieser Gegend im Jahre 1982 zufällig aufgenommen hatte, ist der "Isunguata 3 “ dagegen mit Schmelzwasser randvoll (Taf. 4a). Daher bestand von vornherein kein Zweifel, daß es sich um einen 
instabilen See handelt. Als wir das Seebecken am 23. Juli 1993 erreichten, war es dann auch wirklich fast völlig leer, genauso wie im August 1996.

Auf der Südseite des Seebeckens ist, im Gelände wie auf den Luftbildern, eine deutliche Uferlinie zu erkennen, die offensichtlich die maximale Stauhöhe des Sees nachzeichnet (Taf. 4b). Das S-förmig gekrümmte Seebecken besteht aus zwei sehr unterschiedlichen Teilbecken, die miteinander durch einen schmalen Durchlaß verbunden sind: einem seichten, trogförmigen, länglichen im $\mathrm{E}$ und einem dreieckigen, trichterförmigen, viel tieferen im W (Abb. 7, 9). Das seichtere Teilbecken wird auf der gesamten Nordseite von Eisrandablagerungen begleitet - blockreichen Moränen mit vorgelagerten Schwemmfächern. Unmittelbar an bzw. auf diesen Moränen liegt das Inlandeis (Abb. 8). Dieses trogförmige Becken enthielt bei unserer Ankunft einen etwas über $200 \mathrm{~m}$ langen, ganz seichten Restsee (Taf. 4b). Er nahm vom Eisrand her zuströmendes Schmelzwasser und einen Schmelzwasserbach auf, den Überlauf von "Isunguata 2". Das Becken hat, vom Niedrigwasserspiegel bis zu den Hochwassermarken der maximalen Wasserstände gemessen, eine Tiefe von etwa $15 \mathrm{~m}$. Der Überlauf dieses Restsees verschwand im Bereich der Schwelle zwischen den beiden Teilbecken in einem Tunnel unter dem Eis. Das westlich davon gelegene, tiefere, völlig trockene Teilbecken wird auf der einen Seite von der sehr steilen Front des Inlandeises abgedämmt (Abb. 7, 9 und Taf. 5a). Ganz unten befinden sich Eingänge zu einem Eistunnel, der beim Auslaufen vermutlich als Schluckloch diente. Die tiefste Stelle dieses Teilbeckens, der Seeboden vor dem Schluckloch, liegt $55 \mathrm{~m}$ tiefer als die Uferlinie. Auf den steilen Flanken dieses Teilbeckens lagen einige größere gestrandete Drifteisblöcke (Taf. 5a).

Der mit Schmelzwasser gefüllte See hat dagegen eine keulenförmige Gestalt. An der seichten Verbindungsstelle zwischen den beiden Teilbecken ist er dann kaum $40 \mathrm{~m}$ breit (Abb. 8). Im NE schien er 1982 sogar ein Stück weit auf die Eisoberfläche überzugreifen (Taf. 4a). Auch in gefülltem Zustand muß dieser See unter das Eis hinein entwässern, da keine Spur eines Überlaufes zu finden ist. Obwohl die teilweise schon eingetrockneten Sedimente am Seeboden zahlreiche Trittsiegel von Rentieren aufwiesen, dürfte der See im Sommer 1993, wegen der bis dahin noch nicht abgetauten Drifteisblöcke, doch kaum mehr als bis 2 bis 3 Wochen vor unserer Ankunft ausgelaufen sein. Der Größe und Menge des herumliegenden Drifteismaterials nach zu urteilen schien der See 1996 gar erst wenige Tage vor unserer Ankunft ausgelaufen zu sein. Die beiden von der Form und Größe her schon sehr unterschiedli- chen Teilbecken des „Isunguata 3“ unterscheiden sich auch hinsichtlich ihrer Ablagerungen sehr deutlich. Die Sedimentfüllung des östlichen, größeren und seichteren Teilbeckens besteht größtenteils aus sandigen und schluffigen Ablagerungen. Die Füllung des westlichen, kleineren und tieferen Teilbeckens besteht vor allem aus schluffig-sandigblockigen Sedimenten.

\subsubsection{1 Östliches Teilbecken des I3}

Innerhalb des östlichen Teilbeckens von „Isunguata 3" lassen sich mehrere Faziesbereiche unterscheiden. Ganz im E des Seebeckens, wo heute ein Schmelzwasserbach (der Überlauf von „Isunguata $2^{*}$ ) fließt, finden sich grobsandige, teilweise kiesige Ablagerungen (beiderseits des Baches und einige Meter über dem jetzigen Bachniveau), bei denen es sich um Erosionsreste eines älteren Bachdeltas handelt (Abb. 8 und Taf. 5a). Das Beckentiefste wird von einem ganz seichten, in Verlandung begriffenen Restsee eingenommen, in den der Bach heute sein grobsandig-kiesiges Delta vorbaut. Entlang des Beckennordrandes sind grobsandige Schwemmfächer verbreitet, die von den Schmelzwässern des unmittelbar dahinter liegenden, aktiven Eisrandes ins Seebecken vorgeschüttet werden. Der Süd- und Westrand dieses Teilbeckens aber wird von schluffigen und sandigen Seeablagerungen eingenommen. Eine überdeutliche Uferlinie wie am „Leverett 1", die die jüngst erreichte Stauhöhe des Sees nachzeichnet, ist in diesem Teilbecken des „Isunguata 3“ nirgends zu finden (Taf. 4a). Die Wasserhöchststände lassen sich im $\mathrm{N}$ des Beckens anhand von Wasserstandsmarken an den Moränen, am Südrand des Beckens an der Verbreitung von Seesedimenten ablesen, deren Mächtigkeit vom Beckenrand zum Zentrum hin zunimmt. Der Hang, der hier zum Becken hin abfällt, besteht aus Erdbültenfeldern, die mit gemischter Zwergstrauchheide bewachsen sind. Unterhalb einer Linie, die etwa 15 m über dem Seespiegel des Restsees liegt, ist ein großer Teil der Zwergsträucher abgestorben und mit einer dünnen, eingetrockneten, weißlichgrauen Schluffhaut überzogen. Beim Darüberlaufen staubt es. Wenige Zentimeter dicke, stellenweise mit Pflanzenresten durchsetzte feinsandig-schluffige Sedimentfüllungen finden sich hier nur in den Depressionen zwischen den Erdbülten (i34). Wenige Meter weiter unten verschwinden die Zwergsträucher allmählich unter einer Sedimentdecke, durch die nur noch gelegentlich einige Zweige durchspitzen. Diese Sedimentdecke besteht aus einer Wechselfolge von mittelkörnigen Sanden und Schluffen. In der Sedimentoberfläche finden sich hier, wohl infolge Sackungs- 


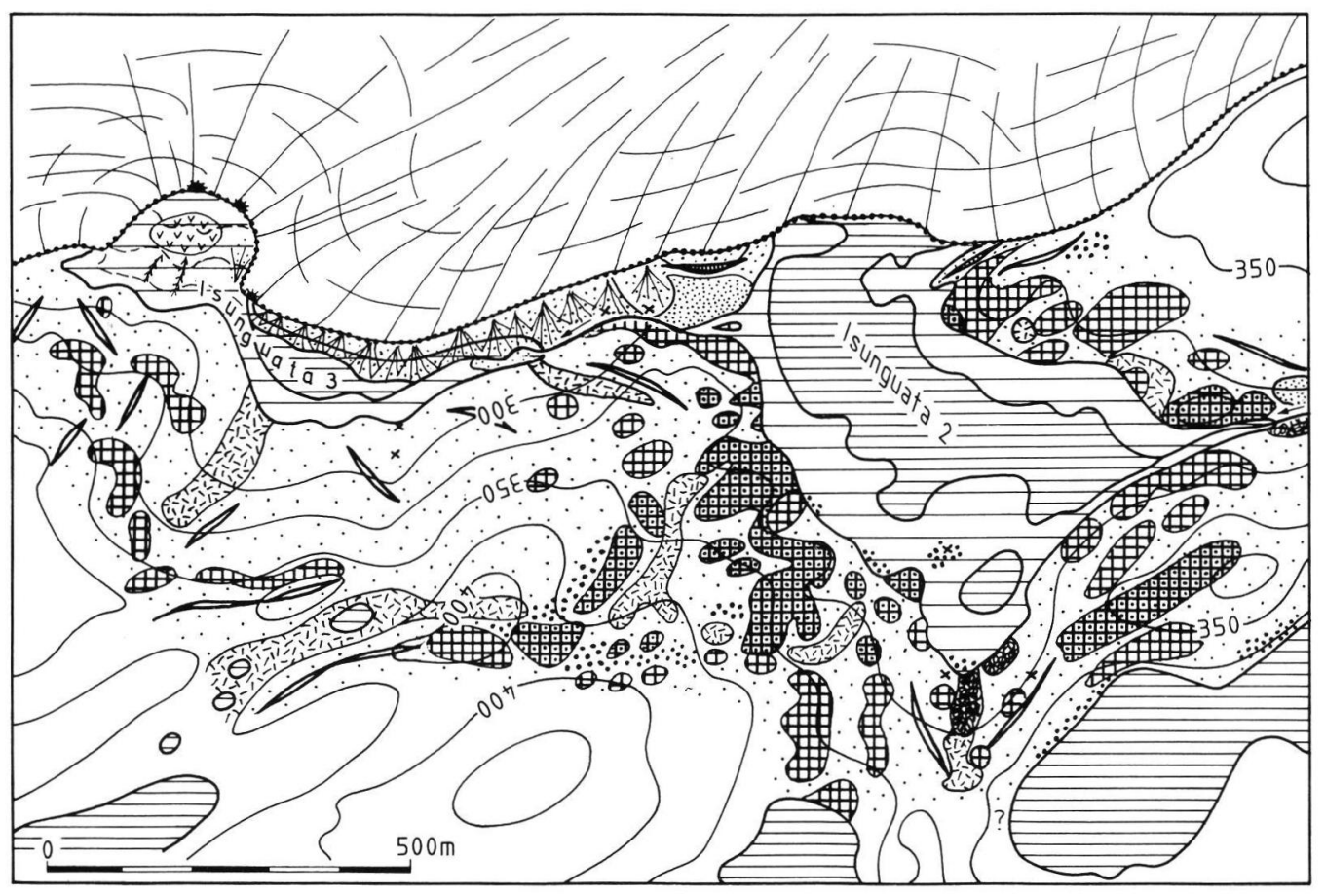

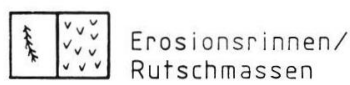

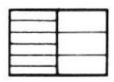

beobachtete Minimalstande/ Maximalstände der Seen

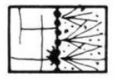

Gletschereis mit Tunnel/

Eisrandablagerungen

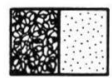

in Senken akkumulierte Fließerden/Flugsand

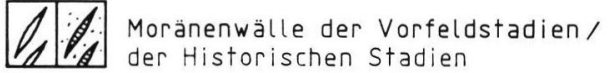

\begin{tabular}{|l|l|l|}
\hline$\times$ & $\because \vdots$ & Erratiker/Ansammlung \\
$\times$ & $\because$ & kleinerer Moränenblöcke \\
\hline
\end{tabular}

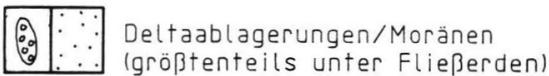

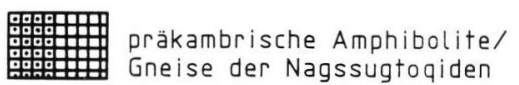

Abb. 7: Geologisches Kärtchen der unmittelbaren Umgebung der instabilen Eisrandstauseen „Isunguata 2" und „Isunguata 3". Aufgenommen auf der Grundlage einer verbesserten Version der Karte von Abb. 3.

Fig. 7: Geological map showing the vicinity of the unstable ice-dammed lakes „Isunguata 2“ and „Isunguata 3“. It was produced on base of a corrected version of the map given in fig. 3 .

erscheinungen, klaffende Risse. Zum Restsee hin nimmt die Sedimentbedeckung schließlich auf etwa $1 \mathrm{~m}$ Mächtigkeit zu. Die flachgepreßte, teilweise in ein bräunliches, torfähnliches Material umgewandelte Vegetationsdecke ließs sich hier unter den Sedimenten noch erbohren (Abb. 9). Die Hauptmasse der geschichteten Sedimente ist mittel- bis grobsandig (i33), enthält aber mehrere $\mathrm{cm}$ dicke Horizonte aus (teilweise feinsandigen) Schluffen (i31, i32). Die Sande sind aus vielen, gleichsinnig nach Westen schräggeschichteten Lagen aufgebaut, bei denen es sich um Strömungsrippeln handeln dürfte (Abb. 9). Auch die wellige Sedimentoberfläche wird von einer lederartig eingetrockneten Schluffla- ge abgedeckt. Diese Schluffe erscheinen im Gelände weitgehend ungeschichtet, zeigen jedoch in Lackabzügen von Stechkastenprofilen eine $\mathrm{mm}$-feine Laminierung. Wo die primären Strukturen der Sedimentoberfläche nicht von Karibus bis zur Unkenntlichkeit zertrampelt sind, kann man verwaschene Rippelmarken (strandparallele Oszillationsrippeln) erkennen. Diese Rippeln sind an die Oberfläche der unterlagernden Sande gebunden und sind von der jüngsten Schlufflage überall in annähernd gleicher Mächtigkeit überdeckt worden. In der Nähe des Beckentiefsten sind bis zu 5 derartige Schlufflagen in die Schichtfolge eingeschaltet, von denen in Profilen weiter oben an der Beckenflanke, wo 


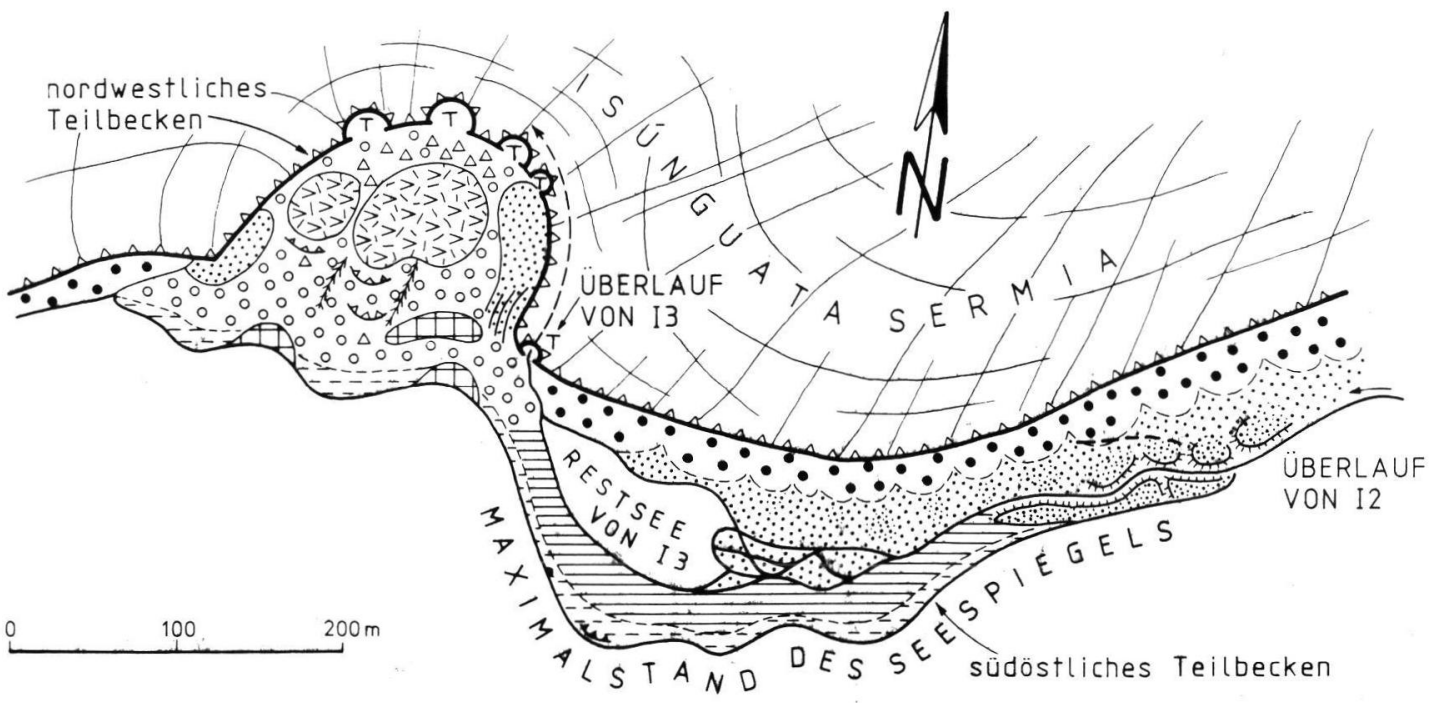

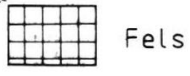

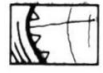

\section{Gletscher mit Stauchmoränen}

\begin{tabular}{|l|l|l}
\hline$\Delta \Delta$ & $\Delta$ & Eisberge und gestrandete \\
$\Delta \Delta$ & $\Delta$ & Drifteisblöke
\end{tabular}

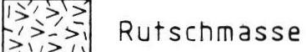

Abrißkanten, Erosions-
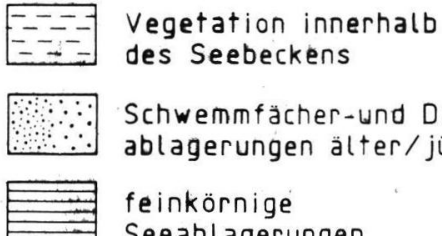

Schwemmfächer-und Deltaablagerungen älter/jünger

feinkörnige Seeablagerungen

\section{0
$0 \% 0$
0}

\section{$\because \because$ blockreiche}

Abb. 8: Die Gliederung des weitgehend wasserleeren Beckens von „Isunguata 3", wie es im Sommer 1993 ausgesehen hat. Die Bereiche außerhalb des maximalen Wasserstandes sind größtenteils nicht dargestellt. Die Tunneleingänge am Eisrand sind mit einem T gekennzeichnet. Aufgenommen auf der Grundlage einer verbesserten Version der Karte von Abb. 3.

Fig. 8: Morphologic pattern of the rather empty basin of „Isunguata 3“, as it appeared in summer 1993. The area outside the maximum water level is ignored here. Tunnel entrances at the ice margin are marked with "T". This map was produced on base of a corrected version of the map given in fig. 3 .

das Sediment ausdünnt, nur noch eine einzige zu finden ist, nämlich die oberste. In der Nähe des Baches bzw. des Restsees, die diese Sedimente in einem wenige $\mathrm{dm}$ hohen Kliff unterschneiden, sind Wasseraustritte und kleine Hangbewegungen zu verzeichnen. An einigen wenigen Stellen liegen knapp unter den höchsten Wasserstandsmarken einzelne Blöcke und kleine Häufchen von Sand und Geröll auf der schluffüberstäubten Vegetationsdecke herum. Es muß sich dabei um Material handeln, das aus gestrandeten, inzwischen aber abgetauten Drifteisblöcken ausgeschmolzen ist. Im SW dieses Teilbeckens, in der Nähe der höchsten Wasserstandsmarken, an einer Stelle, wo eine mit Fließerden gefüllte, rinnenartige Mulde den See erreicht, sind größere Hangbewegungen im Gange, die sich durch klaffen- de, metertiefe Spalten im Boden zu erkennen geben. Die gleiche, lederartig eingetrocknete Schlufflage deckt auch Teile der ebenen Deltaoberfläche am Ostende des Seebeckens ab (Abb. 10). Das Ostende der Deltafläche, die durch die Bacherosion in mehrere Teile zerlegt worden ist, liegt im Bereich des höchsten Wasserstandes, den der See erreicht hat, die westlichsten Erosionsreste liegen jedoch viele Meter darunter (Abb. 8). Diese Teile des Bachdeltas müssen offensichtlich geschüttet worden sein, bevor der See seinen Maximalstand erreicht hatte. Bei weiter steigendem Wasserspiegel müssen die Deltasedimente schließlich ertrunken sein. Ob das Delta ursprünglich eine einzige, nach Westen geneigte Oberfläche besessen hatte oder in mehrere, durch Erosionskanten gegeneinander abgesetz- 
te, unterschiedlich hoch liegende Flächen gegliedert war, ließ sich angesichts der weit fortgeschrittenen Zertalung dieses Deltakörpers nicht mehr feststellen. Durch den Sedimentkörper dieses Deltas, der 1 bis $2 \mathrm{~m}$ mächtig wird, wurde eine Reihe von Profilen gegraben. Er besteht aus mehreren, sedimentologisch einheitlichen kiesig-sandigen Horizonten, die durch cm-mächtige Schluffbänder voneinander getrennt sind (Abb. 10). Über blockreichen Ablagerungen im Liegenden fanden sich fast überall rippelgeschichtete Sande, darüber meist mehrere in westliche Richtungen einsinnig schräggeschichtete Schichtpakete, von denen jedes wenige $\mathrm{dm}$ bis etwa $1 \mathrm{~m}$ Mächtigkeit erreichen kann. Im Hangenden der schräggeschichteten Partien konnten vielfach horizontal geschichtete topsets oder Rinnenfüllungen beobachtet werden. Die zum Hangenden und Liegenden scharf abgegrenzten, fein laminierten Schluffbänder überlagern ein Relief, versiegeln z. B. in immerzu gleichbleibender Mächtigkeit die Oberfläche von Strömungsrippeln.

An einigen Stellen waren erhebliche Störungen der Schichtverbände erkennbar, die sich meist nicht auf Sackungsvorgänge in der Nähe von Erosionshängen zurückführen ließen. Stellenweise sind die Schichten in den obersten Teilen bestimmter Schichtpakete wild verbogen, mitunter ist das Sediment richtiggehend brekziiert und weist chaotische Gefüge auf. Oft schwimmen hier senkrecht gestellte Schollen geschichteter Sande in einer feiner- oder gröberkörnigen Grundmasse, in der eine Schichtung nicht mehr erkennbar ist. Diese Schichtstörungen mögen auf Frostaktivität, auf Deformation durch driftende Eisschollen, gelegentlich aber auch auf Trittsiegel von Rentieren zurückzuführen sein.

Wo kommen der in diesem Delta abgelagerte Sand und die Gerölle eigentlich her? Der Bach, der das Material mitgebracht haben muß, ist der Überlauf des benachbarten Sees I2 (Abb. 6, 7). Zwischen dem I2 und dem I3 fließt das weitgehend geklärte Wasser über ziemlich glatte Felsen, wo es eigentlich auch kein Sediment aufnehmen kann. Es gibt dafür aber eine recht einfache Erklärung. Die steile Kalbungsfront des an den I 2 grenzenden Gletschers ist äußerst aktiv und kalbt jeden Tag mehrmals mit Getöse. Ein großer Teil des Drifteises strandet offensichtlich in der flachen, trichterförmigen Bucht, an deren Ende sich der Überlauf des Sees befindet. Das hier liegende schmelzende Eis scheint genügend Sediment zu liefern, um das Delta vorschütten zu können.

Noch wesentlich komplexer gebaut, zumindest bei näherem Hinschauen, sind die sandig-feinkiesigen „Schwemmfächer" im N des Teilbeckens, die von mehreren Schmelzwasserbächen vom Eisrand her gegen den Restsee vorgeschüttet werden. Am Fuß des Moränenwalles, an dessen Außenseite man deutliche Wasserstandsmarken erkennen kann, sind sie seitlich teilweise zu einem regelrechten Übergangskegel amalgamiert (Taf. 4b). Bei einer Reihe von diesen "Schwemmfächern" ist deutlich zu erkennen, daß sie aus mehreren unterschiedlich alten und verschieden hoch liegenden Teilen bestehen, die durch Erosionskanten gegeneinander abgesetzt und ineinandergeschachtelt sind (Abb. 11). Die höchsten dieser Sandkörper liegen auf einer Verebnungsfläche am First des Moränenwalles unmittelbar vor dem Eis. Ein Teil der Oberflächen dieser Sandkörper ist von einer dünnen Schlufflage abgedeckt. Wenn man ihn aufgräbt, zeigt jeder dieser unterschiedlich alten Teile Schrägschichtungsgefüge, bei denen es sich im einfachsten Fall um topsets und foresets eines kleinen Deltas vom Gilbert-Typ handelt. Es kommt aber auch Deltaschichtung vor, bei der die Grenze zwischen topsets und foresets seewärts deutlich ansteigt (Abb. 12) oder absteigt (Taf. 5b). Stellenweise liegen aber auch, wie beim oben schon beschriebenen Bachdelta am Ostende des Sees, mehrere, von cm-mächtigen Schlufflagen getrennte, einsinnig schräggeschichtete Sedimentkörper übereinander. Es handelt sich also bei diesen Ablagerungen eher um komplex gebaute Deltas als um Schwemmfächer. Stellenweise lassen sich in diesen Schwemmfächern Schichtstörungen nachweisen, die wohl auf schichtparallele Gleitvorgänge zurückzuführen sind (Abb. 12).

\subsubsection{Westliches Teilbecken des I3}

Das westliche Teilbecken zeigt, im Gegensatz zum östlichen, eine ganze Reihe von Besonderheiten, die an das Seebecken des „Leverett 1“ erinnern. Zunächst fällt auf, daß auch hier eine kaum $1 \mathrm{~m}$ hohe, kliffartige Versteilung mit vorgelagerter flacher, bewachsener Schorre ausgebildet ist, die das weitgehend graue, vegetationslose Becken messerscharf vom dicht mit Vegetation bewachsenen, von Erdbülten besetzten Hang abgrenzt. Diese Uferlinie liegt auf genau der gleichen Höhe wie die maximalen Wasserstandsmarken im östlichen Teilbecken. Unterhalb dieser Schorre findet sich auch hier ein mehrere $\mathrm{m}$ breiter Streifen mit abgestorbenen Zwergsträuchern, die mit Schluff bestäubt sind. Auch hier wird der größte Teil des Seebeckens von groben, sandig-schluffigen, von Blöcken durchsetzten Sedimenten eingenommen, auf denen einige metergroße, gestrandete Drifteisblöcke liegen (Taf. 5a). Auch hier sind an den Hängen Massenbewegungen zu beobachten, an denen ältere Moränen und mit organischem Material durchsetzte Fließerden, aber 


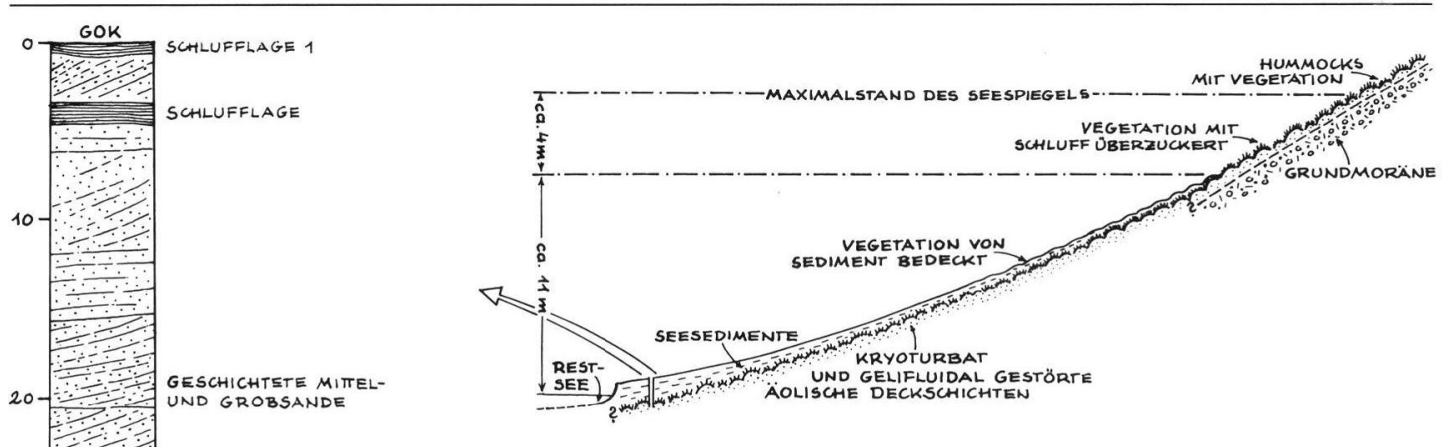

Abb. 9: Schematischer Schnitt durch die südliche Beckenflanke des südöstlichen Teilbeckens von „Isunguata 3“.

SCHLUFFLAGE

SChLUfFLAGE

Links: Detailskizze eines der Sedimentkerne, die im Bereich der südlichen Beckenflanke des südöstlichen Teilbeckens von „Isunguata 3 “ gezogen worden sind (Pfeil). Die Schichtfolge besteht aus geschichteten, mittel- bis grobkörnigen Sanden, in die mehrere Schluffbänder eingelagert sind. Die Basis der Schichtfolge bildet die zu einer torfartigen Substanz zersetzte ehemalige Vegetationsdecke.

Fig. 9: Schematic section through the southern slope of the south-eastern lake basin of "Isunguata 3 ".

left: Detailed sketch of one of the sedimentary cores taken from the southern slope of the south-eastern lake basin of "Isunguata 3" (site indicated by an arrow). The succession consists of several silty layers, intercalated into stratified middle to coarse grained sands. The bottom of the succession is the former vegetation, decomposed to a peat-like stuff.

auch schluffige Seesedimente, die Dropstones enthalten, beteiligt sind (i36, i37, i38, i39). Die Rutschmassen haben sich am Grund des trichterartigen Beckens, kurz vor einem der Tunneleingänge im Eis, zu wulstigen Hangverflachungen und Kuppen akkumuliert (Abb. 8). Die an den Hangbewegungen beteiligten Sedimente sind teilweise intensiv miteinander verfaltet. Auch hier gibt es Höhenlinien-parallelorientierte Sandstreifen, die Wasserstandsmarken darstellen. Größere, schräggeschichtete Sedimentkörper, die aus mit Geröllchen durchsetzten Grobsanden bestehen (i35), finden sich nur in der unmittelbaren Umgebung des am Ostrand fließenden Baches, dem Überlauf aus dem östlichen Teilbecken (Taf. 5a). Es handelt sich dabei wohl um kleine Deltakörper, die vom Bach in den See bei absinkendem Wasserstand vorgeschüttet worden sind.

\subsection{Laboruntersuchungen}

An einer Auswahl der aus Grönland mitgebrachten Sedimentproben wurde in Garching eine Reihe von sedimentologischen Untersuchungen durchgeführt. Die Korngrößenbestimmung erfolgte durch Sieben (> $63 \mu \mathrm{m})$ und Schlämmen $(<63 \mu \mathrm{m}$, Atterberg-Verfahren) der Proben. Außerdem wurden die Gehalte an anorganischem und organischem Kohlenstoff mit einem LECO-Gerät mit der Bezeichnung CS-125 bestimmt. Die Messung der Schwefelgehalte der Proben erfolgte ebenfalls mit dem LECO-Gerät. Zudem wurden Proben mit hohen Schluffgehalten für die Pollenanalyse aufbereitet. Die Aufbereitung folgte dem Verfahren von Beug (1961). Die Pollenanalyse selbst wird von Frau Dr. Angelika Kleinmann am Niedersächsischen Landesamt für Bodenforschung durchgeführt. Über die Ergebnisse der Pollenanalyse soll jedoch an anderer Stelle berichtet werden.

\section{Ergebnisse}

Im Sommer 1993 konnten insgesamt 6 instabile, vom Eisrand aufgestaute Schmelzwasserseen aufgesucht werden. 3 von ihnen wurden in entleertem Zustand angetroffen, konnten so näher untersucht und beprobt werden: der "Nys $\varnothing 2$ ", vor allem aber der „Leverett 1“ und der „Isunguata 3“. Über alle anderen Seen ist nur das Wenige bekannt, was aus der Literatur bzw. den Luftbildern entnommen werden kann, auf denen die Seebecken trocken liegen. Einige zusätzliche Informationen sind auch bis zu einem gewissen Grad über den „Russell 1“ verfügbar, der bei einer kurzen Begehung im Sommer 1987 gleichfalls in leerem Zustand angetroffen worden war. Es lassen sich bei diesen Seen (Abb. 1), dem "Iluliartununnguaq 2“ (Q2), „Nysø 2“ (N2), „Leverett 1“ (L1), „Russell 1“ (R1), „Russell 2“ (R2), „Isun- 
guata 2" (I2) und „Isunguata 3“ (I3), einige Gemeinsamkeiten, aber auch deutliche Unterschiede herausarbeiten (ScHOLZ, 1995a und b).

Die Becken der untersuchten instabilen Schmelzwasserseen haben größte Durchmesser zwischen etwa 250 und $1500 \mathrm{~m}$. In gefülltem Zustand haben alle Seen wenigstens streckenweise direkten Kontakt mit dem Eis. Deshalb ist auf allen mehr oder weniger Drifteis zu finden (Taf. 1a und 4a). Eine vertikale Kalbungsfront ist bei Q2, L1, R1 und I2 entwickelt (Taf. 1a). Besonders viele und besonders große Eisberge wurden am Q2, L1 und R1 beobachtet. Ein Teil des Ufers aller Seen grenzt aber auch unmittelbar an die von Tundren oder Steppen bewachsenen Hügelländer, in allen Fällen mindestens die Hälfte der gesamten Länge ihrer Küstenlinie. Im tieferen Untergrund der Seebecken sind immer Kristallingesteine und ältere, blockreiche Grundmorä- nen zu finden, die teils mehr oder weniger erodierte, feinkörnige, äolische Deckschichten tragen oder von Fließerden aus gelifluidal umgelagerten äolischen Sedimenten bedeckt sind. Diese Fließerden sind durch Verwitterung bräunlich gefärbt und mit organischem Material durchmischt. Den Höhenangaben auf den verfügbaren Karten nach liegen alle diese Seen 200 bis $500 \mathrm{~m}$ höher als die jeweiligen Zungenenden.

Die Seebecken L1, R1, I1, I2 besitzen, wenn sie völlig mit Wasser gefüllt sind, einen Überlauf, alle anderen nicht. Die Becken von I2 und $\mathrm{I} 3$ sind kompliziert geformt und durch Schwellen in mindestens 2 tiefere Teilbecken unterteilt. Alle anderen Seebecken sind relativ einfache, wenig gegliederte, zum Eisrand hin abfallende Hohlformen. Im entleerten Zustand enthalten alle Seebecken einen mehr oder weniger großen Restsee. Fast alle Restseen haben

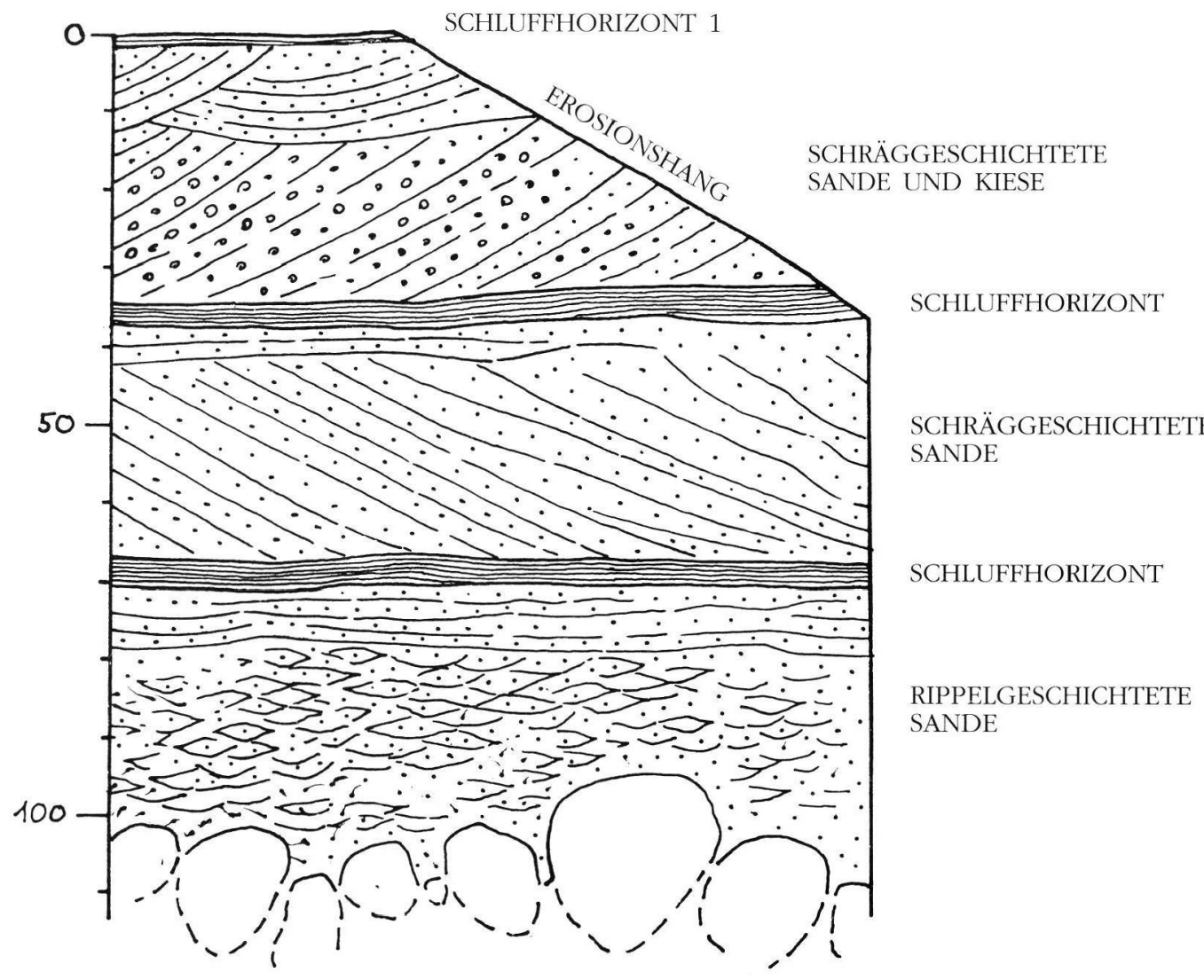

Abb. 10: Detailskizze einer künstlich hergestellten Aufschlußwand vom Westende des Bachdeltas am östlichen Ende des östlichen Teilbeckens von „Isunguata 3“. Mehrere schräggeschichtete Bänke werden hier durch eingelagerte Schluffbänder voneinander getrennt. Die Schichtfolge besteht aus mehreren kleinen Deltakörpern, die bei steigendem Wasserstand immer wieder überflutet worden sind.

Fig. 10: Detailed sketch from an artificial outcrop at the western end of a creek delta within the eastern part of the eastern lake basin of "Isunguata 3“. Several cross-bedded layers are separated by intercalated silty bands. The succession consists of several small deltaic sheets, repeatedly drowned due to the rising water level. 
weiterhin direkten Kontakt mit dem Inlandeis und sind dicht mit schwimmenden Eisbergen bedeckt (Taf. 3a). Nur die von Q2 und I3 sind ganz seicht und frei von Drifteis (Taf. 4b). Alle erhalten vom Eisrand her direkten Schmelzwasserzulauf. Bis auf R2 und L1 wird in alle Seen zusätzliches Schmelzwasser über einen Bach eingespeist, der Teil des peripheren Entwässerungssystems ist - meist der Überlauf eines benachbarten Sees.

\subsection{Uferlinien}

Einige Seen zeigen eine kaum $1 \mathrm{~m}$ hohe, kliffartige Versteilung, die das weitgehend graue, vegetationslose Becken messerscharf vom dicht mit Vegetation bewachsenen Hang abgrenzt (Taf. 3b). Stellenweise ist dieser Versteilung eine flache, bewachsene, einige Meter breite Schorre vorgelagert. Im Bereich der Schorre fehlen die Erdbülten (hummocks), die sowohl oberhalb als auch unterhalb der Uferlinien entwickelt sind (Taf. 2a und 2b). Uferlinien dieses Typs sind auf genau der gleichen Höhe zu finden wie die maximalen Wasserstandsmarken im jeweiligen Becken und konnten im L1, R1 sowie im westlichen Teilbecken des I3 beobachtet werden, fehlen aber im N2 und im östlichen Teilbecken von $\mathrm{I} 3$ (Taf. $1 \mathrm{~b}$ und $4 \mathrm{~b}$ ). Bei den anderen Seen waren entsprechende Beobachtungen unmöglich.

Wie sind diese Uferlinien entstanden? Eine Erosion durch Wellenschlag scheidet aus, denn sonst wäre die Schorre nicht bewachsen. Vielleicht hat ihre Entstehung etwas mit der häufigen Gefrornis der Seen in gefülltem Zustand zu tun. Die Eisplatten erzeugen, wie in zwei Fällen beobachtet werden konnte, offensichtlich einen gegen den Hang gerichteten Schub und schieben die Vegetationsdecke ab. Der vom See weggerichtete Schub wird wohl bei den extrem tiefen Wintertemperaturen erzeugt. An verschiedenen Seen dieses Teils von Westgrönland können durch Eisschub regelrechte Wälle am Ufer aufgeschoben werden (Eisstauchwälle, vergl. Scholz, 1987). Wenn das mehrfach geschieht, werden die Erdbülten wohl allmählich wegerodiert, und eine flache Schorre entsteht. Wegen des bedeutend kleineren Winkels, den diese Schorren zu den Platten des See-Eises haben, ist die sich hier neuerlich ansiedelnde Vegetation durch den Eisschub nicht mehr so bedroht, wie zuvor. Wenn es tatsächlich so ist, würde das bedeuten, daß Seen, die solche Schorren besitzen, im Winter mit Wasser gefüllt sind, die anderen $u$. U. nicht.

Auch unterhalb dieser überdeutlichen Uferlinien oder der weniger deutlichen maximalen Wasserstandsmarken ist bei eigentlich allen begutachteten
Seen, im N2, L1, R1 und L3, noch Vegetation zu finden (Taf. 2a und 2b). Allerdings sind die bewachsenen Bereiche in den Seen L1 und R1 nur auf bestimmte Abschnitte des Seebeckens beschränkt. Zusammen mit den Pflanzen finden sich hier auch immer Erdbülten, maximal noch $15 \mathrm{~m}$ unterhalb der maximalen Seespiegelstände (Taf. 2a). Teilweise scheinen die hier wachsenden Zwergsträucher abgestorben zu sein, teilweise leben sie noch. Jedenfalls sind die Pflanzen mit einer dünnen, eingetrockneten, weißlichgrauen Schluffhaut überzogen, die beim Darüberlaufen staubt (Taf. 1b). Wenige Zentimeter dicke, mit Pflanzenresten durchsetzte Sandhäufchen finden sich hier in Depressionen zwischen den Erdbülten. Gelegentlich liegen hier Sandhäufchen, einzelne Gerölle oder Steincluster auf oder zwischen den Zwergsträuchern, bei denen es sich um Dropstones oder aus gestrandetem Drifteis ausgeschmolzenen Detritus handelt. Nach unten zu nimmt die Mächtigkeit der sandig-schluffigen Sedimente plötzlich oder allmählich zu, die Vegetation ertrinkt allmählich in Sedimenten und ist schließlich ganz verschwunden. Gleichbleibende Sedimentationsraten vorausgesetzt dürfte dies darauf hindeuten, daß die maximale Stauhöhe in den Seebecken jeweils nur relativ kurzfristig erreicht wird. Deutlich längere Zeitabschnitte scheinen sie hingegen nur zu einem gewissen Teil mit Wasser gefüllt zu sein.

\subsection{Massenbewegungen}

Eine weitere Beobachtung konnte in den leeren Seebecken von I1, I 2 und in beiden Teilbecken von I3 gemacht werden: kleinere und größere Massenbewegungen an den Beckenflanken, von denen vor allem Abschnitte der nord- und ostexponierten Hänge betroffen werden. Sie scheinen in den meisten Fällen im Bereich der maximalen Wasserstandsmarken zu wurzeln und geben sich hier durch metertiefe Risse und ein tiefes Einsinken der Geländeoberfläche zu erkennen. In den darunterliegenden Teilen des Beckens führen diese Hangbewegungen zur Bildung von konvexen, beulenartigen Strukturen mit unruhiger Oberfläche (Taf. 2b). Deutliche Abrißkanten sind kaum entwickelt. Die Formen haben im oberen Teil den Charakter von gebundener Gelifluktion, die unteren erinnern teilweise an große Fließerdeloben, wie sie bei ungebundener Gelifluktion entstehen. Solifluktionstrukturen dieses Typs und dieser Größenordnung sind in diesem Teil Grönlands außerhalb der Seebecken nirgends zu beobachten.

Bei Grabungen im Bereich der unteren Abschnitte derartiger Rutschmassen konnte festgestellt werden, daß sowohl grobe als auch feinkörnige Materialien 
an den Massenbewegungen beteiligt sind. Bei den feinkömigen überwiegt schluffig-feinsandiges Material, das bräunlich gefärbt ist, einen ziemlich hohen organischen Anteil besitzt und stark an die gelifluidal umgelagerten, kryoturbat gestörten äolischen Sedimente erinnert, die im oberen Teil des Hanges das Substrat für die Vegetation bilden. Materialien unterschiedlicher Körnung und Färbung liegen hier in Lagen übereinander, sind miteinander verfaltet und zeigen hangabwärts weisende Sattelumbiegungen. Diese Massenbewegungen werden vermutlich durch einen lokalen Zusammenbruch des Permafrostes im Untergrund ausgelöst, der wohl durch das relativ warme Schmelzwasser im gefüllten Seebecken provoziert wird. An diesen Massenbewegungen scheinen neben äolischen Deckschichten auch die darunterliegenden Grundmoränen, gelegentlich auch Seesedimente beteiligt zu sein, die im Laufe der Hangbewegungen miteinander vermischt werden.

\subsection{Geschichtete Sande}

In allen Seebecken scheinen unscharf gegen die Umgebung abgegrenzte, höhenlinienparallele Streifen von einigen $\mathrm{dm}$ bis etwa $1 \mathrm{~m}$ Breite vorzukommen, die aus mit Geröllchen durchsetzten Grobsanden bestehen (Taf. 3b). Sie sind allerdings nur in den Beckenteilen entwickelt, wo der Untergrund vegetationslos ist. Zuweilen ist eine undeutliche, hangparallel einfallende Schichtung zu beobachten. Es handelt sich um Wasserstandsmarken, die bei steigendem oder sinkendem Wasserspiegel entstanden sein dürften. Der Sand ist offensichtlich am Ufer durch den Wellenschlag aus dem sandig-blockigen Untergrund ausgewaschen und streifenförmig angereichert worden. Im L1 und im westlichen Teilbecken vom I3 konnten zudem kleinere Sandkörper beobachtet werden, die Schwemmfächer darstellen. Sie entstehen am Ende von nur wenige Dezimeter eingetieften Erosionsrinnen, die vom Schmelzwasser gestrandeter Drifteisblöcke gespeist werden.

Größere geschichtete Sandkörper, die lagenweise auch Gerölle enthalten, scheinen auf Seebecken beschränkt zu sein, die von einem Ast des peripheren Entwässerungssystems durchflossen werden, bzw. wo Schmelzwasserbäche vom Eisrand her direkt in den See laufen. Sedimente dieses Typs konnten nur im $\mathbf{3} 3$ direkt untersucht werden, sind aber zweifellos auch im I2, R1 und Q2 vorhanden. Es handelt sich zum größten Teil um ziemlich komplex gebaute Deltabildungen, die bei ganz unterschiedlichen Seespiegelständen geschüttet worden sein müssen. Diese Sandkörper haben ebene oder schwemmkegelartig gewölbte Oberflächen und bestehen aus mehreren unterschiedlich alten und ver- schieden hoch liegenden Teilen, die durch Erosionskanten voneinander abgesetzt und teilweise ineinandergeschachtelt sind (Taf. 4a und 5b). Mitunter sind sie auch durch nachfolgende Erosion in mehrere Teile zerschnitten worden. Die höchstgelegenen Sandvorkommen dieses Typs liegen auf einem Niveau, das der maximalen Stauhöhe des Sees entspricht.

Diese Sandvorkommen sind nur zu einem kleinen Teil rippelgeschichtet, zu einem größeren Teil bestehen sie aus einer oder mehreren seewärts einsinnig schräggeschichteten Lagen mit Mächtigkeiten bis zu $1,5 \mathrm{~m}$, von denen die meisten von horizontal gelagerten topsets abgedeckt sind (Taf. 5b). Zwischen einzelnen Lagen dieses Typs liegen oft trennende, cm-dünne, laminierte Schluffbänder, bei denen es sich offensichtlich um Stillwassersedimente handelt (Abb. 10). Die gesamte Schichtfolge muß als eine Abfolge mehrerer, übereinanderliegender kleiner Deltakörper gedeutet werden, die bei steigendem Seespiegel ein Stück weit vorgeschüttet und immer wieder unter Wasser geraten sind. Dazu passen auch Schichtgefüge, bei denen die Grenze zwischen topsets und foresets seewärts stetig ansteigt (Abb. 12). Dazu paßt auch, daß ein Teil der ebenen Oberflächen dieser komplex gebauten Deltas mit einer cm-dünnen, lederartig eingetrockneten Schlufflage abgedeckt ist. Daneben gibt es aber ebene Oberflächen von schräggeschichteten Sandkörpern, die durch keine Schlufflage abgedeckt werden. Stellenweise sinkt die Grenze zwischen topsets und foresets seewärts stetig ab (Taf. 5b). Dabei dürfte es sich um die jüngeren Teile dieser komplexen Deltas handeln, die bei sinkendem Seespiegel entstanden und deshalb nicht mehr unter Wasser geraten konnten.

An einigen Stellen sind erhebliche Störungen der Schichtgefüge erkennbar, die sich meist nicht auf Sackungsvorgänge in der Nähe von Erosionshängen zurückführen lassen. Stellenweise sind die Schichten in den obersten Teilen bestimmter Schichtpakete wild verbogen, mitunter ist das Sediment richtiggehend brekziiert und weist chaotische Gefüge auf. Diese Schichtstörungen mögen teilweise auf Frostaktivität, auf Deformation durch driftende Eisschollen, gelegentlich aber auch auf Trittsiegel von Rentieren zurückzuführen sein. An den Stellen, wo die Sedimente talwärts anerodiert sind, spielen aber auch schichtparallele Gleitvorgänge eine wichtige Rolle (Abb. 12).

\subsection{Laminierte und nicht laminierte Seesedimente}

Bei zahlreichen mächtigeren feinsandigen Schluffvorkommen in den Seebecken, die ich im ersten 


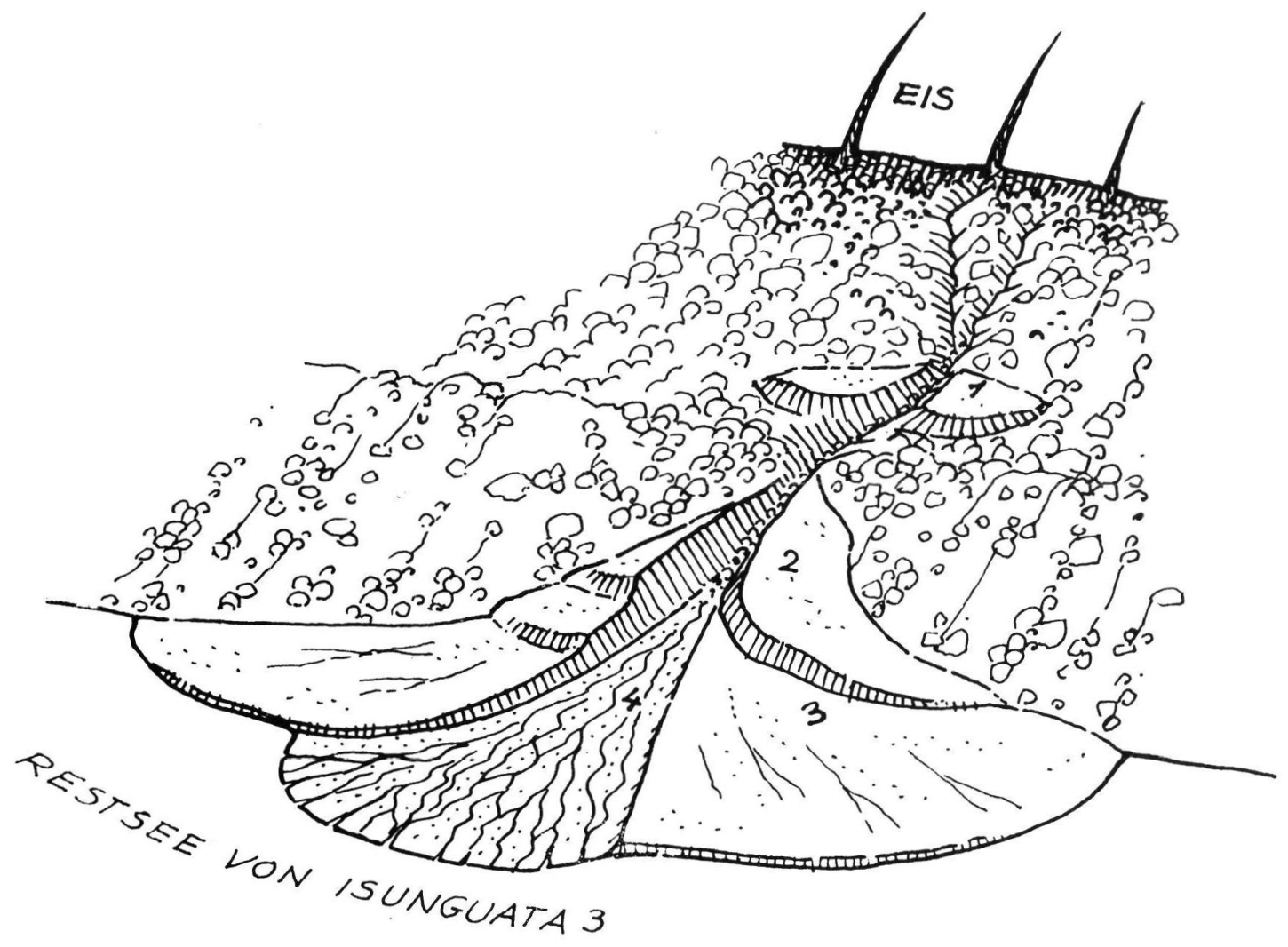

Abb. 11: Vereinfachte Geländeskizze eines der sandigen Schwemmfächer, die dem Eisrand auf der Nordseite des östlichen Teilbeckens von „Isunguata 3“ vorgelagert sind. Der Fächer besteht aus 4 unterschiedlich alten und verschieden hoch liegenden Teilen, die als Deltas in den See vorgeschüttet worden sind. Der älteste (1) ist während des maximalen Seespiegelstandes abgelagert worden, der am Hang der Endmoräne etwa bis dahin hinaufgereicht hat. Die jüngsten Teile (3 und 4) sind bzw. waren noch vor kurzem aktiv in Bildung und werden in den kleinen Restsee vorgebaut. Am Aufbau dieser teilweise sehr komplexen Fächer sind auch ältere Teile beteiligt, die bei steigendem Wasserspiegel entstanden sind (2). Die Höhendifferenz zwischen dem höchstliegenden Erosionsrest eines Deltas (1) und dem Restseespiegel beträgt etwa $15 \mathrm{~m}$.

Fig. 11: Simplified sketch of one of the sandy alluvial fans, deriving at the ice margin on the northern slope of the eastern lake basin of "Isunguata 3". The fan consists of 4 parts, different in altitude and age, remnants of deltas prograding into the meltwater lake. Nearly topping the moraine ridge the oldest (1) corresponds with the maximum lake level. The youngest parts (3 and 4$)$ are or have been active until very recently, deposited within the small residual lake. Older deltaic sediments, generated during a rising water level (2), participate in the arrangement of this very complex fan. The difference in altitude between the highest remnant of a delta (1) and the level of the residual lake attains about $15 \mathrm{~m}$.

Moment für Seeablagerungen gehalten hatte, stellte sich bei näherem Hinsehen heraus, daß es sich letztlich um äolische Deckschichten handeln muß, die durch Massenbewegungen umgelagert worden sind. Sie zeigen schwach bräunliche Verwitterungsfarben und sind, wie die vergleichsweise hohen Corg-Werte und Schwefelgehalte belegen, mit organischem Material durchmischt. Schluffig-feinsandige Sedimente, bei denen es sich eindeutig um Seeablagerungen handelt (THEAKSTONE, 1976; SMITH \& SYVITZKI, 1982; SмrTH et al., 1982), spielen in den untersuchten Seebecken dagegen überraschenderweise eine sehr untergeordnete Rolle und hatten eigentlich nur im I2 eine größere Verbreitung.
Sie kommen als mm- bis cm-mächtige Einschaltungen in die oben beschriebenen sandigen Deltasedimente vor, sind gleichfalls als cm-dünne Horizonte in rippelgeschichtete Sande eingelagert, die im östlichen Teilbecken des I3 in der Umgebung des seichten Restsees zu finden sind. Mitunter überkleiden Schluffhorizonte augenscheinlich ein Relief So wurden mehrfach Schlufflagen entdeckt, die die foresets einer Deltasequenz abdeckten. Teile dieses Seebeckens und der Deltasedimente sind zudem mit einer dünnen, lederartig eingetrockneten Schlufflage überzogen. Darüber hinaus kommen im L1 wie im I3 mehrere $\mathrm{cm}$ mächtige Seesedimente auch im Bereich von Rutschungen vor, wo sie mit äolischen 


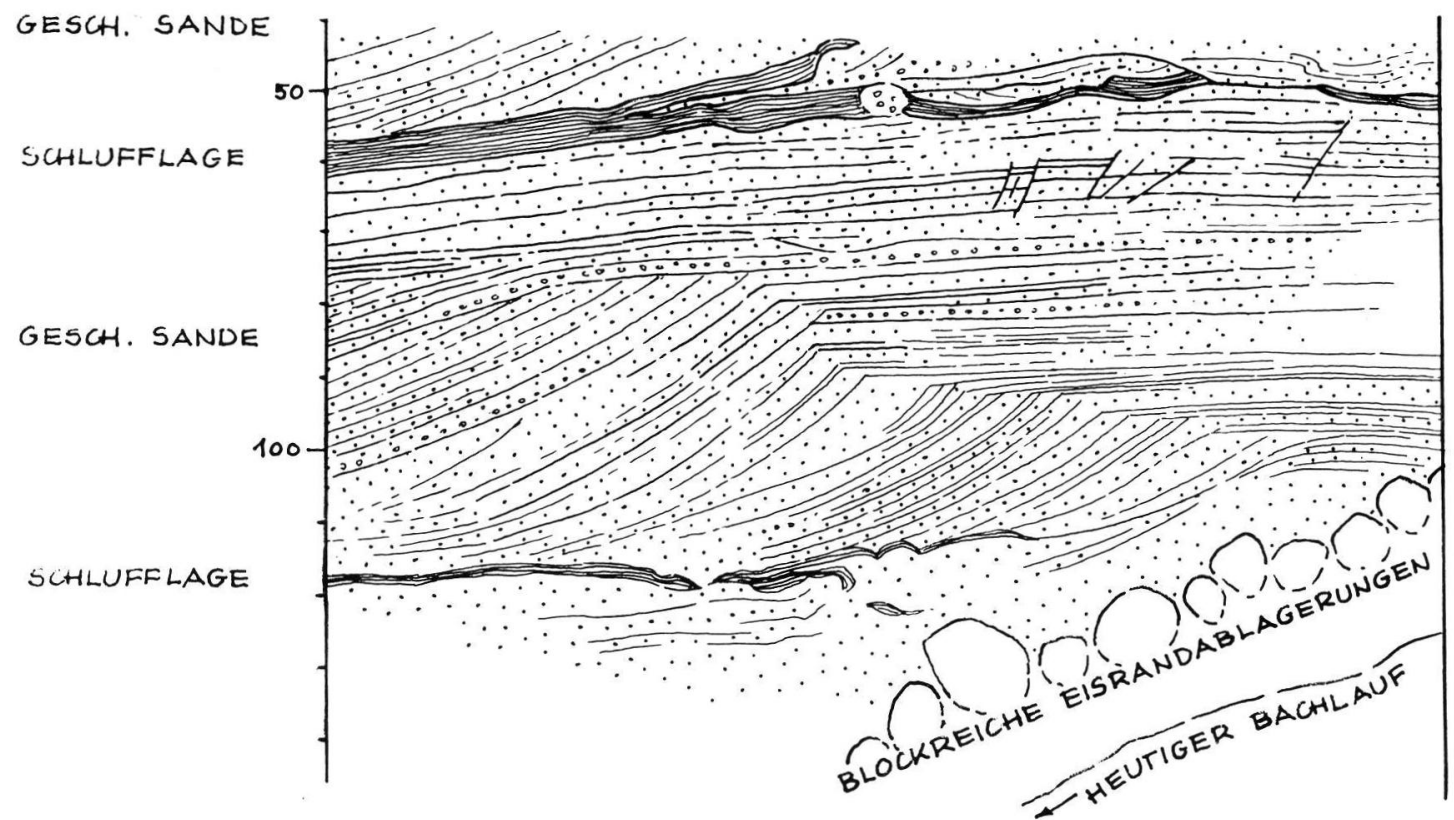

Abb. 12: Detailskizze einer künstlich hergestellten Aufschlußwand im Zentrum eines der Schwemmfächer, die dem Eisrand auf der Nordseite des östlichen Teilbeckens von „Isunguata 3“ vorgelagert sind. Die Schichtfolge besteht aus mehreren kleinen Deltakörpern, die von Schluffbändern getrennt sind. Das Ansteigen des Wasserspiegels ist am Klettern der Kontaktstelle zwischen topsets und foresets schön zu verfolgen. Die Schichtfolge ist teilweise gestört, was vor allem auf Trittsiegel von Rentieren und schichtparallele Gleitvorgänge beim Trockenfallen zurückzuführen sein dürfte.

Fig. 12: Detailed sketch from an artificial outcrop in the centre of one of the alluvial fans, deriving at the ice margin on the northern slope of the eastern lake basin of „Isunguata 3“. The succession consists of several small deltaic sediment bodies, separated by thin silty layers. A synsedimentarily rising lake level is clearly demonstrated by the climbing foresets. The stratification is disturbed in places, most likely caused by foot prints of reindeers and slumping after the drainage of the lake.

Schluffen, Moränen und sandigen Ablagerungen verfaltet und durchmengt sind. Die ursprünglichen Schichtverbände sind hier aber leider nicht mehr zu rekonstruieren.

Im bergfeuchten Zustand betrachtet wirken diese Sedimente fast immer ungeschichtet. Nur bei den Schluffen in den distalen Teilen des Beckens von I2 und einer mehr als $5 \mathrm{~cm}$ mächtigen Schlufflage, die durch Massenbewegungen etwas gestört schien und sich auf einer Hangverflachung im L1 fand, konnte man die Laminierung schon im Gelände deutlich erkennen. Auf Lackabzügen, die von diesen Seeablagerungen mit Hilfe von Stechkästen hergestellt wurden, ist zu sehen, daß sie im mm-Bereich fein laminiert sind. Bei Schluffhorizonten von $1,5 \mathrm{~cm}$ Mächtigkeit wurden 10 bis 15 Laminae gezählt. In den an verschiedenen Stellen des Beckens sehr unterschiedlich mächtigen Bänderschluffprofilen des I2 konnten Warven zwischen 1 und $12 \mathrm{~mm}$ Breite beobachtet werden.

Die Südflanke des südöstlichen Teilbeckens von I3 sowie die proximalen Teile des I 2 sind mit bis zu $1 \mathrm{~m}$ mächtigen geschichteten Sedimenten überdeckt.
Es handelt sich um eine Folge von geschichteten, mittel- bis grobkörnigen Sanden, in die mehrere Schlufflagen eingeschaltet sind (Abb. 12). Die gesamte Schichtfolge keilt nach oben, zur Uferlinie hin, aus und wird durch eine Schlufflage abgedeckt. Den hier beobachteten Schichtungsgefügen nach zu urteilen sind die Sande durch Strömungsrippeln entstanden, die von $\mathrm{E}$ nach $\mathrm{W}$ geschüttet worden sind. Das Substrat der Schichtfolge bildet die abgestorbene Vegetationsdecke, die ihrerseits von bräunlichen, kryoturbat gestörten, äolischen Feinsanden und Schluffen unterlagert wird. Die lederartig eingetrocknete hangende Schlufflage überdeckt an vielen Stellen strandparallel orientierte Oszillationsrippeln, die auf der Oberfläche der unterlagernden Sande entwickelt sind. Vielfach ist die Sedimentoberfläche durch zahlreiche Trittsiegel von Karibuhufen bis zur Unkenntlichkeit zertrampelt. Es konnte nicht mit letzter Sicherheit geklärt werden, ob die unterschiedlichen Schlufflagen, die hier übereinander folgen, aus unterschiedlichen Jahren stammen oder nicht. Daß in Becken dieses Typs auch im praktisch stehenden Wasser vorwiegend Sande an den Flan- 
ken abgelagert werden können, zeigen auch die geschichteten Feinsandhäubchen auf den Zwergsträuchern im Becken des N2. Rippelgeschichtete Sande bilden auch die Unterlage des Bachdeltas am Ostende des Beckens. Bei ihnen dürfte es sich um Prodelta-Sedimente handeln.

Die distalen Teile des Seebeckens von 12 sind weithin mit schluffigen, deutlich gebänderten Sedimenten bedeckt. Die Oberfläche dieser Ablagerungen ist von Trockenrissen überzogen. Die Mächtigkeit dieser Warvenschluffe überstieg in keinem der aufgegrabenen Profile $20 \mathrm{~cm}$, die Anzahl der Warven nirgends 30. Auch hier wird das Substrat dieser Schichtfolge von der abgestorbenen Vegetationsdecke gebildet, die ihrerseits von bräunlichen, kryoturbat gestörten, äolischen Feinsanden und Schluffen unterlagert wird. Ich deute das als einen Hinweis darauf, daß dieser See, ähnlich wie auch die anderen Eisrandstauseen im Untersuchungsgebiet, noch nicht sehr lange besteht. Sie scheinen erst im Laufe der letzten Jahrzehnte (!) vor den im ganzen stetig vorrückenden Eisrändern auf bis dahin mit Vegetation bewachsenen Teilen des Vorlandes neu entstanden zu sein (Scholz, 1991).

\subsection{Drifteis-Sedimente und Diamikte}

Auf den schluffigen Sedimentoberflächen, aber auch auf den vegetationsbedeckten Bereichen, die Zeichen einer Überflutung zeigen, liegen isolierte Gerölle und Gesteinsbrocken herum, bei denen es sich um dropstones handeln dürfte, die aus Drifteisblöcken abgeregnet sind (Taf. 1/2 und 3/1). Daneben finden sich auch Häufchen aus Sand und Geröllen, die auf der Sedimentoberfläche liegen. Dabei dürfte es sich um die Sedimentfracht von gestrandeten Drifteisblöcken handeln, deren Liegemarken oft noch zu entdecken sind und auf die Größe des Eisblockes schließen lassen. Im Becken des L1 und des I3 waren ja die größeren gestrandeten Drifteisblöcke noch nicht abgeschmolzen, als wir die Becken untersuchten (Taf. 5a). Hier und 1987 auch am damals leeren Becken des R1 konnte der Prozeß des Abschmelzens und der Entstehung der Liegemarken direkt beobachtet werden (Taf. 3b).

Wenn man an die Größe und Zahl der in den Becken des L1 oder R1 gestrandeten Eisberge denkt, sollte man meinen, daß von Eisbergen abgeregnete oder aus gestrandetem Drifteis ausgeschmolzene Sedimente (iceberg till, Dreimanis, 1979: 171 oder Eisberg-Moräne, SCHrfiner 1992: 38 f.) einen bedeutenden Anteil an den Sedimentfüllungen dieser Seebecken haben sollten. Im nordwestlichen Teilbecken des 13 lagen 1993 zwar nur relativ wenige und nicht sehr große, im südöstlichen Teilbecken gar keine
Drifteisblöcke herum. Im Sommer 1982 aber, als dieser See wassergefüllt war, konnte man sehen, daß das nordwestliche Teilbecken fast ganz mit Eisbergen bedeckt, das südöstliche dagegen frei von Drifteisblöcken war (Taf. 4a). Die relativ seichte Engstelle zwischen beiden Teilbecken scheint für größere Eisberge unpassierbar gewesen zu sein.

Es fällt nun auf, daß die Flanken gerade der Becken bzw. Beckenteile, die viel Drifteis enthalten, größtenteils mit blockig-sandigen, teilweise schluffigen, ungeschichteten und unklassierten Sedimenten bedeckt sind, die wir neutral Diamikte nennen wollen (Taf. 5a). Die Kornverteilung dieser Diamikte schwankt stark und ist teilweise der einer Grundmoräne in diesem Gebiet nicht unähnlich. Im Vergleich zu Moränen des Alpenvorlandes haben sie jedoch einen deutlich geringeren Schluff- und praktisch keinen Tonanteil. Könnte es sich dabei nicht um Drifteis-Sedimente handeln? Dafür spricht u. a., daß in den Becken, in denen es kaum Eisberge gibt, im N2 und im südöstlichen Teilbecken von I3, genau diese Sedimente nicht vorkommen.

Dagegen spricht aber auch einiges. An einigen ziemlich steilen Beckenflanken kommt der nackte Fels heraus, an anderen, weniger steilen Stellen ist der Untergrund von Vegetation bedeckt. Diese Vegetation stellt offensichtlich keinen sekundären Bewuchs auf Seeablagerungen dar. Das Substrat dieser Pflanzen besteht in allen Fällen vielmehr aus den schon öfters erwähnten kryoturbat und solifluidal gestörten äolischen Decken, die schon wegen ihrer leicht bräunlichen Farbe und der Neigung, in nordexponierten Hanglagen Erdbültenfelder zu bilden, leicht zu identifizieren sind. Wo diese Deckschichten wegerodiert sind, kommen darunter meist blockreiche Moränen heraus. Es scheint sich also vielmehr um Reste des ehemals geschlossenen Pflanzenkleides zu handeln, das hier schon existierte, als es an dieser Stelle noch keinen Eisrandstausee gegeben hat. Sowohl auf diesen Vegetationsresten als auch auf den glattgeschliffenen Felsen liegen nun relativ wenige Blöcke herum, die man als dropstones deuten muß, während man in benachbarten Teilen des gleichen Beckens in vergleichbarer Höhe nur diese chaotisch gelagerten, blockig-sandig-schluffigen Diamikte findet. Eine Möglichkeit wäre, daß die Eisberge vom Wind vornehmlich in bestimmten Buchten zusammengetrieben werden, wo sie dann allmählich abschmelzen und ihre Sedimentfracht abregnen. Dann wären die bewachsenen Flankenabschnitte genau die Stellen, wo die Eisberge regelmäßig weggetrieben werden. Dann sollte man aber unter blockreichen Diamikten die verschüttete Vegetationsdecke ergraben können. Das gelang zwar nicht, doch waren an Massenbewegungen, die mit- 
ten in diesen Diamikten im Becken des L1 und im nordwestlichen Teilbecken des I3 zu beobachten waren, auch bräunliche äolische Deckschichten und viel organisches Material beteiligt. Es gibt also tatsächlich von den Diamikten zugedeckte Böden, zumindest stellenweise.

Es gibt aber Beobachtungen im Bereich der Massenbewegungen, die darauf hindeuten, daß zumindest ein Teil dieser Diamikte tatsächlich keine im See abgelagerten Sedimente sind, sondern durch Wellenerosion freigespülte oder durch Massenbewegungen umgelagerte Grundmoränen darstellen. Da beide Sedimenttypen ähnliche Komponentengrößen, Kornformen und Korngrößenspektren aufweisen, läßt sich im Einzelfall die Genese meist nicht einfach klären. Wahrscheinlich liegt die Wahrheit jedoch in der Mitte. An der Entstehung der Diamikte, die den größten Teil der Beckenflanken bedecken, dürften freigespülte bzw. gelifluidal umgelagerte Moränen genauso wie Drifteisablagerungen (Eisberg-Moränen) beteiligt sein.

\section{Danksagung}

Herzlichen Dank möchte ich allen denjenigen aussprechen, die am Gelingen dieses Unternehmens beteiligt waren. Dazu gehören vor allem meine beiden Begleiter im Gelände, Dr. Jürgen Froh und Thomas Herzog sowie die Studentischen Hilfskräfte, die bei den Laborarbeiten geholfen haben, Arno Pabst und Christian Brand. Besonderer Dank gilt der DFG, die das Vorhaben (DFG-Projekt II C 6 - Scho 277/ 4-1) finanziell unterstützt hat.

\section{Schriftenverzeichnis}

Ashiey, G. M., Shaw, J. \& Smith, N. D. (1985): Glacial sedimentary environments.- S.E.P.M. short course, 16, 246 S.; Tulsa, Ok.

BeEcroft, I. (1983): Sediment transport during an outburst from Glacier Tsidjiore Nuove, Switzerland, 16-19 June 1981.- Jour. Glaciology, 29, S. 185-190; London.

BelKNap, R. L. (1941): Physiographic Studies in the Holsteinsborg District of Southern Greenland.- University of Michigan Studies, Scientific Series 4, Reports upon the Greenland Expeditions of the University of Michigan (1926-1933), Part 2, S. 200255; Norwood, Mass.

Beschel, R. B. (1961): Dating Rock Surfaces by Lichen Growth and its Application to Glaciology and Physiography (Lichenometry).- In: RaAsch, G. O., ed. (1961): Geology of the Arctic, 2, S. 1044-1062; Toronto.

Bøcher, T. W. (1954): Oceanic and Continental Vegetational Complexes in Southwest Greenland.- Meddr Grønland, 148 (1) 336 S.; Kopenhagen.

-(1959): Floristic and ecological studies in middle West Greenland.- Meddr Gronland, 124, 8 S.; Kopenhagen.

- (1975): Nogle hovedtraek: Grønland og det nordatlantiske omraades plantegeografi.- In: Grønland og Faerøerne, Danmarks Natur, 10, S. 287-304; Kopenhagen.

- Holmen, K. \& Jakobsen, K. (1968): The Flora of Greenland. 326 S.; Kopenhagen (Haase-Verl.).

BrodziKowski, K. \& LOON, A. J. vaN (1991): Glacigenic Sediments. Developments in Sedimentology, 49, 674 S.; Amsterdam, Oxford, New York, Tokyo.
Church, M. \& Gilbert, R. (1975): Proglacial fluvial and lacustrine environments.- In: Jopling, A. V. \& McDonald, B. C., ed. (1975): Glaciofluvial and Glaciolacustrine Sedimentation, S.E.P.M., Spec. Publ. 23, S. 22-100; Tulsa, Ok.

Dawson, A. G. (1983): Glacier-dammed lake investigation in the Hullet lake area, South Greenland.- Meddr Grønland, Geoscience 1983 (11), 24 S.; Kopenhagen.

Dijkmans, J. W. A. (1989): Frost Wedges in an eolian sand sheet near Søndre Strømfjord, W. Greenland and their paleoenvironmental implications.- Z. Geomorph. N. F., 33, S. 339353; Berlin

- \& TÖRnQuist, T. E. (1990): Modern periglacial eolian deposits and landforms in the Sondre Strømfjord area, West Greenland, and their paleoenvironmental implications.Dissertation, Geografisch Instituut, Rijksuniversiteit Utrecht, S. 67-112; Utrecht.

Dreimanis, A. (1979): The problem of waterlain tills.- In: SCHLUCHTER, A., ed. (1979), Moraines and Warves, S. 167-177; Rotterdam (Balkema).

Ekicson, K. I. (1987): Environment and processes of till-like sediments at the margin of Russell's glacier, near Söndre Strömfjord, West Greenland.- Report of Kvartärgeologiska Institutionen, 9, S. 1-40; Stockholm.

EsCHER, A., SøreNsen, K. \& ZECK, H. P. (1976): Nagssugtoqidian mobile belt in West Greenland.- In: Escher, A. \& WATT, W. S. ed. (1976): Geology of Greenland, S. 77-103; Kopenhagen (Grønlands geol. Unders.).

- \& WATT, W. S. ed. (1976): Geology of Greenland.- 603 S; Kopenhagen (Grønlands geol. Unders.).

ETAC (1970): AWS Climatic Brief Sondrestrom AB/ Greenland. Søndre Strømfjord.

Feilberg, J., Fredskild, B. \& Holt, S. (1984): Flowers of Greenland.100 S.; Ringsted (Regnbuen-Verl.).

Gilbert, R. (1971): Observations on ice-dammed Summit Lake, British Columbia, Canada.- Journal of Glaciology, 10, S. 351-356; London.

Hoвbs, W. (1931): Loess, Pebble Beds and Boulders from Glacial Outwash of the Greenland Continental Glacier.- In: KING, C. A. M., ed. (1976): Periglacial Processes, Benchmark Papers in Geology, 27, S. 372-376; Stroudsburg (Dowden, Hutchingson \& Ross)

JAHN, A. (1968): Geomorphological deductions from observations of the bottom of an ice-dammed lake,- Geogr. J., 39, S. 117123; Warschau.

LORI, M. L. \& KeHEw, A. E. (1987): Sedimentology and paleohydrology of glacial-lake outburst deposits in southern Saskatchewan and Northwestern North Dakota.- Geol. Soc. America Bulletin, 99, S. 663-673; New York.

Marcus, M. G. (1960): Periodic drainage of glacier-dammed Tulsequah Lake, British Columbia.- Geogr. Rev., 50, S. 89-106; New York.

MINISTERIET FOR GRØNLAND ed. (1980): Holsteinsborg, Sisimiut kommune, natur- og kulturforhold.- 88 S.; Kopenhagen.

Putnins, P. (1970): The Climate of Greenland.- In: LandsberG, H. E. ed. (1970), World Survey of Climatology, 14, 128 S.; Amsterdam, London, New York (Elsevier).

Russell, A. J. (1989): A comparison of two recent jökulhlaups from an ice-dammed lake, Søndre Strømfjord, West Greenland. Journal of Glaciology, 35 (120), S. 157-162; London. - (1993): Obstacle marks produced by flow around stranded ice blocks during a glacier outburst flood (jökulhlaup) in west Greenland.- Sedimentology, 40, S. 1091-1111; London.

-\& De Jong, C. (1989): Lake Drainage Mechanisms for the Ice-Dammed Oberer Russellsee, Søndre Strømfjord, West Greenland.- Z. f. Gletscherkunde u. Glazialgeologie, 24 (2), S. 143-147; Innsbruck.

- \& Aitken, J. F. \& De Jong, C. (1990): Observations on the Drainage of an ice-dammed lake in West Greenland.- Journal of Glaciology, 36 (122), S. 72-74; London.

Schol., H. (1984): Westgrönland - ein lebendiges Modell für die Eiszeit im Alpenvorland.- Natur und Museum, 114 (4), S. 89103; Frankfurt a.M.

- (1986a): Das Allgäu im Hochglazial - Grönland heute: ein Vergleich.- Ber. Naturwiss. Ver. Schwaben, 90 (1), S. 1-26; Augsburg.

- (1986b): Actuogeology in Westgreenland 1986.- Newsletter Sci. Res. Greenland, 13, S. 11; Kopenhagen. 
- (1987): Beiträge zur Geologie und Botanik eisrandnaher Gebiete in der Umgebung des Örkendals westlich von Söndre Strömfjord (Westgrönland).- unveröff. Abschlußbericht zum DFG-Projekt "Aktuogeologie in Westgrönland", mit Beiträgen von $\mathrm{H}$. Gilck und W. Grottenthaler (Antrag II C 6 - Scho 277/2-1 vom 9.10.1985), 88 S.; Garching.

- (1988): Sedimentologie von Sanderflächen am Russell-Gletscher bei Söndre Strömfjord in Westgrönland.- unveröff. Abschlußbericht eines durch die "Prof. Dr.-Ing. Lorenz-Stiftung" geförderten Projektes, 28 S.; Garching.

- (1991): Ein Vorstoß des Inlandeises in Westgrönland - Dokumentation des vorrückenden Eisrandes bei Sondre Strømfjord.- Eiszeitalter u. Gegenwart, 41, S. 119-131; Hannover. - (1993): Der Grenzbereich zwischen Falten- und Vorlandmolasse im Gebiet zwischen Rhein- und Illergletscher im Westallgäu (Exkursion am 16. April 1993).- Jber. Mitt. oberrhein. geol. Ver., N. F. 75, S. 155-176; Stuttgart.

- (1995a): Sedimente und Ablagerungsmechanismen in instabilen proglaziären Seen (Eisrandstauseen) Teil 1: Rezente Beispiele aus Westgrönland.- unveröff. Abschlußbericht zum DFG-Projekt „Aktuogeologie in Westgrönland“ (Antrag II C 6 - Scho 277/4-1 vom 9.10.1993), 58 S.; Garching.

- (1995b): Sedimentfüllungen instabiler Eisrandstauseen - aktuogeologische Untersuchungen am Rande des Inlandeises in Westgrönland.- Vortrags-Kurzfassung, Nachr. Dt. Geol. Ges., 54, S. 163-164; Hannover.

- \& Funk, H. \& SChreiner, B. (1988): Der Einfluß von Gletscherläufen auf die Schmelzwasserablagerungen des RussellGletschers bei Søndre Strømfjord (Westgrönland).- Z. f. Gletscherkunde und Glazialgeologie, 24 (1), S. 55-74; Innsbruck. - \& Peter, I. (1995): Sedimente und Sedimentationsgeschichte des späthochglazialen "Kemptener Sees" (Würmglazial, Südwest-Bayern).- Geologica Bavarica, 99, S. 187-222; München. - \& Grottenthaler, W. (1988): Beiträge zur jungholozänen Deglaziationsgeschichte Westgrönlands.- Polarforschung, 58 (1), S. 25-40; Münster.

SchreINER, A. (1992): Einführung in die Quartärgeologie.- 257 S.; Stuttgart (Schweizerbart-Verlag)

SмrTH, N. D. \& Syvitzki, J. P. H. (1982): Sedimentation in a glacierfed lake: the role of pelletisation on deposition of fine-grained suspensates.- J. Sed. Petr., 52, S. 503-513; Tulsa, Ok.
- \& Venol, M. A. \& Kennedy, S. K. (1982): Comparision of sedimentation regimes in four glacier-fed lakes of western $\mathrm{Al}-$ berta.- In: Davidson-ArNotT, D., Nickling, W. \& FAhEY, B. D. eds. (1982): Research in glacial, glacio-fluvial and glacio-lacustrine systems, Proc. Gth Guelph Symp. Geomorphol., 1980 S. 203-238;

StÄBLEIN, G. (1975): Eisrandlagen und Küstenentwicklung in Westgrönland.- Polarforschung, 45 (2), S. 71-86; Münster.

- (1977a): Periglaziale Formengesellschaften und rezente Formungsbedingungen in Grönland.- Abh. Akad. Wiss. in Göttingen, 31, S. 18-33; Göttingen.

- (1977b): Rezente Morphodynamik und Vorzeitreliefinfluenz bei Hang- und Talentwicklung in Westgrönland-- Z. Geomorph., N. F. 28, Suppl., S. 181-199; Berlin.

Stone, K. H. (1963): Alaskan ice-dammed lakes.- Ann. Assoc. Amer. Geogr., 16, 5. 332-349; Lawrence, Kansas.

Sugden, D. E., Clapperton, C. M. \& Knight, P. G. (1985): A Jökulhlaup near Søndre Strømfjord, West Greenland, and some effects on the Ice sheet Margin.- Journal of Glaciology, 31 (109), S. 366-368; London.

TEN BRINK, N. W. (1975): Holocene history of the Greenland ice sheet based on radiocarbon-dated moraines in West Greenland.- Meddr Grønland, 201 (4), S. 9-28; Kopenhagen.

THEakstone, W. H. (1976): Glacial lake sedimentation, Austerdalsisen, Norway.- Sedimentology, 23, S. 671-688; Amsterdam.

Thorarivsson, S. (1953): Some new Aspects of the Grimsvötn problem.- Jour. Glaciology, 2, S. 267-274; London.

WArTT, R. B. (1980): About fourty last-glacial Lake Missoula jökulhlaups through Southem Washington.- J. Geol, 88, S. 653-674; Chicago.

WeIDIck, A. (1963): Some Glacial Features at the Inland Ice Margin South of Sdr. Strømfjord.- Meddr dansk geol. Foren., 15 $S$; Kopenhagen.

- (1968): Observations on some Holocene glacier fluctuations in West Greenland.- Meddr Gronland, 165 (6), 202 S.; Kopenhagen.

-(1972): Holocene shore lines and glacial stages in Greenland - an attempt at correlation.- Rapp. Gronlands geol. Unders., 41, 39 S.; Kopenhagen.

-(1988): Gletschere i Sydgrønland.- In: Geologi i Grønland 2, $80 \mathrm{~S}$; Kopenhagen (GGU).

Manuskript eingegangen am 01.03.1996 


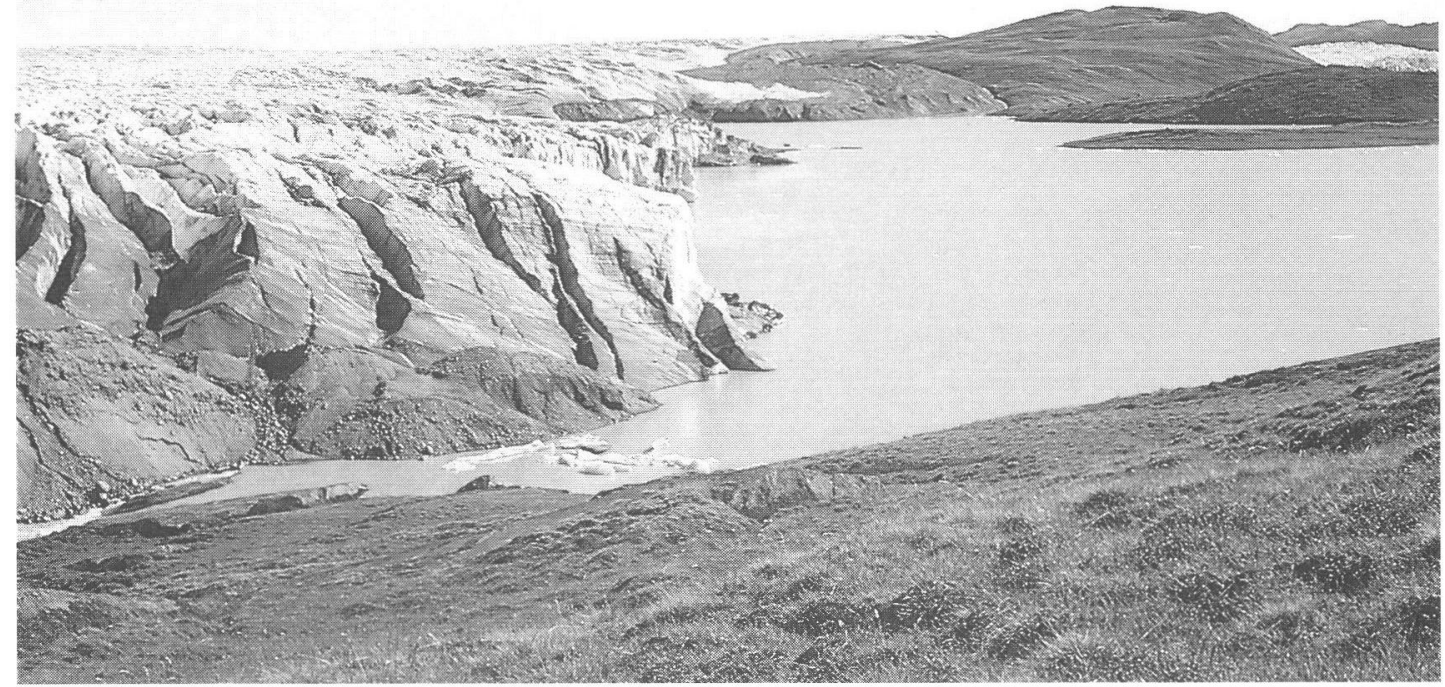

a: Der aus zwei Teilbecken bestehende Eisrandstausee „Iluliartununnguaq“, einer der instabilen Eisrandstauseen am . Orkendal-Gletscher" im mittleren Westgrönland bei Søndre Strømfjord, von $\mathrm{N}$ her gesehen. Der Überlauf des momentan bis zum Maximalstand gefüllten Sees, der links vorne zu erkennen ist, verschwindet knapp außerhalb des Bildrandes in einem Eistunnel. Mitunter läuft das Wasser aus und das nördliche Teilbecken (vorderer Seeteil bis zur Halbinsel) fällt weitgehend trocken. Der Wasserspiegel im südlichen Teilbecken (hinter der Halbinsel) sinkt dagegen nur um einige Meter ab, während das Becken selbst wassergefüllt bleibt.

a: The ice-dammed lake .Iluliartununnguaq" seen from the North consists of two basins. It is one of several unstable ice-contact lakes dammed by the „Ørkendal-Glacier“ in centrai West Greeland near Sondre Strømfjord. The outlet of the lake, completely filled with meltwater at the moment, can be seen at the lower left. A short distance outside of the picture it disappears in a glacier tunnel. From time to time the water drains and the northern basin (in front, ending at the peninsula) is mostly dry. The southern basin (behind the peninsula) remains filled however, the water level decreasing only a couple of metres.

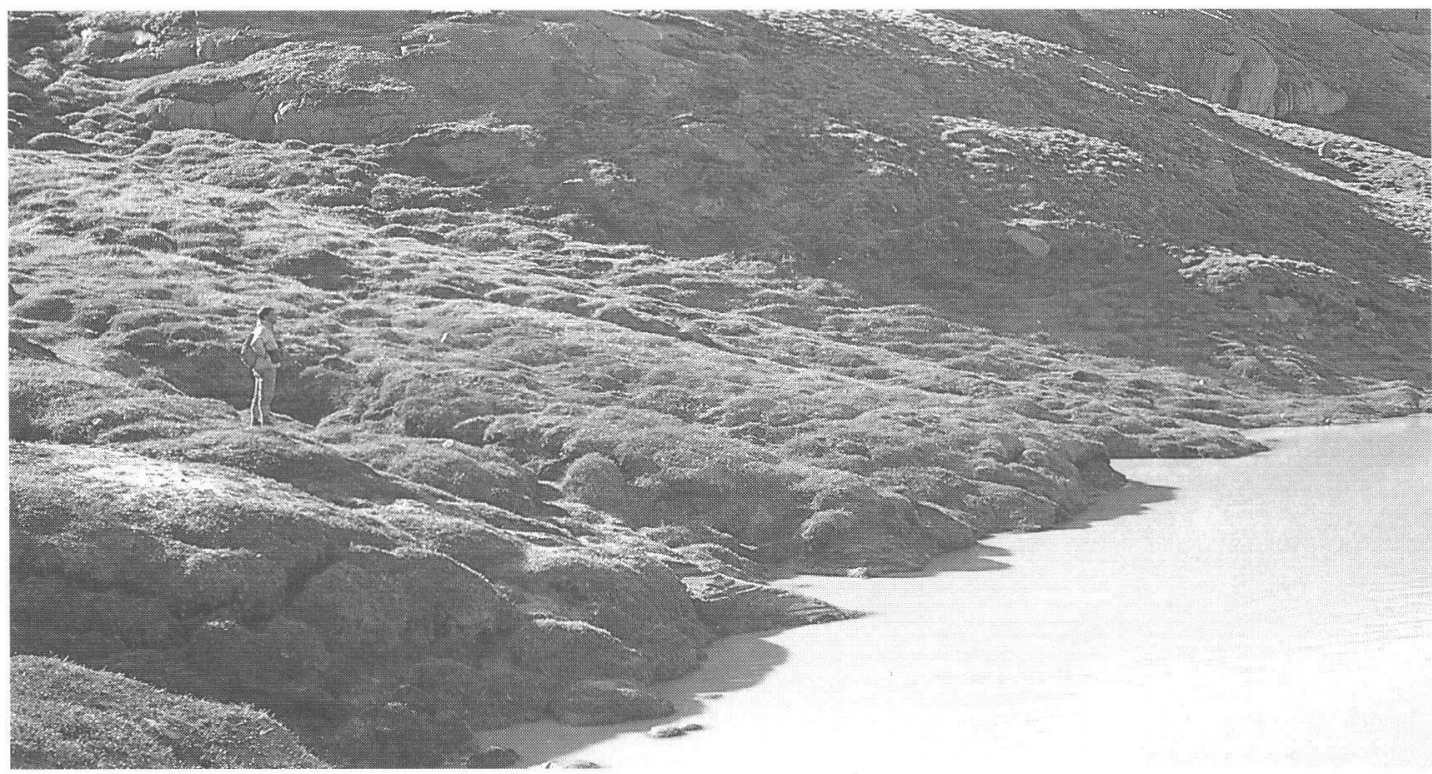

b: Das nur kurzfristig unter Wasser geratene schmale, aber lange Becken des „Nysø 2“ am "Ørkendal-Gletscher“. Die maximale Stauhöhe des Beckens lag etwa da, wo die Person als Größenvergleich steht. Bis dort hin ist die immer noch grüne Vegetation mit Schluff weiß überzuckert. Noch etwa $1 \mathrm{~m}$ über dem Wasserspiegel des Restsees tragen die Zwergsträucher Häubchen aus Sand. Der abdämmende Eisrand liegt rechts außerhalb des Bildrandes.

b: The narrow but long basin of lake „Nysø 2" dammed by the „Ørkendal-Glacier" was drowned only for a short time. The maximum lake level nearly attained the site with the standing man. The green vegetation is powdered with pale silt below this line Until $1 \mathrm{~m}$ above the water level of the residual lake the dwarf-shrubs wear thick caps of sand. The damming ice margin is situated shortly outside the picture to the right. 
Tafel 2

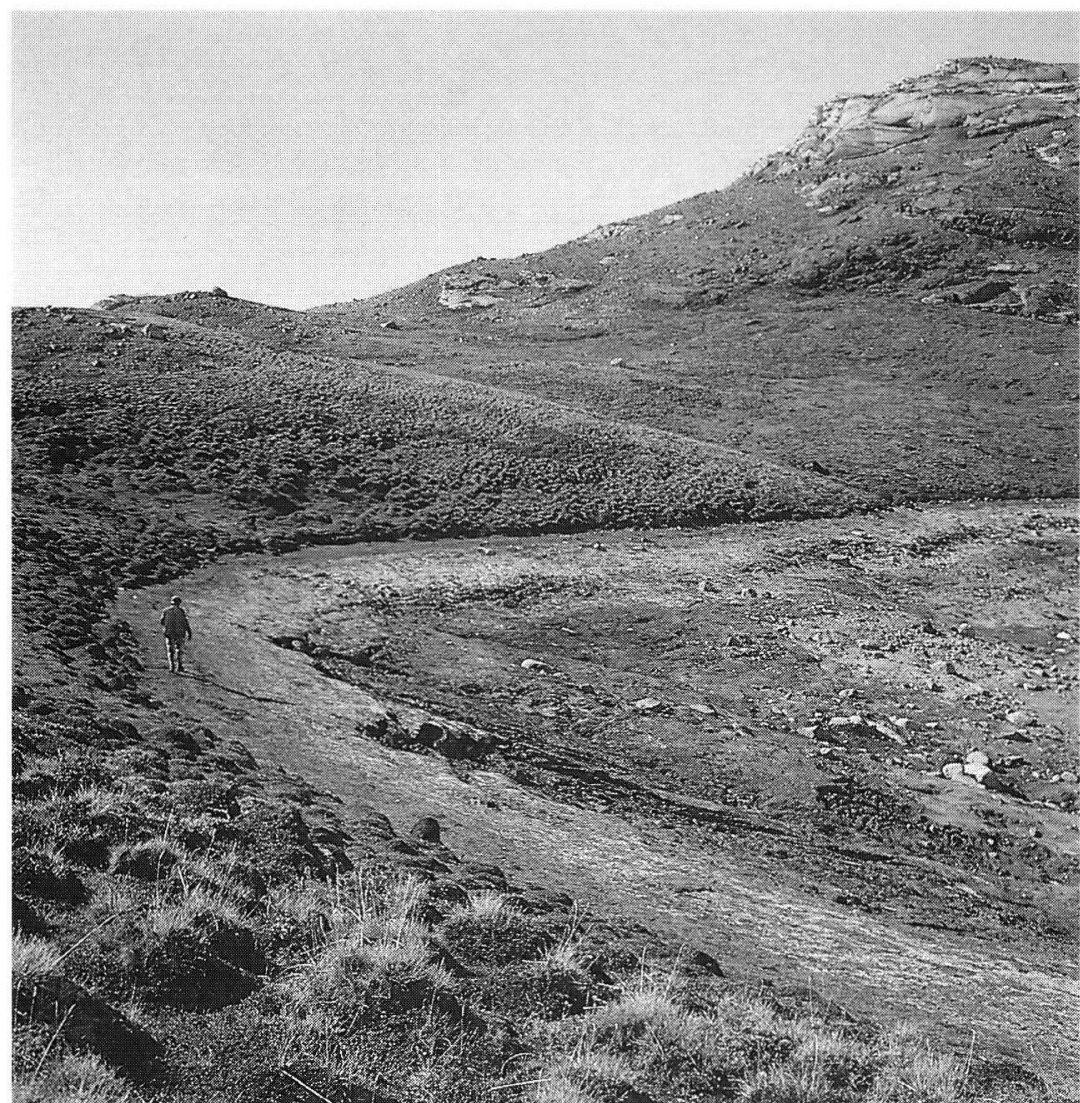

a: Das Südwestende des leeren Seebeckens von "Leverett 1“. Deutlich zu erkennen ist die einige $m$ breite Schorre mit dem niedrigen Kliff, die den maximal erreichbaren Wasserstand im See markiert (mit einer Person als Größenvergleich). Oberhalb dieser Uferlinie ein Erdbültenfeld mit Pflanzengesellschaften, die von Grä sern dominiert werden (moosreiche Nordhangwiese). Auch unterhalb der Schorre sind einige verwaschene Erdbülten und Vegetation zu erkennen, auf der aus Eisbergen abgeregnete dropstones herumliegen.

a: The south-western end of the empty lake basin of "Leverett 1". A narrow wave-cut platform bordered by a low cliff is visible, a couple of metres wide (scaled by a man), indicating the maximum water level of this lake. Above the shore line hummocks are visible, covered by a vegetation rich in grass and herbs. Even below the shore line some weak hummocks and vegetation are visible, covered by some dropstones derived from drifting ice.

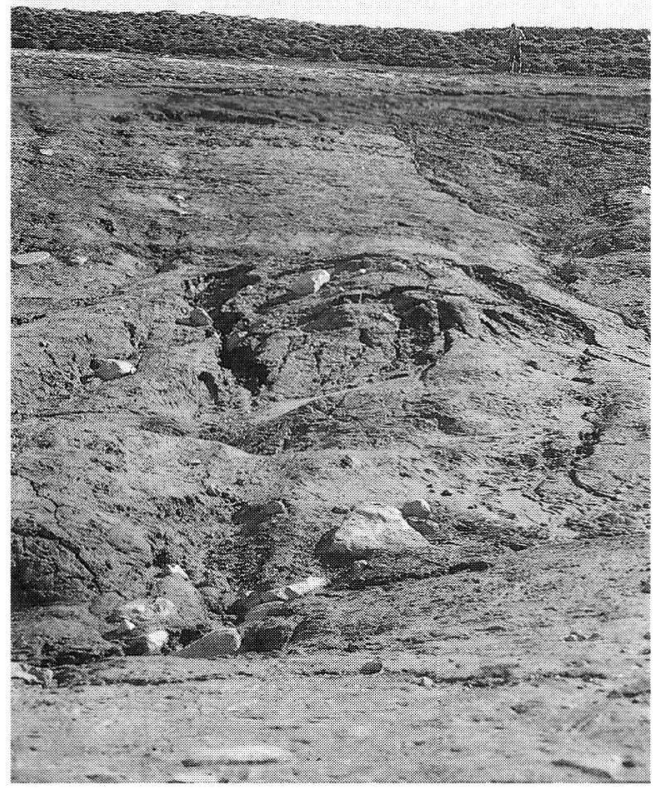

b: Massenbewegungen an der Südwestflanke des Beckens von „Leverett 1“. Eine Person steht als Größenvergleich auf der Schorre. Dahinter sind die Erdbültenfelder außerhalb des Seebeckens zu sehen. Bis zu der Schorre hinauf reichen Risse und Depressionen im Untergrund, die auf einen Zusammenbruch des Permafrostes im Untergrund hinweisen. Im unruhigen Gebiet am unteren Bildrand beginnt sich das oben abgeflossene Marerial zu akkumulieren, vor allem gelifluidal umgelagerte äolische Deckschichten und Moränen.

b: Mass movements at the south-western slope of the lake basin of „Leverett 1 “. Outside the lake basin behind a man standing on the wave-cut platform an area with hummocks is visible. The thawing of the permafrost below the bottom of the lake basin is indicated by cracks and depressions at the slope below the shore line. The material flows downwards, accumulates within the hilly area in the lower part of the picture, consisting mostly of tills and eolian sediments disturbed by gelifluction. 
Tafel 3

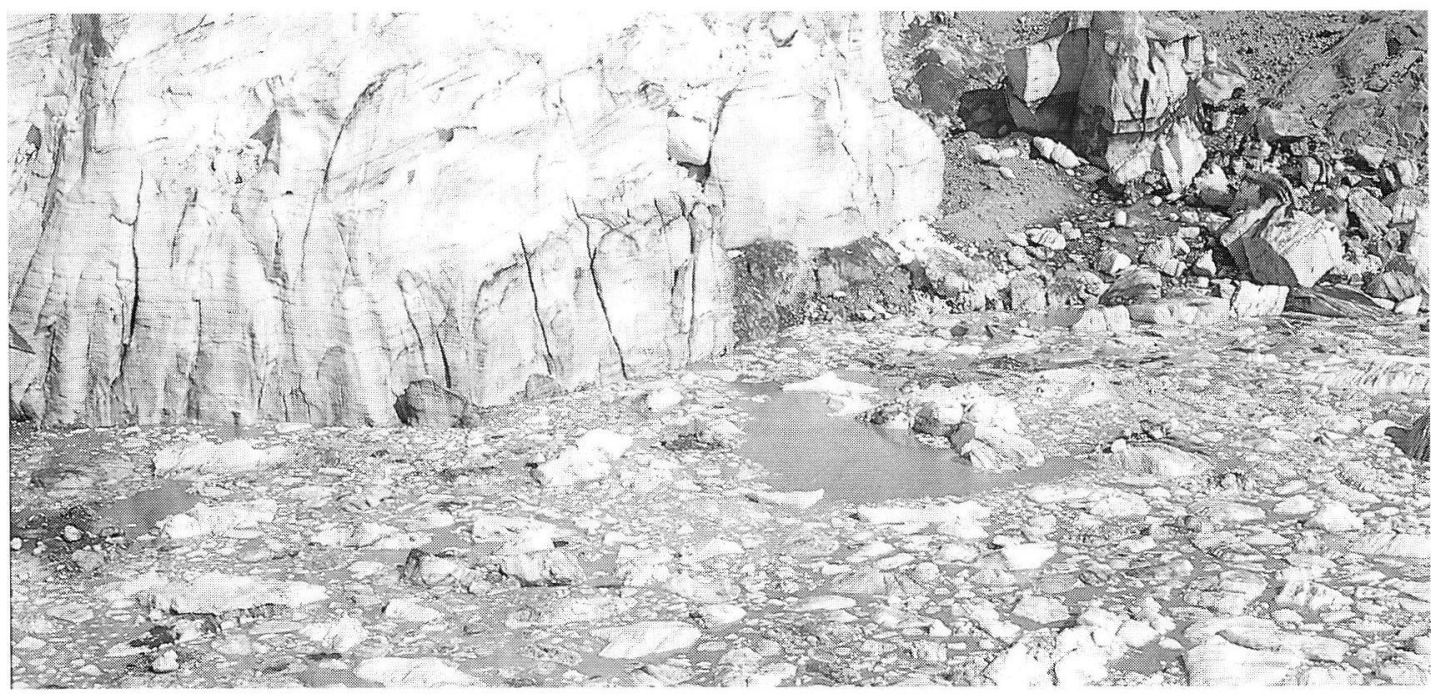

a: Der mit Drifteis fast völlig bedeckte Restsee des ausgelaufenen instabilen Eisrandstausees „Leverett 1“. Links ist die Kalbungsfront an der Südseite des Leverett-Gletschers, rechts hinten sind gestrandete Eisberge zu erkennen. Der Durchmesser des Restsees beträgt etwa $200 \mathrm{~m}$.

a: The residual lake covered by drift ice within the empty basin of the unstable lake "Leverett 1". The calving front at the sou thern ice margin of the Leverett-Glacier is visible to the left, stranded icebergs are visible in the back to the right. The diameter of the residual lake is about $200 \mathrm{~m}$.

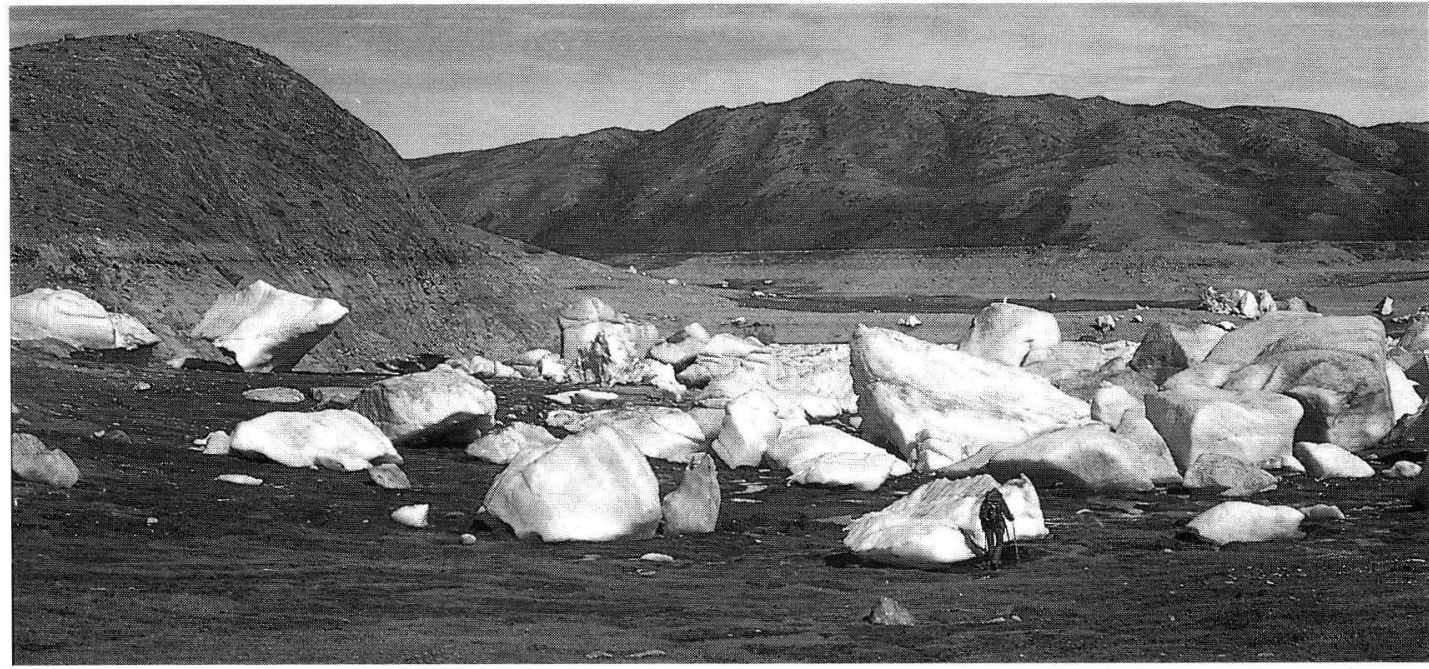

b: Blick über das weitgehend wasserleere Seebecken von „Russell 1“ („Oberer Russellsee“), wie er sich im Juli 1987 darbot, wenige Tage nachdem er ausgelaufen war. Das an dieser Stelle etwa $1 \mathrm{~km}$ breite und fast $40 \mathrm{~m}$ tiefe Becken ist ungefähr von der Stelle aus gesehen, wo der See im gefüllten Zustand einen Überlauf besitzt. Der das Becken abdämmende Eisrand des Russell-Gletschers liegt rechts außerhalb des Bildrandes. Schluffig-sandige, mit Blöcken durchsetzte Diamikte, die Sedimentfracht von Eisbergen, bedecken den größten Teil der vegetationslosen Flanken. Deutlich zu erkennen sind die Wasserstandsmarken am Gegenhang des Beckens, an denen die maximale Stauhöhe ablesbar ist. Die großen Eisberge im Vordergrund (mit einer Person als Größenvergleich), die einen im Beckentiefsten liegenden Restsee verdecken, sind auf schluffüberzuckerten Zwergsträuchern gestrandet, die nur kurzfristig unter Wasser geraten waren.

b: View over the empty lake basin of „Russel 1" (,Oberer Russellsee“), seen in July 1987, only a few days after it had suddenly drained. The lake basin is about $1 \mathrm{~km}$ wide and nearly $40 \mathrm{~m}$ deep here, seen from the lake outlet, active only when the lake is filled. The ice margin of the Russell Glacier damming the lake is just outside the margin to the right. The unvegetated basin slopes are covered with deposits derived from drift ice, silty to sandy diamictons containing boulders. Water level marks are clearly visible at the opposite basin slope, indicating the maximum lake level. The big icebergs in the foreground (scaled by a man) hide a residual lake within the profoundess of the basin. They rest on dwarf-shrubs, powdered with pale silt and drowned only for a short time. 
Tafel 4

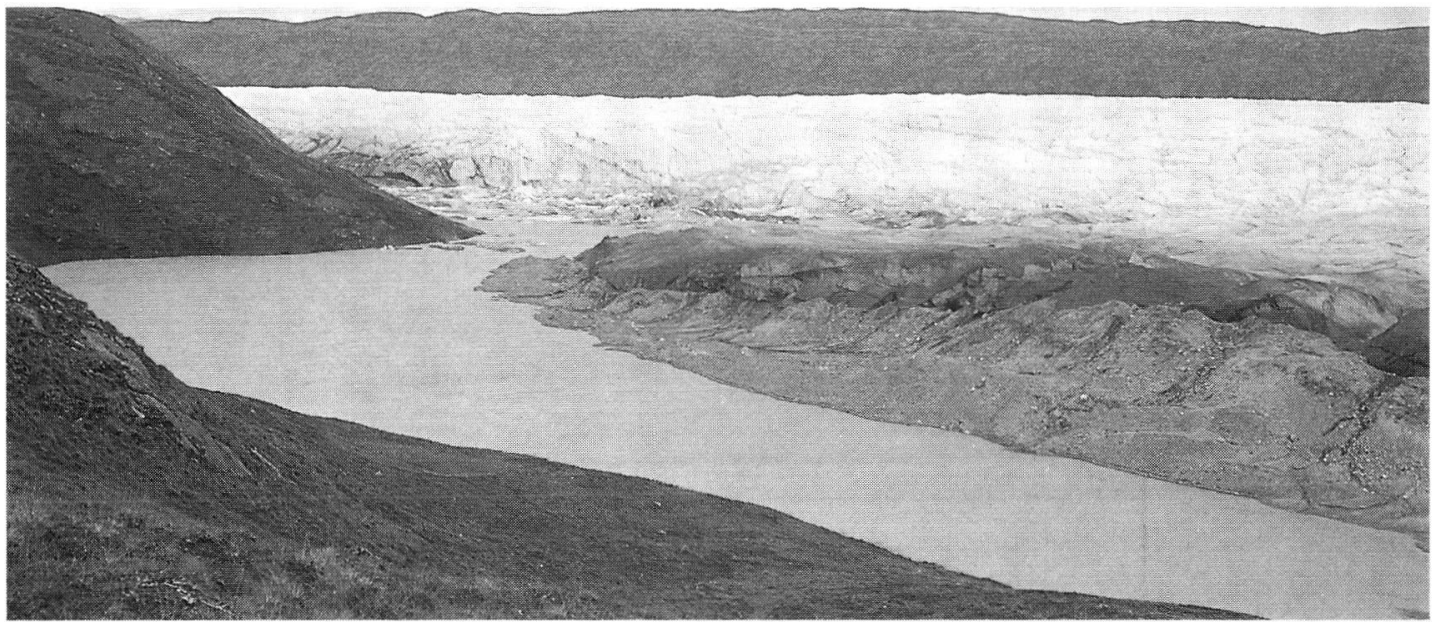

a: Der instabile Eisrandstausee „Isunguata 3“ von SW her gesehen, der von der viele Kilometer breiten Inlandeiszunge des Isunguata Sermia abgedämmt wird, war im Juli 1982 mit Schmelzwasser gefüllt. Der S-förmig gekrümmte See besteht aus 2 Teilbecken, die nur durch einen schmalen Durchlaß miteinander verbunden sind. Nur das tiefe, nordwestliche Teilbecken ist mit Drifteis bedeckt. Im Vergleich mit Taf. 4b ist zu erkennen, daß der Eisrand damals um Dekameter weiter im Norden lag. Zu erkennen sind die Schmelzwasseraustritte, die kleine Deltas in den See vorbauen.

a: The unstable ice-dammed lake „Isunguata 3“, dammed by the many kilometres wide outlet glacier Isunguata Sermia, seen from the SW. This lake was filled with meltwater in July 1982. The S-shaped lake consists of two separate basins connected only by a narrow swell. Only the deep north-western basin is covered by drift ice. The ice margin was 1982 still situated a bit further to the north, compared with the later situation on Plate 4b. Small meltwater creeks are visible, forming prograding deltas.

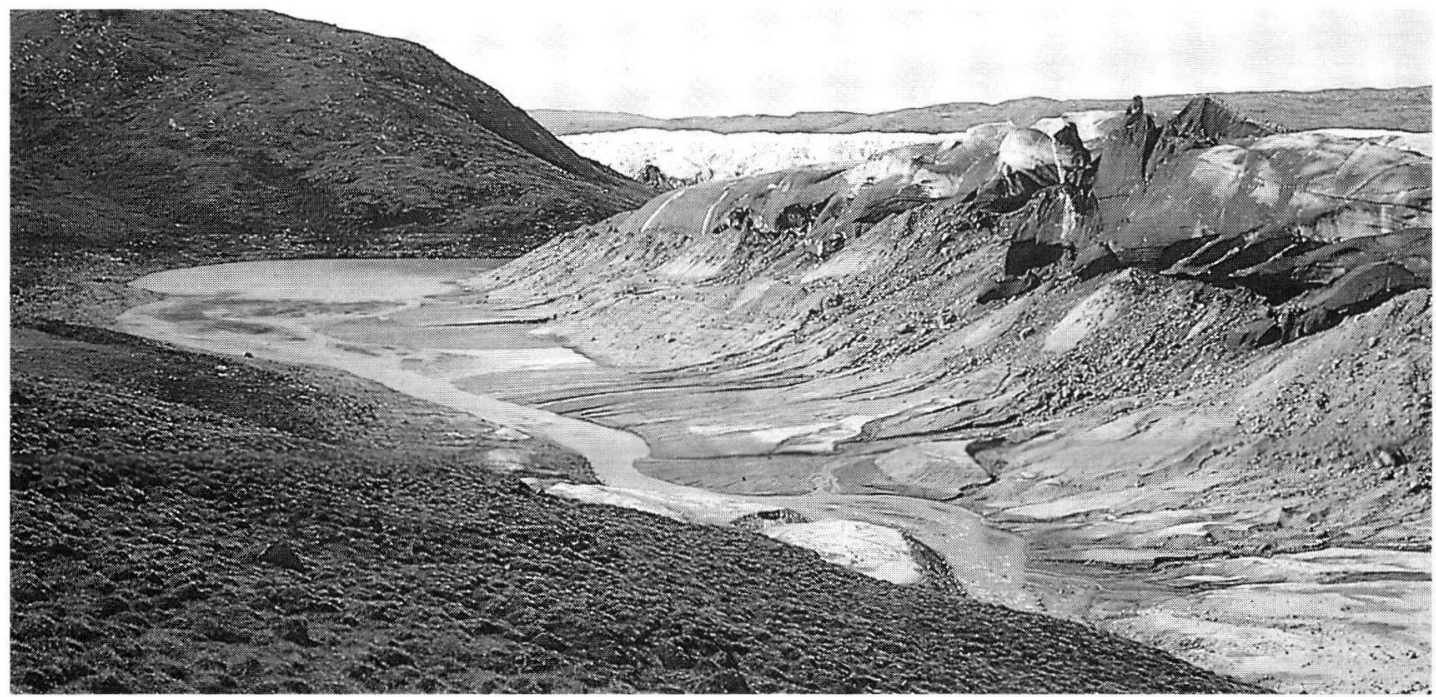

b: Blick über das südöstliche Teilbecken des instabilen Eisrandstausees „Isunguata 3 “ nach NW, der im Juli 1993 weitgehend wasserleer war. Übrig ist lediglich ein kleiner, seichter Restsee, in den zahlreiche Schmelzwasserbäche Deltas vorbauen. Deutlich sind bei den Schwemmfächern, die sich am Fuß des Moränenwalls zu einem Übergangskegel zusammengeschlossen haben, aktive und inaktive, helle Bereiche unterscheidbar. Auf der Gegenseite des Baches kommen, vom Hügel halb verdeckt, Erosionsreste des Bachdeltas heraus. Die besonders hell erscheinenden Flächen sind von einer dünnen, ausgetrockneten Schlufflage bedeckt. An der Außenseite des Moränenwalles sind Wasserstandsmarken erkennbar, von denen die höchsten etwa $15 \mathrm{~m}$ über dem Restseespiegel liegen. Im Vergleich zur Aufnahme von Taf. 4a ist der Eisrand deutlich vorgerückt, der Doppelwall weitgehend verschwunden.

b: View towards the NE over the south-eastern basin of the unstable ice-dammed lake .Isunguata 3", rather empty in July 1993. Only a small and shallow residual lake is visible, bordered by small deltas, formed by meltwater creeks deriving from the ice margin. Their alluvial fans have amalgamated laterally to form a transitional ramp in front of a moraine ridge. Darker active and lighter inactive parts of the alluvial fans are distinguishable. Erosional remnants of a relatively large delta on the left side of a small creek are nearly hidden behind a hill. The pale surfaces are covered by a thin dried silty layer. On the slope of the moraine ridge water level marks are visible, $15 \mathrm{~m}$ as a maximum above the level of the residual lake. Compared with Plate $4 a$ the ice margin has clearly advanced and the formerly double crested moraine ridge has nearly disappeared. 


\section{Tafel 5}

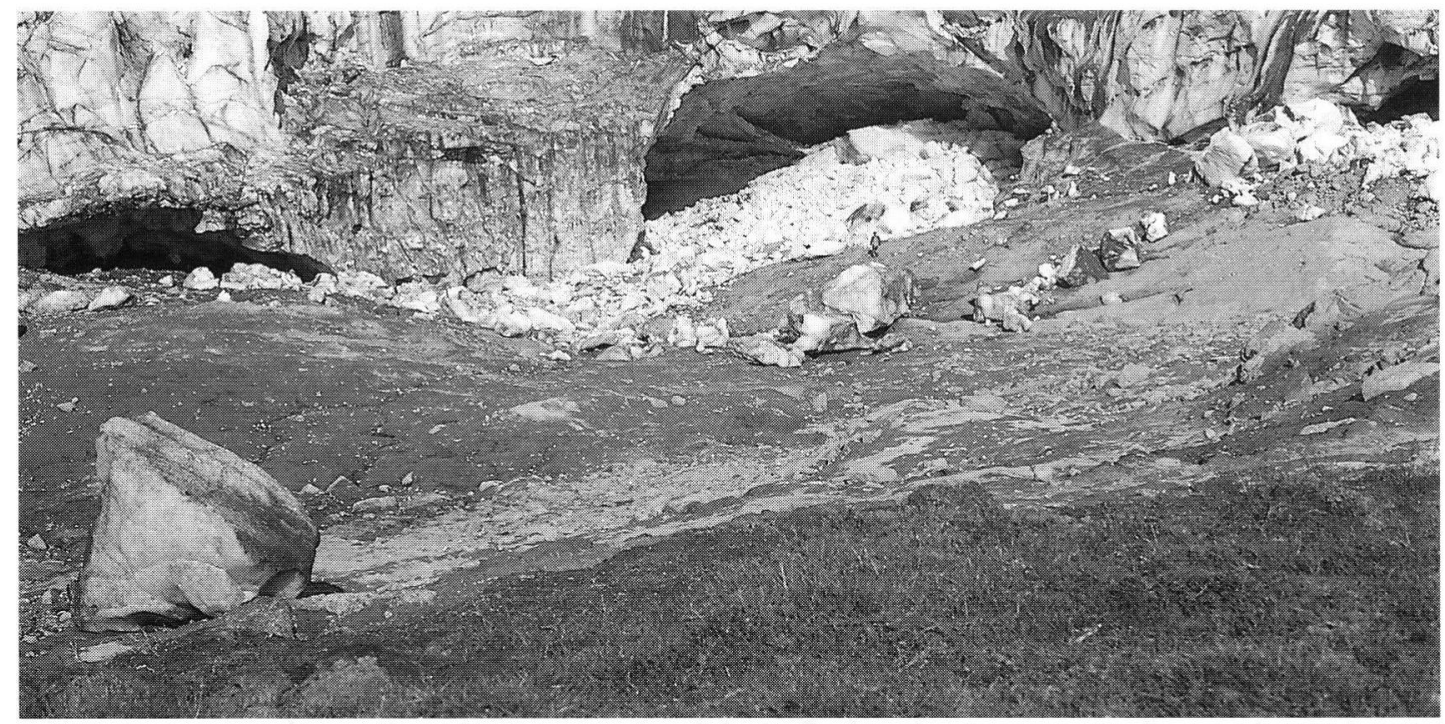

a: Blick in das etwa $60 \mathrm{~m}$ tiefe, trichterartige, nordwestliche Teilbecken des „Isunguata 3“, das im Juli 1993 leer, im Juli 1982 (Taf. 4a) jedoch wassergefüllt war. Blick von der Uferlinie des Maxi-malstandes nach Norden. Die im Vordergrund sichtbare Vegetation ist schluffüberstäubt und war noch vor kurzem von Schmelzwasser bedeckt. In den tiefsten Teilen des Beckens sind teilweise verstürzte Eingänge zu einem Eistunnel zu sehen. Ganz links unten sowie bei der Person oberhalb des rechten Tunneleinganges liegen gestrandete Drifteisblöcke. Beim dunklen Material am linken Bildrand handelt es sich um eine größere Rutschmasse.

a: An approximately $60 \mathrm{~m}$ deep view into the cone-shaped north-western basin of "Isunguata 3 “, seen from the maximum shore line in the South. The basin was empty in July 1993, filled with meltwater, however, in July 1982 (Plate ta). The vegetation in the foreground is powdered with pale silt and has been drowned only a short time ago. Within the deepest parts of the basin partly collapsed entrances of an ice tunnel are visible. Boulders of stranded drift ice in the lower left, scaled by the man near the tunnel entrance to the right. The dark material at the left margin of the picture are large slide masses accumulating here.

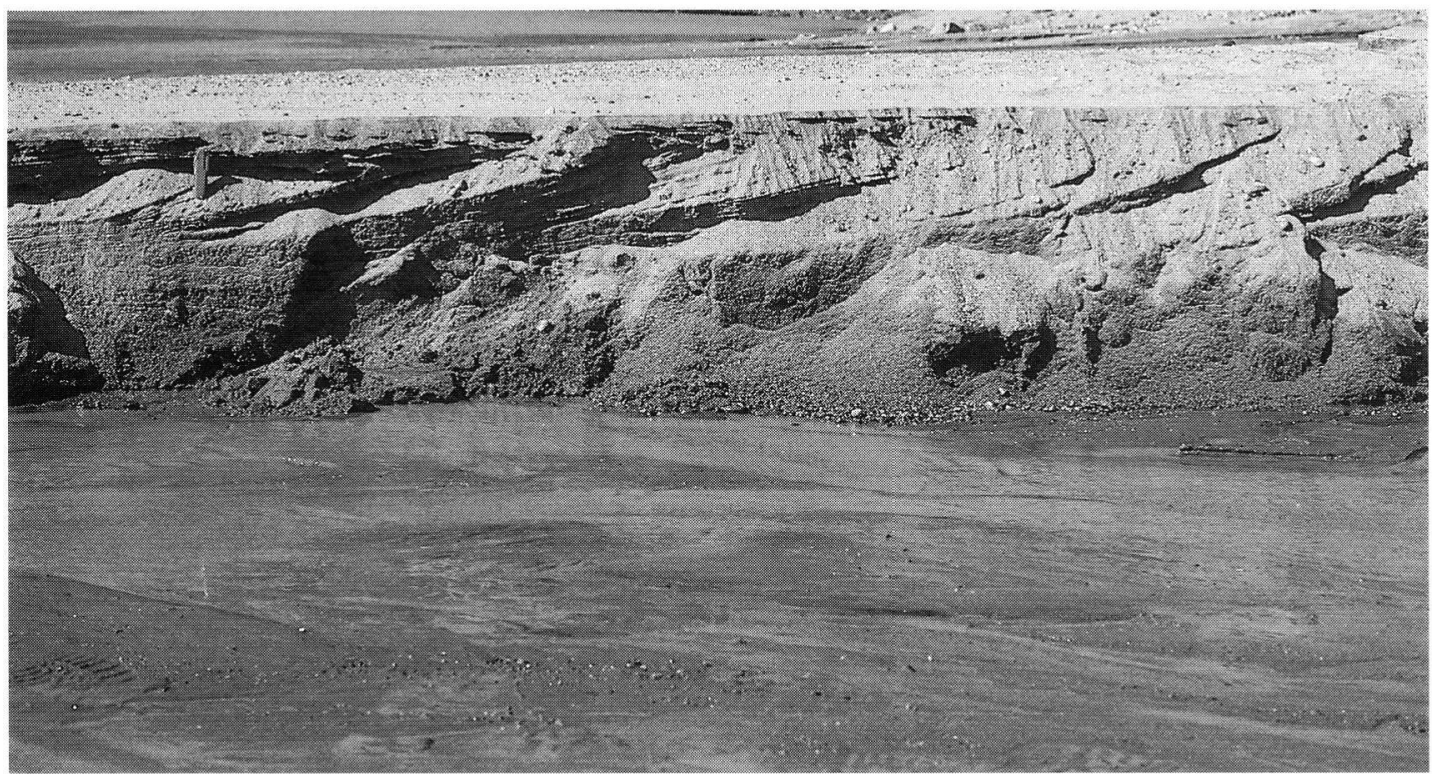

b: An einem niedrigen Erosionshang, der inaktive Teile des Übergangskegels zu Füßen der Moräne am „Isunguata 3“ anschneidet, ist eine Deltasequenz mit foresets und geringmächtigen topsets aufgeschlossen (am linken Bildrand ein Taschenmesser als Größenvergleich). Das Delta wurde in den See vorgeschüttet, während der Wasserspiegel allmählich auf das heutige Niveau absank.

b: A delta sequence with foresets and thin topsets is exposed at a small erosional slope, cutting inactive parts of a transitional fan in front of the moraine ridge of "Isunguata $3^{4}$. The picture is scaled by a pocket knife visible at the margin of the picture to the left. The delta prograded into the lake with a slowly sinking water level. 
Tafel 6

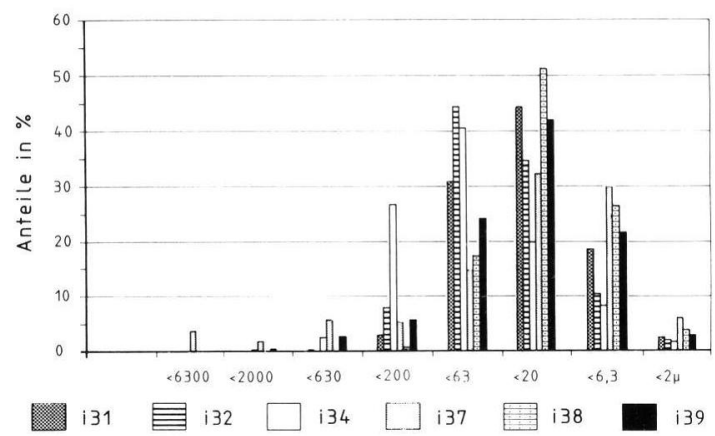

Diagramm 1: Korngrößenverteilung (Siebkorn und Schlämmkorn) von Proben schluffiger Seesedimente von Proben aus dem „Isunguata 3“, Beispiele dargestellt als Histogramme.

Diagram 1: Granulometry of samples from silty lake sediments taken within the lake basin of „Isunguata $3^{4}$. Examples presented as histograms.

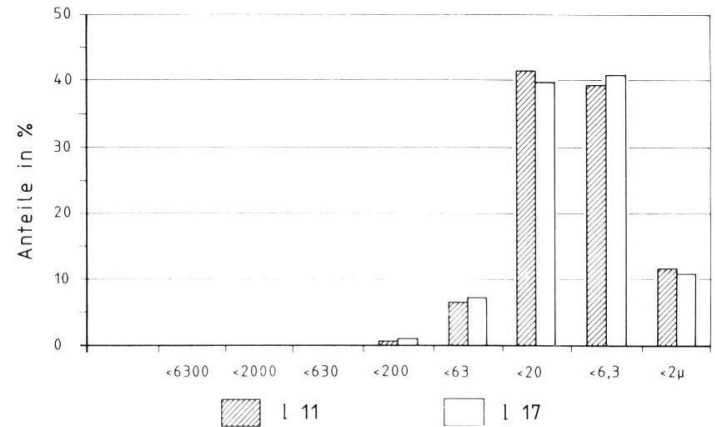

Diagramm 3: Korngrößsenverteilung (Siebkorn und Schlämmkorn) von Proben sandiger Seesedimente aus dem „Isunguata 3" und dem „Nysø 2", Beispiele dargestellt als Histogramme.

Diagram 3: Granulometry of samples from sandy lake sediments taken within the lake basin of „Isunguata 3" (i) and Nysø 2" (n). Examples presented as histograms.

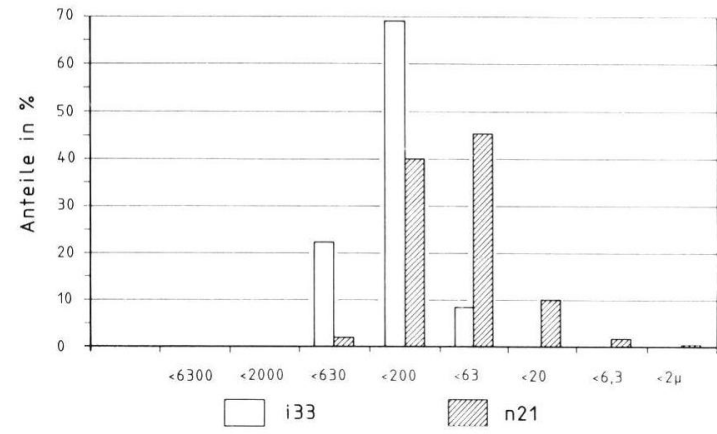

Diagramm 2: Korngrößenverteilung (Siebkorn und Schlämmkorn) von Proben schluffiger Seesedimente aus dem „Leverett 1“, Beispiele dargestellt als Histogramme.

Diagram 2: Granulometry of samples from silty lake sediments taken within the lake basin of "Leverett 1“. Examples presented as histograms.

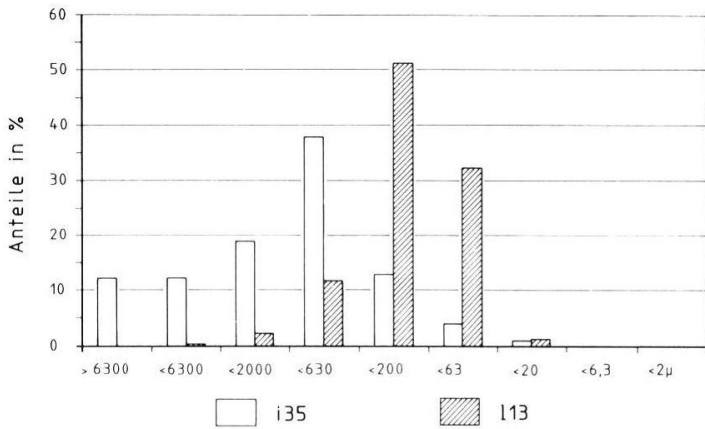

Diagramm 4: Korngrößßenverteilung (Siebkorn und Schlämmkorn) von Proben sandiger Delta- und Schwemmfächerablagerungen aus dem „Isunguata 3 “ und dem „Leverett $1 "$, Beispiele dargestellt als Histogramme.

Diagram 4: Granulometry of samples from sandy sediments from deltas and alluvial fans taken within the lake basin of "Isunguata 3“ (i) and „Leverett 1" (1). Examples presented as histograms. 
Tafel 7

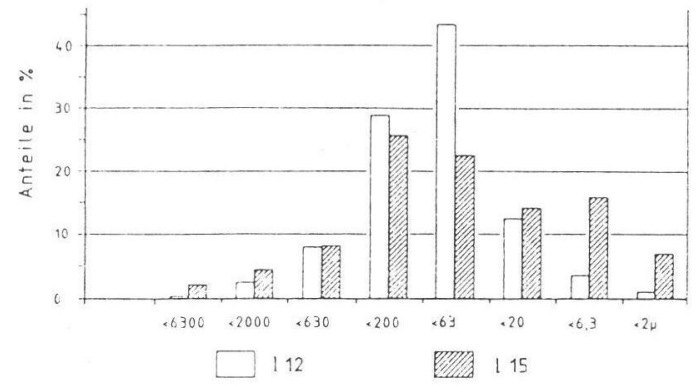

Diagramm 5: Korngrößenverteilung (Siebkorn und Schlämmkorn) von Proben gelifluidal umgelagerter äolischer Deckschichten aus Rutschkörpern im Seebecken des „Leverett 1“, Beispiele dargestellt als Histogramme.

Diagram 5: Granulometry of samples from slide masses within the lake basin of „Leverett 1“, containing eolian sediments disturbed by gelifluction, partly mixed with tills. Examples presented as histograms.

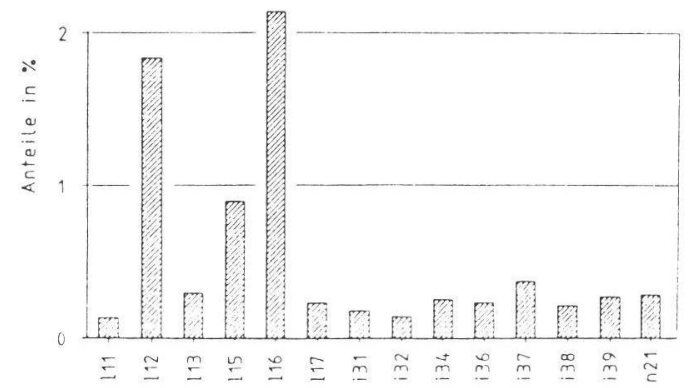

Diagramm _ 7: LECO-Analysen des organischen Kohlenstoffes von einer Auswahl von Proben aus dem „Isunguata 3", dem „Leverett 1“ und dem „Nysø 2“.

Diagram 7: LECO-analysis of the organic carbon content from a selection of samples taken within the lake basins of „Isunguata 3“ (i), „Leverett 1 (1) and „Nysø 2“ (n). .

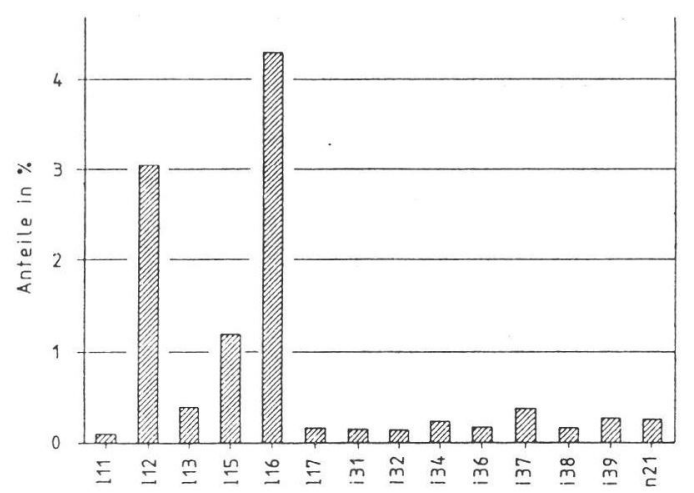

Diagramm 6: LECO-Analysen des Gesamtkohlenstoffes von einer Auswahl von Proben aus dem „Isunguata 3“, dem „Leverett 1" und dem „Nysø 2“.

Diagram 6: LECO-analysis of the total carbon content from a selection of samples taken within the lake basins of "Isunguata 3“ (i), „Leverett 1" (1) and „Nysø 2" (n).

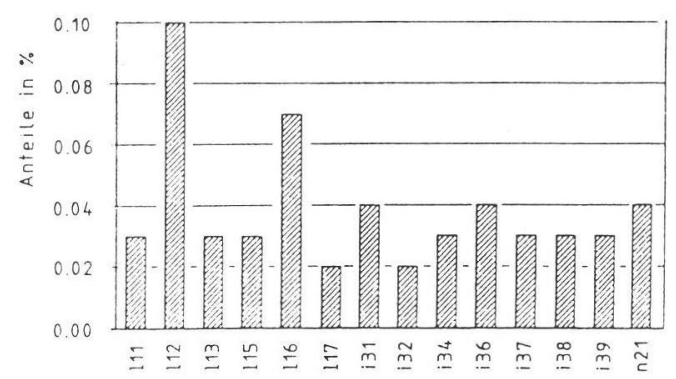

Diagramm 8: LECO-Analysen der Schwefelgehalte von einer Auswahl von Proben aus dem „Isunguata 3“, dem „Leverett 1" und dem "Nysø 2".

Diagram 8: LECO-analysis of the sulphur content from a selection of samples taken within the lake basins of "Isunguata 3“ (i), "Leverett 1" (I) and "Nysø 2“ (n). 